Portland State University

PDXScholar

$1-1-2010$

\title{
The Effects of Ageism Climates and Core Self- Evaluations on Nurses' Turnover Intentions, Organizational Commitment, and Work Engagement
}

David Michael Cadiz

Portland State University

Follow this and additional works at: https://pdxscholar.library.pdx.edu/open_access_etds Let us know how access to this document benefits you.

\section{Recommended Citation}

Cadiz, David Michael, "The Effects of Ageism Climates and Core Self-Evaluations on Nurses' Turnover Intentions, Organizational Commitment, and Work Engagement" (2010). Dissertations and Theses. Paper 50.

https://doi.org/10.15760/etd.50

This Dissertation is brought to you for free and open access. It has been accepted for inclusion in Dissertations and Theses by an authorized administrator of PDXScholar. Please contact us if we can make this document more accessible: pdxscholar@pdx.edu. 
The Effects of Ageism Climates and Core Self-Evaluations on Nurses' Turnover

Intentions, Organizational Commitment, and Work Engagement

by

David Michael Cadiz

A dissertation submitted in partial fulfillment of the requirements for the degree of

Doctor of Philosophy

in

Applied Psychology

Dissertation Committee:

Donald Truxillo, Chair

Talya Bauer

Berrin Erdogan

Leslie Hammer

Cynthia Mohr

Diana White

Portland State University

(C) 2010 


\begin{abstract}
It is estimated that by 2018 , workers age 55 or older will compose nearly a quarter of the labor force (Tossi, 2009). The aging workforce is dramatically affecting the nursing workforce. Indeed, the nursing workforce is expected to face staffing shortages of epidemic proportions because of the impending retirement of nurses who are Baby Boomers (Buerhaus, et al., 2006). Moreover, the nursing shortage is exacerbated by younger nurses' greater willingness to turn over (Aiken et al., 2001). Consequently, investigating how the workplace context affects retention of nurses is important. The present study sought to address the nursing shortage concern through examining how the workplace climate associated with age-related worker treatment and individual characteristics affect nurse retention. In this study, I developed and validated new ageism climate measures, which include younger worker, older worker, and general ageism climates. I examined how ageism climates affect people's job withdrawal intentions, organizational commitment, and work engagement. Additionally, I investigated whether Core Self-Evaluation (CSE; Judge, Locke, Durham, 1998) moderates the ageism climates relationships with the outcome variables.
\end{abstract}


During the scale development and validation process, I found that assessments of younger and older worker ageism climates depend on the age of the respondent, whereas general ageism climate did not have this dependency. Because younger and older ageism climates displayed measurement non-equivalence across age groups, I tested each of my hypotheses using three sample variations (under 40, 40 and older, and combined sample). In the under 40 sample, CSE buffered the negative effects of negative older and younger worker ageism climates, and CSE enhanced the positive effects of a positive general age climate on turnover intentions and organizational commitment. In the 40 and older sample, I found that less ageist younger and older worker climates were associated with decreased turnover intentions and increased affective commitment. Finally, in the combined sample, I observed that a less ageist general ageism climate was associated with lower turnover intentions and greater affective commitment.

The results contribute to our understanding of how perceptions of age-related treatment affect important workplace outcomes. The findings also support ageism climates as separate measures. However, additional measure development and validation is needed because this was the initial study to investigate ageism climate. This study has implications for the relational demography paradigm (Tsui \& O'Reilly, 1989) in that people's age group identification may affect their ageism climate perceptions. This potentially explains the differential relationships among the ageism climates on the outcomes between the under 40 and 40 and older age groups. From a practical perspective, improving ageism climates in the workplace could positively affect nurse retention, which could alleviate some of the nursing shortage concerns. 


\section{DEDICATION}

I dedicate this dissertation to my son, Benjamin. I hope that I will make you as proud of me as I am of you. 


\section{ACKNOWLEDGEMENTS}

I would like to acknowledge and thank my wife, Shauna, and the rest of my family for their unwavering support throughout my pursuit of my doctorate. I would also like to acknowledge and thank my advisor and dissertation chair, Donald Truxillo, for his guidance and passion as an advisor which has inspired me to try to be the best I/O graduate student I could be. Additionally, I would like to thank my dissertation committee for their time and the feedback that they have provided. Finally, I would like to thank the ONRP Research Team, Sue Davidson from the Oregon Nurses Association, and Northwest Health Foundation because without your effort, collaboration, and financial support, this dissertation would not have been possible. 
TABLE OF CONTENTS

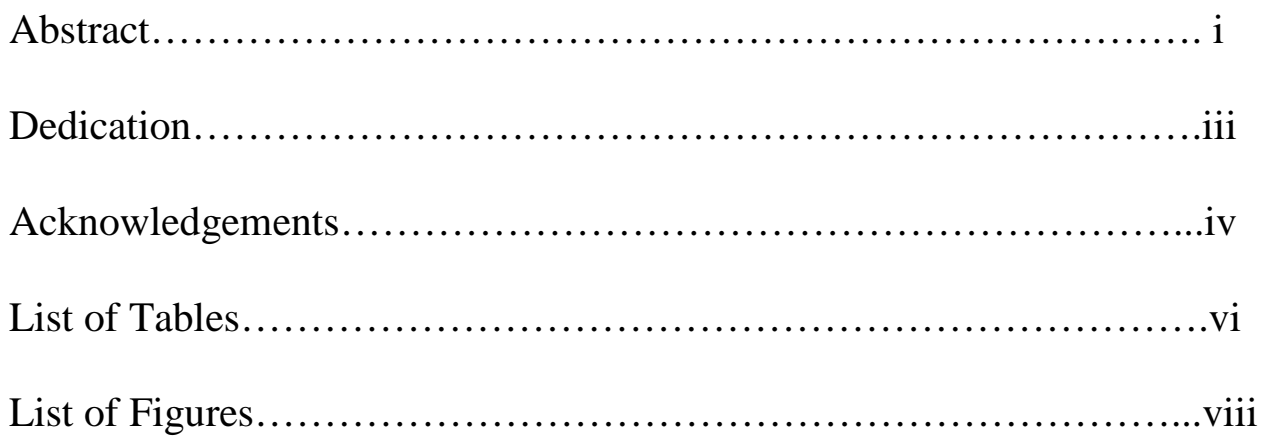

Chapter 1: Introduction..............................................

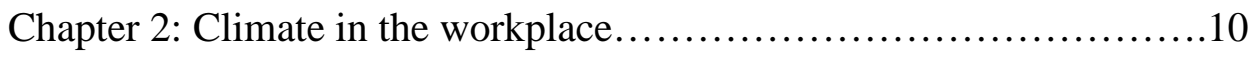

Chapter 3: Age Bias, Diversity, and Ageism climates....................21

Chapter 4: Core Self-Evaluations....................................47

Chapter 5: Model Outcomes and Hypotheses.............................57

Chapter 6: Method.................................................... 71

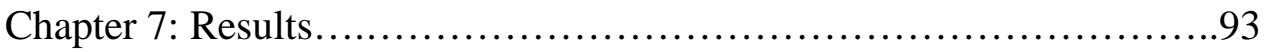

Chapter 8: Discussion................................................ 139

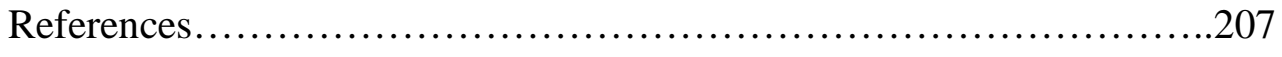

Appendix: Informed Consent Form and Utilized Oregon Nurse

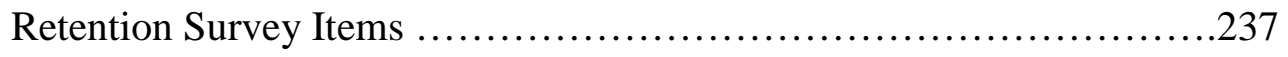




\section{LIST OF TABLES}

Table 1. Summary of Hypotheses.................................175

Table 2. Ageism Climate Scale Items and Their Relationship

with Age Stereotypes and Diversity Climate Research..................... 176

Table 3. Means, Standard Deviations, and Correlations among

Study Variables .................................................. 177

Table 4. Ageism Climates Inter-Item Correlations.......................179

Table 5. Exploratory Factor Analysis for the Ageism Climate Scales.......180

Table 6. Confirmatory Factor Analysis Results........................181

Table 7. Older Worker Climate Measurement Equivalence Analysis....... 182

Table 8. General Age Climate Item Correlation Investigation............... 183

Table 9. Younger Worker Climate Item Correlation Investigation ............184

Table 10. Convergent and Discriminant Validity Results...................185

Table 11. Regression Analysis with Time 2 Organizational

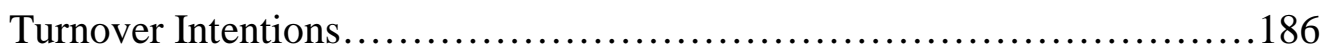

Table 12. Regression Analysis with Time 1 Organizational

Turnover Intentions............................................ 187

Table 13. Regression Analysis with Time 2 Affective Organizational

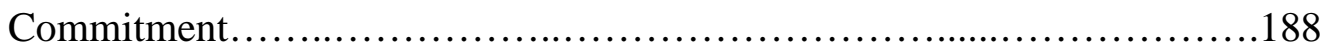

Table 14. Regression Analyses with Time 1 Affective Organizational

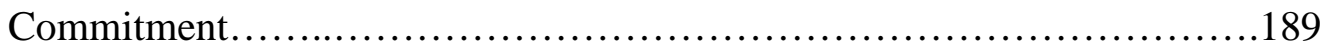

Table 15. Regression Analysis with Time 2 Work Engagement.................190

Table 16. Regression Analysis with Time 1 Work Engagement.............191 
Table 17. Regression Analysis with General Age Climate and

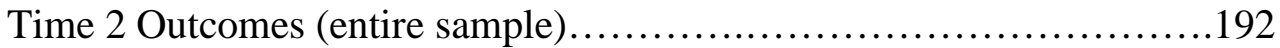

Table 18. Regression Analysis with General Age Climate and

Time 1 Outcomes (entire sample)..................................193

Table 19. Summary of Significant Regression Coefficients Across

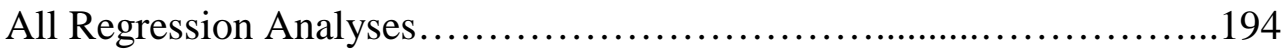

Table 20. Post Hoc Power Analysis................................... 195

Table 21. $\mathrm{R}_{\mathrm{wg}(\mathrm{j})}$ and ICC Analysis for the Ageism

Climate Measures..................................................196 


\section{LIST OF FIGURES}

Figure 1. Hypothesized Conceptual Model.......................197

Figure 2. Best Fitting Ageism Climate Model .....................198

Figure 3. Young Age Climate X CSE Interaction on Time 2

Organizational Turnover Intentions (Under 40)...................199

Figure 4. General Age Climate X CSE Interaction on Time 2

Organizational Turnover Intentions (Under 40)..................200

Figure 5. Older Worker Climate X CSE Interaction on Time 2

Organizational Turnover Intentions (40 and older)...............201

Figure 6. Younger Worker Climate X CSE Interaction on Time 1

Organizational Turnover Intentions (under 40)..................202

Figure 7. Older Worker Climate X CSE Interaction on Time 1

Organizational Turnover Intentions (under 40)...................203

Figure 8. General Age Climate X CSE Interaction on Time 1

Organizational Turnover Intentions (under 40).....................204

Figure 9. Younger Worker Climate X CSE Interaction on Time 1

Affective Organizational Commitment (under 40).................205

Figure 10. General Age Climate X CSE Interaction on Time 1

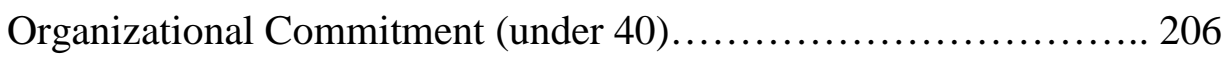


Ageism Climate 1

\section{Chapter 1: Introduction}

The fact that the United States workforce is aging is having a dramatic impact on organizations. Indeed, by 2018 it is estimated that approximately one quarter of the workforce will be age 55 or older (Tossi, 2009). However, due to advances in medical technology, life expectancies and quality of life in mid-to-late adulthood are also increasing, which means that our "traditional" conceptions about a person's life course or trajectory are also changing. In fact, the increase in older workers in the labor pool may not only reflect a scarcity of replacement resources, but it could also reflect a change in the perceptions of aging, among both older workers and their co-workers. Additionally, as a response to the recent dramatic decline in economic conditions, people may be working longer and harder to maintain employment in order to supplement their evaporating retirement savings.

The confluence of these events has led to an increasingly age diverse workplace. On the one hand, an age-diverse workplace may provide a great opportunity for organizations to integrate a variety of perspectives and experiences accumulated through their workers' life spans. On the other hand, greater age diversity in the workplace could also lead to increased problems such as workplace age stereotypes and discrimination, negatively affecting people's perceptions of and attitudes about their organizational environment and their job.

Psychological climate and organizational climate research examines how people experience and make sense of organizations (Schneider, 2000). A basic assumption of climate research is that individuals respond to their work environments based on their 
Ageism Climate 2

appraisals and perceptions of these environments (James \& James, 1989). Therefore, individual perceptions and evaluations are affected by the workplace context in which they are embedded. The workplace context encompasses organizational policies, practices, and procedures (Schneider, 2000), as well as interpersonal interactions with internal personnel (e.g., coworkers and supervisors) and external contacts such as clients and customers. For instance, experiencing workplace age bias is one contextual factor that could affect people's organizational climate perceptions. Indeed, age bias research has generally found negative associations with being an older worker (Finkelstein \& Farrell, 2007; Posthuma \& Campion, 2009) which manifest as stereotypes and could lead to discrimination in the form of adverse workplace decisions. For instance, older workers are viewed as being resistant to change, having lower physical ability, and being untrainable (Rosen \& Jerdee, 1976b; 1977). Moreover, with regard to adverse workplace decisions, older workers have been observed to receive less training (Maurer \& Rafuse, 2001), lower assessments of promotability (Shore, Cleveland, \& Goldberg, 2003), and harsher consequences for lower performance (Rupp, Vodanovich, \& Credé, 2006). Consequently, these adverse workplace conditions for older workers may be contributing to the increase in claims of age discrimination, which are a concern for organizations (McCann \& Giles, 2002). However, age discrimination may not be limited to older workers. Younger workers also face negative age-related experiences (Gee, Pavalko, \& Long, 2007). Indeed, Gee and colleagues (2007) found that both younger and older workers reported exposure to age discrimination. 
Ageism Climate 3

Accordingly, negative age-related encounters, experienced by people of any age, may influence appraisals of the workplace environment leading to negative climate perceptions. Negative workplace climate perceptions could lead to negative individual outcomes including performance, satisfaction, and motivation (Baltes, 2001). Indeed, meta-analyses examining the effect of climate on work outcomes have found that climate perceptions are significantly related to an individual's work attitudes, motivation, performance, psychological well-being, and withdrawal (Carr, Schmidt, Ford, \& Deshon, 2003; Parker, Baltes, Young, Huff, Altmann, Lacost, \& Roberts, 2003). As workplace age diversity continues to increase, a worker's age may become an increasingly important factor when investigating people's workplace experiences and perceptions of those experiences. Therefore, it is imperative to examine how age climate perceptions affect workers in organizations.

Considerable research attention has focused on the effects of climate, diversity, and age bias on workplace outcomes. However, gaps exist in these in these literatures, several of which were addressed in this dissertation. First, the climate literature has focused on various types of organizational climate, but not age climate specifically. For example, considerable work has examined climates for safety (Clarke, 2006) and customer service (Bowen \& Schneider, 1988; Schneider, 1990; Schneider, White, \& Paul, 1998; Schneider \& Gunnarson, 1990), but I have been unable to identify research examining age climate. Second, research has also examined diversity climate (e.g., McKay, Avery, \& Morris, 2008), but there is no existing research examining ageism climates in organizations. Therefore, I created ageism climate measures, which reflect 
Ageism Climate 4

people's perceptions of an organization's treatment of workers with regard to their age, and investigated how ageism climates affect workplace outcomes.

Moreover, most of the research on age bias and stereotypes has focused on older workers (Kite, Stockdale, Whitley, \& Johnson, 2005), but as previously described, younger workers also face negative age-related issues in organizations. In fact, I found a significant negative correlation between chronological age and experienced age discrimination in my master's thesis (Cadiz, 2009), which verified that younger nurses face age discrimination in the workplace. However, I did not examine contextual factors in my master's thesis, which could be an explanation for my observations. Therefore, both younger and older workers are affected by age bias, and my ageism climate measures address this fact by not only measuring a general age climate, but also an older worker and younger worker climate. The multi-faceted treatment of workplace climate allowed me to examine whether people's perceptions of the treatment of older versus younger workers have differential effects on individual outcomes.

Additionally, individual characteristics have generally been ignored in the climate literature. However, cognitive-affective personality system theory (Mischel \& Shoda, 1995 ) indicates that individuals differentially focus on different elements of the environment, how cues are cognitively and affectively categorized, and how the consequences of encoding interact with existing cognitions. Therefore, the processes associated with the cognitive-affective personality system suggest that individual personality characteristics could influence the cognitive appraisal processes when evaluating one's work environment. Core self-evaluation (CSE; Judge, Locke, \& 
Durham, 1997) is a personality trait that may influence how individuals appraise and react to their work context. CSE is argued to be the "fundamental premises that individuals hold about themselves and their functioning in the world" (p. 168; Judge, Erez \& Bono, 1998). These fundamental beliefs are argued to influence individuals' appraisals of external events (Judge et al., 1997). This is congruent with psychological climate in that psychological climates are described as being people's response to their work environments based on their appraisals and perceptions of these environments (James \& James, 1989). Therefore, I investigated the combined influence of CSE and age climate perceptions on work outcomes.

Furthermore, this dissertation expanded CSE's nomological network through exploring its relationship with age-related contextual variables (i.e., ageism climates), as well as investigated CSE's relationship with turnover intention, work engagement, and organizational commitment-three relationships that little or no previous research has examined. Since its introduction to the organizational literature, the CSE construct has received a considerable amount of research attention, and empirical evidence is mounting for CSE's direct and moderating influence on several important workplace outcomes. Therefore, I examined how core self-appraisals may also affect people's commitment to their organization, engagement with their work, and job withdrawal intentions.

I took an interactionalist perspective (Tett \& Burnett, 2003) as to how personal characteristics and the work context affect job withdrawal, work attitudes, and worker well being. Specifically, I examined the interaction between CSE and ageism climates on turnover intentions, organizational commitment, and work engagement. Conservation of 
Ageism Climate 6

Resources Theory (COR; Hobfoll, 1989) and Trait Activation Theory (TAT; Tett \& Burnett, 2003) provided the theoretical explanation for my hypothesized relationships. Briefly, COR theory is based on the assumption that people strive to retain, protect, and build resources, and what is threatening to them is the potential or actual loss of these valued resources (Hobfoll, 1989). TAT assumes that individual differences are enacted only when the situation provides a trait-relevant cue signaling that it is appropriate to demonstrate or display that propensity (Tett \& Gutterman, 2000).

The combination of COR and TAT theories provides a useful framework to explain how personal and contextual characteristics can affect people in the workplace. COR theory provides a broad explanation as to how personal and contextual resources can be allocated in the workplace to enhance or hinder people's ability to achieve success. Indeed, Hobfoll and Wells (1998) describe the convergence of different sources of resources as a resource caravan, which they define as being the accumulation of resources that people have obtained, protected, and lost through their life experiences and used to face current and future stressors. For instance, having greater levels of personal resources and a supportive age climate could result in a greater caravan of resources to allocate to being successful in the workplace, resulting in a greater likelihood of positive individual work outcomes. Furthermore, TAT complements COR theory because it explains how specific contextual cues activate certain individual tendencies to behave and react when exposed to certain environments. Therefore, positive ageism climates may be a CSE-relevant cue that triggers some, but not all people to take advantage of their favorable environment and accumulate personal resources in their resource caravan. 
Therefore, the COR and TAT approaches provided the conceptual explanation for how CSE and ageism climates affect work attitudes, well-being, and job withdrawal.

Finally, my dissertation utilized a sample of registered nurses, which was an appropriate population to study the influence of age-related treatment in the workplace for two reasons. First, the nursing workforce is growing older and a significant proportion of the nurses are close to retirement. In fact, it is projected that $41 \%$ of current nurses in Oregon are going to retire by 2025 (Burton, Morris, \& Campbell, 2005). Nationally, it is projected that within the next 10 years, $40 \%$ of RNs will be over the age of 50 . In fact, I previously observed a mean age of 45.75 years $(S D=11.31)$ in a sample of Oregon registered nurses, and the ages ranged from 22 to 69 years old (Cadiz, 2009). Therefore, the nursing workforce exemplifies the aging workforce trend that is being faced across U.S. organizations, and was an appropriate population to investigate age-related treatment in the workplace.

Second, the growing population of older and elderly adults is placing increased demands on the healthcare system, highlighting the need for additional healthcare personnel including registered nurses (RNs). RNs are the largest group of health care professionals in the United States (BLS, 2000). However, the nurse workforce is experiencing a nurse shortage of epidemic proportions (Buerhaus, Staiger, \& Auerbach, 2000). Buerhaus et al. (2000) estimated that there will be a $20 \%$ deficit in the registered nurse (RN) workforce by the year 2020. Furthermore, the nursing profession experiences high turnover rates because the job is highly stressful and extremely physically demanding (Buerhaus, Donelan, Ulrich, Norman, \& Dittus, 2006). In 2000, it was 
reported that the national average turnover rate for hospital staff nurses was $21.3 \%$ (AONE, 2002), which means that, on the average, more than one out of every five hospital staff nurses turned over during that year. Moreover, research has identified that younger nurses are more susceptible to feeling overwhelmed and stressed (Symes, Krepper, Lindy, Byrd, Jacobus, \& Throckmorton, 2005), which could explain why they are more willing to turn over (Aiken et al., 2001). Consequently, my research focused on providing insight into how to alleviate nurse shortages and staffing issues through investigating how ageism climates and CSE affect retention-related outcomes for nurses across the age spectrum.

In summary, my dissertation contributes to the literature in several ways. First, I develop and validate measures of ageism climate, which have not been previously discussed in the diversity climate literature. Second, I examine how ageism climates affect important workplace outcomes, contributing to the aging workforce and diversity literatures. Third, I examine the relationships between core self-evaluations and ageism climates. This is the first time CSE has been examined in conjunction with diversity climate measures; thus, my dissertation extends CSE's nomological network. Fourth, I broaden the conceptualization of ageism climate by not only investigating general ageism climate, but also age climates associated with older and younger workers. Fifth, I investigate CSE as a moderator of the relationship between ageism climates and job withdrawal, work attitudes, and well-being; thus this dissertation provides a comprehensive investigation of how age-related personal and contextual variables affect multiple aspects of people's work experiences. Finally, I utilize a sample of registered 
nurses and examine how ageism climates affect retention-related variables, which has important societal implications because preventing improper nurse staffing could increase the health care system's ability to administer quality care.

In the subsequent chapters, I first review the organizational and psychological climate literature. Second, I review the age bias and diversity literatures, which informed the development of my measures of ageism climate. Third, I provide an overview of the conceptualization, correlates, and outcomes of core self-evaluations (CSE). Fourth, I build the theoretical and empirical arguments for my hypothesized relationships among ageism climates, CSE, and three individual outcome variables. Fifth, I describe my study's research method. Sixth, I outline the results of my construct validation of my ageism climate measures and review the tests of my hypotheses. Finally, I discuss the theoretical and practical implications of the findings, my study's potential limitations, and provide suggestions for future research. 
Ageism Climate 10

Chapter 2: Climate in the workplace

Organizational climate is a construct that captures how employees perceive and interpret the environmental and contextual factors in the workplace. Climate researchers have found empirical support for how people's perceptions of the environment affect their workplace behaviors and attitudes (Ostroff, Kinicki, \& Tamkins, 2003). In this chapter, I discuss the distinction between climate and culture, explain how climate has been conceptualized, and summarize empirical research investigating the antecedents and outcomes of climate.

\section{Organizational Climate versus Culture}

Organizational climate and culture research examines how people experience and make sense of organizations (Schneider, 2000). Organizational climate and culture are derived from the common assumption of shared meaning of some aspect of the organizational environment (Ostroff et al., 2003). Moreover, both concepts are related to organizational structure, policies, practices, and procedures. However, climate and culture have been approached from different scholarly traditions and are rooted in different research disciplines (Ostroff et al., 2003). Organizational climate was introduced by Kurt Lewin and colleagues when they described the creation of social climates (Lewin, 1951; Lewin, Lippit, \& White, 1939). Climate encompasses what people experience, observe, and report in organizational situations (Schneider, 2000). Furthermore, it includes employee's perceptions of formal and informal organizational policies, practices, and procedures (Reichers \& Schneider, 1990). Organizational climate is focused on the individual, and how that person perceives, feels about, and behaves in 
specific organizational situations. Therefore, climate is subjective, temporal, and situation-specific (Dennison, 1996).

In contrast, organizational culture has its roots in anthropology, and it has mainly relied on qualitative methods to assess how shared meanings and common ways of viewing events are derived. Schein (1992) defined culture as "a pattern of shared basic assumptions that the group learned as it solved its problems of external adaption and internal integration, that has worked well enough to be considered valid" (p.12). Schein further explained that organizational members will pass this learned culture to new members through socialization and communication processes as the correct way to perceive, think, and feel in relation to the organization. Culture represents an evolved context that is in embedded systems, is rooted in history, and is resistant to manipulation (Dennison, 1996). Therefore, climate focuses on experiential descriptions and perceptions of what happens, and culture helps identify why these things happen (Ostroff et al., 2003).

\section{Conceptualization, Antecedents, and Outcomes of Climate}

Although there is merit in studying culture in organizations, the focus of the present study is on psychological climate. One issue that has plagued climate and culture research is the confusion around the appropriate use of these two concepts in regards to levels of theory, measurement, and analysis (Parker, Baltes, Young, Huff, Altmann, Lacost, \& Roberts, 2003). Whereas organizational culture is a group-level construct, climate is focused on the individual. In this dissertation, I focus on individual's perceptions of their organization in terms of age climate and how they affect individual- 
level outcomes. The strength of organizational climate as a concept is that research supports the impact of psychological climate on important individual outcomes (Carr, Schmidt, Ford, \& DeShon, 2003; Parker et al., 2003). In the subsequent paragraphs, I will briefly review the climate research including the distinction between general and specific climate, predictors of psychological climate, and the individual outcomes that it affects.

Conceptualization of climate. A point of contention in climate research is the conceptual distinction between molar (general) and specific climate constructs. Initially, psychological climate was treated as a general concept that describes different general psychological constructs that individuals use to interpret and derive meaning from the work environment (James, Choi, Ko, McNeil, Minton, Wright, \& Kim, 2007). General climate proponents argue that climate can be organized into general latent factors which influence individual perceptions and reaction to the organizational environment (Carr et al., 2003). For instance, leveraging Locke's (1976) personal and work-related values theory, James and James (1989) identified four psychological climate composites that focused on individuals' valuations of their work environment. Their climate dimensions included role stress and lack of harmony, job challenge and autonomy, leadership facilitation and support, and work-group cooperation, friendliness, and warmth. The researchers argued that their research suggests that perceptions of the work environment appear to factor into domains that are congruent to personal values (James \& James, 1989; James et al., 2007). In fact, James and James (1989) proposed that these domains or dimensions can be collapsed into a general psychological climate, $\mathrm{PCg}$, which they 
argued represents an overall view of an individual's work environment as being personally beneficial or detrimental.

Furthermore, Carr et al. (2003) utilized the molar climate perspective in their meta-analysis examining climate and individual outcomes. They proposed that three general climates—affective, cognitive, and instrumental—influence job performance, psychological well-being, and withdrawal through the mediating process of cognitive and affective states, which were defined as being job satisfaction and organizational commitment. They found general support for their proposed model and concluded that molar climates may be most appropriately applied in research focused on predicting broader individual-level outcomes, while specific climates may be more appropriate when analyzing specific outcomes.

Although most of the initial theory and empirical research utilized the molar perspective of climate, a recent trend in climate research has been to examine specific climates with specific outcomes. Parker et al. (2003) described this type of research as the objective perspective of organizational climate which encompasses employees' descriptions of areas of strategic focus and organizational functioning. For instance, research has focused on important organizational functions such as customer service (Schneider \& Bowen, 1985), training (Noe, 1986), safety (e.g., Zohar, 2000), and diversity (McKay, Avery, \& Morris, 2008). The specific climate perspective is ingrained in the argument that climates must have a referent in order to have meaning (Pritchard \& Karasick, 1973). In other words, several "climates for something" are embedded in organizations (Schneider \& Reichers, 1983). Moreover, some researchers believe that 
collapsing multiple climate dimensions into a single indicator of psychological climate could lead to overlooking meaningful relationships between lower level climate factors with outcome variables (Baltes, Zhdanova, \& Parker 2009). For instance, Parker (1999) found that common method variance leads to inflated correlations between climate dimensions leading to spurious support for the general psychological climate variable. Since the present study focuses on individual perceptions of how the organization specifically treats employees in regards to their age, it is appropriate that I utilize the specific climate perspective.

Moreover, there has been further delineation of the perspective or referent in which the person evaluates the specific climate. Baltes, Zhdanova, and Parker (2009) discussed and examined the distinction between psychological climate measured with an individual referent and psychological climate measured with an organizational referent. They argued that when respondents are asked about their own experiences (e.g., 'I' or 'my' referent), they may focus within and ignore experiences of others whereas respondents asked about experiences of everybody in the organization (e.g., 'We', 'employees here' referent) may answer from the perspective of people in the organization. They found that individual and organizational referents had unique relationships with job satisfaction supporting the perspective that individuals take when evaluating their environment does matter. Furthermore, support for self-assessments being context dependent is observed in the frame of reference (FOR) literature. For instance, research found that people's assessments of their personality are affected by their FOR (Hunthausen, Truxillo, Bauer, \& Hammer, 2003). 
Antecedents of climate. In general, the research examining the antecedents of climates has been sparse (Ostroff, Kinicki, \& Tamkins, 2003). Indeed, more research has been focused on the outcomes of climate rather than on how climate develops (Dennison, 1996). Climate emergence has been approached from a number of different theoretical perspectives including structuralist, attraction-selection-attrition (ASA), social interaction, and leadership processes (Ostroff et al., 2003; Schneider \& Reichers, 1983). Although the focus of this dissertation is not to determine which approach is most efficacious, I feel it is useful to briefly discuss each perspective below.

The structuralist perspective argues that climate develops from structural (i.e., hierarchy, authority system, structure of role tasks) and contextual (i.e., organizational purpose, size, resources, and technology) characteristics of the organization (Payne \& Pugh, 1976). The major assumption of this perspective is that organizational characteristics create a common reality that facilitates shared perceptions, but it has received only modest support (Jones \& James, 1979). However, the introduction of specific strategic conceptualizations of climate may be a promising way of examining how organizational context produces climate (Ostroff et al., 2003). Indeed, Kozlowski and Hults (1987) found that technical, structural, and reward systems are related to a climate for technical updating.

The ASA or homogeneity perspective of climate development argues that individuals are attracted to and want to gain membership into organizations that have similar characteristics and views to their own (Schneider, 1987). Organization hiring and selection practices are used to find the applicants that best fit the organizational context, 
and attrition occurs when people's personal characteristics are incompatible with their work context. Therefore, the ASA processes lead to greater homogeneity within the organization resulting in similar perceptions and interpretations of the organization (Schneider, 1987). Ostroff, Kinicki, and Tamkins (2003) noted that there is a lack of empirical work that has examined homogeneity leading to greater shared perceptions of work context. However, some research has found that group cohesiveness has been positively related to climate perception agreement (Naumann \& Bennett, 2000).

A third approach for examining climate emergence is focused on social interactions. This perspective is embedded in the symbolic-interactionalist tradition, which focuses on the interdependent relationship between individuals and their context. Individuals create the work context, and the interaction between the context and people's interpretation of the context affect behavior (Schneider \& Reichers, 1983). Furthermore, shared perceptions and meaning are derived from interdependencies, social exchange, and transactions among employees (Ostroff et al., 2003). Equivocal results have been observed with regard this prospective, but some argue that the levels of formality associated with the interactions may be moderating the relationship between interactions and climate emergence (Ostroff et al., 2003).

Lastly, leadership processes are argued as another way to approach climate development (Ostroff et al., 2003). Leaders and supervisors, through their development, implementation, and enforcement of organizational policies, procedures, and practices guide employees' interpretation of the organizational environment (Naumann \& Bennett, 2000). For instance, high-quality leader-member exchange relationships are related to 
climate perceptions (Kozlowski \& Doherty, 1989). Little research has been conducted from this perspective, but it could be a promising area for future research.

In summary, there are several perspectives that have been theorized to influence the development and emergence of climate. Each approach could be useful in explaining how climate emerges in organizations. Moreover, these approaches could also provide insight into why individual characteristics may affect peoples' climate perceptions through the way they frame and interpret information from their workplace experiences.

Outcomes of climate. Although research analyzing the antecedents of climate is limited, research examining the outcomes of psychological climate has been quite extensive. Two types of studies have been used to analyze the relationship between climate and individual outcomes: (a) studies that focus on the individual level of analysis and examine the relationship among psychological climate perceptions and individual outcomes and (b) cross-level studies where aggregated climate scores are assigned to individuals and relationships with individual outcomes are examined (Ostroff et al., 2003). Since the focus of this study is on psychological climate, an individual-level variable, it is appropriate to focus my review on the individual outcomes that have been explored in the literature. In general, climate perceptions are thought to be the mediating link between organizational characteristics and individual outcomes (Parker et al., 2003). Climate perceptions provide a cognitive schema of the workplace, which facilitates the interpretation and sense-making that individuals attribute to organizational events and their response to these events to achieve desired outcomes (Parker et al., 2003). Indeed, climate variables have been found to have an effect on a variety of individual work 
outcomes including performance, attitudes, motivation, withdrawal, and well-being (Baltes, 2001; Carr et al., 2003; Parker et al., 2003).

Carr et al. (2003) and Parker et al. (2003) conducted meta-analyses that established the empirical relationship between climate and job performance. In both quantitative reviews, the researchers approached their analysis from the molar climate perspective and tested models focused on the indirect effect of climate perceptions on performance. Their models were based on the theorized assumption that the relationship between climate and performance is mediated by cognitive and affective states like work attitudes (e.g., job satisfaction, commitment) and motivation (Kopelman, Brief, \& Guzzo, 1990). Carr et al. (2003) found that job satisfaction and commitment mediated the relationship between three higher level climates - affective, cognitive, and instrumental — and performance. Moreover, Parker et al. (2003) also found that job satisfaction and commitment mediated the relationship between climate and performance. These researchers also observed that job involvement and work motivation mediated the relationship between climate and performance. In both meta-analyses, positive climates lead to positive affective and cognitive states, which lead to greater performance.

Withdrawal and psychological well-being are additional individual outcomes that have been analyzed in climate research. Carr et al. (2003) found support for the indirect effect of climate on withdrawal and psychological well-being through job satisfaction and organizational commitment. The researchers observed that positive affective, cognitive, and instrumental climates resulted in increased psychological well-being and decreased withdrawal, and this relationship was mediated by job satisfaction and organizational 
commitment. Thus, positive climates affect worker well being and withdrawal through their influence on job attitudes.

Evidence that specific climates predict behavioral outcomes is mounting. For instance, safety climate has been found to predict safety behavior (Christian, Bradley, Wallace, \& Burke, 2009; Ostroff, Kinicki, \& Tamkins, 2003; Schneider, 2000; Zohar, 1980). In addition, climate for justice was found to be related to helping behaviors (Naumann \& Bennett, 2000). Finally, climate for tolerance of sexual harassment was related to reporting of sexual harassment incidents (Hulin, Fitzgerald, \& Drasgow, 1996).

Climate researchers are also investigating climate at different levels of analysis. The results from this cross-level climate research suggest that climates aggregated at the unit or organizational level affect individual outcomes. For instance, store-level diversity climate was found to be related to sales performance (McKay, Avery, \& Morris, 2008), organizational-level justice climate affects helping behavior (Naumann \& Bennett, 2000), and unit-level safety climate is related to workplace accidents (Christian et al., 2009; Zohar, 2000).

In summary, empirical research suggests that climate is related to several different individual outcomes including work attitudes, withdrawal, and psychological well-being. However, I identified that a measure for age climate is missing from this literature. Therefore, in the following chapters, I develop the measures of ageism climate and examine the possible direct and moderated effect of workplace age climate on work attitudes, withdrawal, and psychological well-being. In the next chapter, I review the age 
Ageism Climate 20

bias, diversity, and climate literatures, which informed the development of my ageism climate measures. 
Ageism Climate 21

Chapter 3: Age Bias, Diversity, and Ageism Climates

As described in the previous chapter, psychological climate influences

individuals' attitudes, behaviors, and well-being. However, age climate perceptions have received no attention in the psychological climate literature (Jex, Wang, \& Zarubin, 2007). Since workforce projections suggest that the workforce age diversity will continue to increase well into this century (Tossi, 2009), it is important to understand how an organization's age-related climate affects individuals in the workplace. Accordingly, in this chapter, I review the age bias, workplace diversity, and diversity climate literature to show how these literatures informed the development of my ageism climate measures. Age Bias in the Workplace

An extremely rich literature has examined age biases in the workplace. Empirical research has found that older workers are generally viewed more negatively than younger workers (Gordon \& Arvey, 2004; Kite, Stockdale, Whitley, \& Johnson, 2005; Posthuma \& Campion, 2009). Bias can take the form of stereotypes, prejudice, and discrimination (Fiske, 2004). Fiske (2004) argued that stereotypes are associated with cognition, prejudice is related to affect, and discrimination is aligned with behavior. Finkelstein and Farrell (2007) leveraged Fiske's bias framework for their chapter on age bias and called it the tripartite view of age bias. I will utilize this framework to organize my brief review of the age bias literature.

Age stereotypes. In general, stereotypes are beliefs and expectancies that individuals assign to people due to their group membership (Finkelstein \& Farrell, 2007). Stereotypes help to simplify cognitive processing in regards to groups of people (Fiske, 
Ageism Climate 22

2004), and can influence the way individuals interact with each other (Hedge, Borman, \& Lammelin, 2004). The majority of age bias research focuses on age stereotypes as a key variable of interest (Finkelstein \& Farrell, 2007; Posthuma \& Campion, 2009). The inherent assumption of age stereotype research is that age-related stereotypes affect how workplace decisions are made (Shore, Chung-Herrera, Dean, Ehrhart, Jung, Randel, \& Singh, 2009).

Empirical research has identified a variety of stereotypes associated with older workers. In their comprehensive review of the age stereotype literature, Posthuma and Campion (2009) categorized and summarized several common workplace stereotypes. The researchers identified five major categories of negative older worker stereotypes including having poorer performance, being resistant to change, having lower ability to learn, having shorter tenure, and being more costly. I will discuss each of these common stereotypes in more detail below.

In general, research suggests that people expect older workers to have lower job performance compared to younger workers (Gordon \& Arvey, 2004; Hedge et al., 2006). Moreover, older workers are also seen as less competent and as having less ability, motivation, and lower productivity compared to younger workers resulting in decreased job performance (Kite et al. 2005; McCann \& Giles, 2002; Rosen \& Jerdee, 1976a). Cuddy and Fiske (2002) argued that this stereotype may stem from the idea that older workers are associated with less desirable traits than younger workers, thus affecting people's perceptions of older worker's ability to perform. However, research generally refutes the idea that age is negatively related to job performance (McEvoy \& Cascio, 
1989; Waldman \& Avolio, 1986), and in some cases, certain types of performance are actually positively related to age ( $\mathrm{Ng} \&$ Feldman, 2008). Indeed, results from a recent meta-analysis examining the age and performance relationship indicated that chronological age was positively related to several types of performance including organizational citizenship behaviors and safety performance ( $\mathrm{Ng} \&$ Feldman, 2008).

Posthuma and Campion (2009) identified resistance to change as another common older worker stereotype found in the workplace. The resistance to change stereotype encompasses the belief that older workers are set in their ways and are difficult to train (Posthuma \& Campion, 2009). For instance, research has found that managers feel older workers are less flexible and more resistant to change (Rosen \& Jerdee, 1977; Weiss \& Maurer, 2004). Likewise, research also suggests that older workers are viewed as less adaptable (Chiu, Chan, Snape, \& Redman, 2001; DeArmond, Tye, Chen, Krauss, Rogers, Sintek, 2006), which is conceptually similar to the resistance to change stereotype.

Decreased ability to learn is a third common older worker stereotype identified by Posthuma and Campion (2009). Rosen and Jerdee (1976a), for instance, found that older workers are viewed as having less potential. Additionally, meta-analytic findings suggest that people feel that older workers have less potential for development (Finkelstein, Burke, \& Raju, 1995). The decreased ability to learn has also been reflected in lower expectations for older workers to be trained. Indeed, research has found that older workers are perceived as being less able to grasp new ideas and learn quickly (Warr \& Pennington, 1993). In addition, Maurer et al. (2008) investigated the effects of negative stereotypes associated with older workers' ability to develop, and found that these 
Ageism Climate 24

negative stereotypes have an adverse impact on people's career development self-efficacy and their interest in career development. Therefore, research not only supports the existence of this lack of ability stereotype, but also its negative effects on older workers' intent to participate in career development activities.

Another negative stereotype associated with older workers is they are perceived as having shorter tenure with an organization or less time left before retirement (Posthuma \& Campion, 2009). These perceptions result in the belief that older workers will provide less return on investments, which may result in less access to training and opportunities for development (Posthuma \& Campion, 2009). However, the perception of older workers not being a good return on investment may not match reality. For example, research has found that older workers are less likely to turnover (Hedge et al., 2006) and they are remaining in the workforce longer than in the past (Tossi, 2009), which arguably would increase the likelihood that organizations would see a return on their investment since the older worker may stay with an organization longer than previously expected.

The final common workplace stereotype of older workers is that they are seen as being more costly than younger workers (Cox \& Nkomo, 1992; Posthuma \& Campion, 2009). Older workers are perceived as more costly because they are generally paid higher wages, use more benefits, and are closer to drawing a pension (Capowski, 1994). Remery, Henkens, Schippers, and Ekamper (2003) found that the majority of company officials associated increases in the average age of their workforce with greater labor costs. Additionally, Finkelstein, Higgins, and Clancy (2000) found support for an 
economic-based stereotype when they analyzed participant justifications as to why a younger person was selected as better applicant over an older person.

Not all stereotypes of older workers are negative. Indeed, older workers are seen as being more dependable than younger workers (Posthuma \& Campion, 2009). Moreover, older workers are also seen as being more experienced (Finkelstein et al., 2000) and wise (Kogan \& Shelton, 1960). In addition, Truxillo, McCune, Bertolino, and Fraccaroli (2008) found that older workers, in comparison to younger workers, are perceived as having several positive attributes including being more conscientious, having more crystallized intelligence, and being more emotionally stable in regards to the anxiety, self-consciousness, immoderation, and vulnerability facets of neuroticism. The research on positive stereotypes of older workers adds a level of complexity as to how age stereotypes may function in the workplace, and may explain the inconsistent results with regard to some research finding a lack of endorsement of negative older worker stereotypes (Weiss \& Maurer, 2004). In other words, people may have conflicting positive and negative stereotypes associated with older workers, which may affect the way they are viewed in the workplace. For instance, Fiske, Cuddy, Glick, and Xu (2002), found that older people are viewed as being warm, but are also viewed as being less competent. Warmth may be a positive characteristic in certain circumstances, but competence (or incompetence) may be considered more important in the workplace which could lead to denial of workplace opportunities (Shore \& Goldberg, 2005).

Most of the research on age stereotypes has focused on older workers. However, younger workers also face negative stereotypes in the workplace. The lack of research 
focusing on young age-stereotypes may be due to the fact that in a lot of the older worker stereotype research, the referent or comparator is a younger worker. Therefore, the negative stereotypes held about older workers may be a reflection of the positive stereotypes held about younger workers (Avolio \& Barrett, 1987). Nevertheless, the limited research investigating negative younger worker stereotypes indicates that younger workers are perceived as being less trustworthy (Loretto, Duncan, \& White, 2000), more apt to 'job hop' or have less loyalty to organizations (Coy, Conlin, \& Thorton, 2002), and are seen as performing less individually-focused organizational citizenship behaviors (Truxillo et al., 2008).

In summary, evidence supports the existence of relatively common age stereotypes in the workplace. Arguably, the internalization of the negative stereotypes can lead to people feeling that they have lower value to an organization (Ostroff \& Atwater, 2003). In addition, these stereotypes could impact the way individuals interact with each other and may shape people's climate perceptions about the treatment of workers regarding their age (Hedge et al., 2006). Age-related policies and procedures may affect worker perceptions and sense-making of the organizational environment. Therefore, the age stereotype literature could inform how individual age climate perceptions may develop.

Age discrimination. Although a great deal of research has examined age stereotypes in the age bias literature, an abundance of research also analyzes age discrimination in the workplace (Gordon \& Arvey, 2004). Age discrimination is considered the behavioral aspect of age bias and is related to people's tendency to treat 
others in a particular way due to their membership in a particular age category (Finkelstein \& Farrell, 2007). Thus, age discrimination captures the behavior toward individuals due to their age-group membership, and it may lead to adverse workplace conditions based on age. Indeed, age-discrimination claims are increasing, which indicates it is an important concern in organizations (McCann \& Giles, 2002).

Age stereotypes are one of the many antecedents that lead to age discrimination (Finkelstein \& Farrell, 2007). Indeed, a modest relationship between stereotypes and discrimination has been observed in social bias research (Fiske, 2004). However, institutional discrimination may not be solely based on stereotypes, and external societal forces may also be involved with discrimination, such as a scarcity of resources due to bad macroeconomic conditions (Shore \& Goldberg, 2005). Nevertheless, age-related discriminatory behavior could at least be partially explained by common ageist stereotypes that exist in organizations. For instance, the lower performance stereotype associated with older workers could lead to increased chances of being laid off and a harder time finding jobs (Goldberg, 2007; Osborne \& McCann, 2004). In addition, the resistance to change may lead to having decreased opportunities for advancement or promotion in the workplace (Shore et al., 2003). Decreased ability to learn and shorter tenure may lead to less access to training (Maurer \& Rafuse, 2001). Finally, the stereotype of being perceived as more costly may result in older workers having a greater risk of being laid off or being offered early retirement (Osborne \& McCann, 2004).

In addition, younger worker stereotypes can also lead to discriminatory behaviors toward younger workers. As the average age of workers in the workforce increases, it 
Ageism Climate 28

may result in changes in how ageist beliefs and behaviors function in the workplace. Indeed, Weiss and Maurer (2004) found far fewer negative stereotypes of older workers in their replication of Rosen and Jerdee's original studies (1976a, 1976b). Moreover, the graying of the workforce is resulting in a decrease in the proportion of younger workers, leading to younger workers becoming a minority in the workforce, which may result in an increase of younger worker biases due to negative out-group biases. In fact, Gee, Pavalko, and Long (2007) found that both younger and older workers reported exposure to age discrimination. Empirical research has found that younger workers were given fewer responsibilities at work because they were perceived as less trustworthy (Loretto et al., 2000). In addition, evidence suggests that younger workers are denied access to promotions because they were perceived as less experienced and as lacking in skills (O’Higgins, 2001) or they need to 'pay their dues' (Lieber, 1999).

The workplace literature has approached age discrimination by examining the relationship between age and adverse workplace decisions such as applicant selection, performance assessment, training access, and promotions. Two meta-analyses have quantitatively summarized the literature examining age biases in applicant selection situations. First, Finkelstein, Burke, and Raju (1995) examined age bias and discrimination in simulated employment contexts. They found that younger applicants were assessed more favorably than older applicants $(d=.29)$. They also observed that age bias was moderated by several factors including the age of the evaluators, whether positive or negative information was provided about the applicant, and whether a within or between subjects design was used. A more recent meta-analysis of age bias and 
Ageism Climate 29

discrimination was conducted by Gordon and Arvey (2004). Similar to Finkelstein et al. (1995), they found that younger workers were evaluated more favorably than older workers. However, they observed a smaller effect size $(d=.11)$ than the analysis provided by Finkelstein et al. (1995). This discrepancy may be explained by Gordon and Arvey's use of broader inclusion criteria (both laboratory studies and field studies) resulting in an analysis that included more independent samples (52 versus 15 , respectively), and arguably, this analysis provides a better estimate of the true population value.

However, Landy (2008) provided another perspective of how to interpret the difference between the two meta-analyses. In his critique of stereotype and discrimination research, Landy suggested that the relationships observed between stereotypes and discrimination may be limited by the research methods being used to conduct the research. He argued that laboratory experiments create artificial circumstances that are far removed from the real life complexity that occurs in a work setting because lab studies generally do not provide individuating information (i.e., specific information of what we know about an individual's work-related behavior and attitudes) about the target to the participants in order to make an evaluation. In other words, in a work setting, people have job-relevant information about the target, which reduces the need to use stereotypes to make work-related decisions and evaluations; thus the effects of age stereotypes observed in lab studies may overstate the actual effects in an organizational setting. Therefore, in general, older workers may face discrimination in selection contexts, but as the selection 
context becomes more realistic, the effects may be reduced (Gordon \& Arvey, 2004; Landy 2008).

In addition to examining age discrimination in a selection context, researchers have also investigated age discrimination in regards to performance appraisals. Saks and Waldman (1998) found that older employees received lower performance assessments compared to younger workers. Furthermore, some evidence indicates that older workers receive harsher consequences for lower performance (Rupp, Vodanovich, Credé, 2006). However, meta-analytic investigations have generally found weak support for the age-job performance relationship (Avolio, Waldman, \& McDaniel, 1990; McEvoy \& Cascio, 1989; Waldman \& Avolio, 1986). In fact, a recent meta-analysis found that age was largely unrelated to core task performance (Ng \& Feldman, 2008). Several researchers have been critical of age-performance relationship research, and argue that the majority of the primary studies used in these meta-analyses have several methodological limitations including overreliance on the use of cross-sectional designs and not using samples with workers older than 60 years of age (Salthouse \& Maurer, 1996; Waldman \& Avolio, 1993). Moreover, some of the research suggests that a non-linear relationship between age and performance and the age-performance relationship may be moderated by unexplored third variables such as type of occupation (Salthouse \& Maurer, 1996; Waldman \& Avolio, 1993). Additionally, some argue that perceptions of older workers may have changed since the time when some of these studies were conducted (Weiss \& Maurer, 2004). Weiss and Maurer (2004), in their replication of Rosen and Jerdee's (1976a) study, observed significantly less effects than the original study. In fact, the 
Ageism Climate 31

resistance to change stereotype was the only significant effect that they found in the evaluation of older and younger workers.

Age discrimination in a training context has also been examined. For instance, Maurer and Rafuse (2001) discovered that 55 to 60 year olds are less likely to receive training than 35 to 44 year olds. Moreover, empirical research suggests that organizations and managers are less willing to support access to training opportunities for older workers (Cleveland \& Shore, 1992; Shore, Cleveland, \& Goldberg, 2003). Additionally, Steiner, Bertolino, Fraccaroli, and Truxillo (2007) found in samples from France and Italy that both older and younger workers face difficulty in obtaining most organizational resources (i.e., promotions, pay raises, task assignments), but that older workers have the greatest difficulty getting training resources. Finally, older workers were also observed to receive less mentoring time and career-related mentoring compared to younger workers (Finkelstein, Allen, \& Rhoton, 2003).

A final line of age discrimination research investigates older workers and career advancement. In general, it appears that older workers face a difficult challenge when it comes to upward mobility (Goldberg, 2007). In fact, older workers have been found to receive lower managerial assessments of promotability (Lawrence, 1988; Shore et al., 2003). Furthermore, Goldberg, Finkelstein, Perry, and Konrad (2004) found that older workers actually received fewer promotions. However, a possible confounding variable in this research is that older workers may already hold higher level positions in the organization, and therefore, may not have additional room for upward advancement. 
Ageism Climate 32

Nevertheless, as people age in the workplace, they may find it more difficult to find advancement opportunities in their organizations.

In summary, age discrimination research suggests that organizational decisionmaking may be affected by a person's age. This could provide an explanation as to why the number of age discrimination claims has been increasing (McCann \& Giles, 2002). However, depending on the context and type of decision being made, age discrimination may also be directed at younger workers as well, which could account for why younger workers also report feeling age discrimination (Gee, Pavalko, \& Long, 2007). It is theorized that organizational structures, values, and technology activate age stereotypes that could influence decision-making processes resulting in age discriminatory practices (Perry \& Finkelstein, 1999). Accordingly, these organizational factors may also affect people's perceptions of their organization's age climate. It is important to note, however, that situational influences external to the organization may also affect discriminatory behaviors. For instance, in a difficult macroeconomic environment there may be increased competition for limited resources, which could lead to increased perceptions of discrimination. Nevertheless, people's perceptions of these organizational processes may also be related to workplace age discrimination.

Prejudice. Prejudice is considered the affective component of age bias, and it has received the least amount of attention in the bias literature (Finkelstein \& Farrell, 2007). In general, prejudice encompasses people's evaluation of a social object as being good or bad (Kite et al., 2005). Specifically, age prejudice could manifest itself as having a dislike, feeling uncomfortable about, or even hating someone due to their age (Finkelstein 
\& Farrell, 2007). In other words, age prejudice may be linked with people's emotions toward others due to their age. Fiske et al. (2002) found that people reported feeling pity for elderly people whom they viewed as warm, but incompetent. Rupp et al. (2005) argued that a reason for the lack of research examining prejudice is because our measures are more focused on cognitive evaluations and fail to include affective assessments. Nevertheless, negative feelings or prejudices about working with certain-aged individuals may negatively affect those who experience the prejudice, thus influencing their organizational climate perceptions regarding age.

In summary, a tremendous amount of literature has examined the different components of age bias and its influence on individuals in the workplace. Worker perceptions and interpretations of their organizational environment may be influenced by negative age-related experiences associated with stereotypes, discriminatory behaviors, and prejudice. Consequently, the age bias literature informed the development of my ageism climate scales because it provides the foundation of how various types of age bias (i.e., stereotypes, discrimination, prejudice) against workers can manifest itself in the organizational context.

\section{Diversity and Diversity Climate Research}

The workplace diversity literature provides another line of research that investigates the impact of age in organizations. The definition of diversity in the workplace literature has been the focus of considerable debate (see Ashkanksy, Hartel, \& Daus, 2002), but most researchers refer to diversity as the “...distribution of personal attributes among interdependent members of a work unit" (Jackson, Joshi, \& Erhardt, 
2003 , p. 802). Inherent in this broad definition of diversity is the recognition of a variety of personal attributes that are considered characteristics of diversity including those that are readily apparent upon first meeting a person (e.g., age, sex, ethnicity) and those that are less visible attributes such as personality, knowledge, and values (Jackson et al., 2003). Of particular interest to this dissertation is the diversity research focused on age diversity and diversity climate.

Age diversity. The age bias and age diversity literature share a common conceptual overlap. Both lines of research are interested in examining how age differences may affect people in the workplace. Moreover, they both consider stereotypes as an important explanatory mechanism on the outcomes of age bias and diversity, respectively. However, there are distinct differences between these literatures. First, these literatures differ as to the level of the organization in which they approach age differences. For instance, age diversity research focuses more on groups and the organization as a whole. In contrast, age bias research generally focuses on the individual level of analysis. Second, age diversity research generally conceptualizes age diversity in terms of objective measures such as the age composition of groups or organizations, whereas the age bias literature generally focuses on an individual's perceptions and attitudes. For example, diversity studies may focus on the effect of age composition of applicant pools (e.g., Cleveland, Festa, \& Montegomery, 1988) on employee selection decisions whereas age bias research may examine people's perceptions of the applicant. Therefore, diversity research generally approaches the investigation of age differences in 
organizations from a broader perspective. In this section, I review the antecedents, outcomes, and theoretical perspectives associated with age diversity research.

In a recent review of the workplace diversity research, Shore et al. (2009) noted that very little research has examined antecedents of age diversity in the work setting. However, the workforce is becoming more age diverse, and examining the effects of the changing age distribution in organizations is imperative. Shore and colleagues identified two environmental forces that are contributing to increased age diversity in the workforce. First, people's traditional career path of staying with a single organization throughout their work lives is disappearing due to globalization and increased competition resulting in flatter and leaner organizational structures (Shore et al., 2009). Second, we are facing a potential labor shortage because the baby boomer generation is nearing retirement age and fewer workers are entering the workforce than are projected to exit. The combination of these two workforce trends means that organizations need to seriously consider recruiting and retaining older workers to meet their future human resource needs. Consequently, researchers have investigated recruitment and retention of older workers as lines of research focused on the antecedents of workplace age diversity.

Doverspike, Taylor, Shultz, and McKay (2000) investigated and discussed the strategies that organizations could use to recruit older workers. They noted that a lot of attention is paid to recruiting older workers in the popular press. From their review of the extant empirical research, they suggest that successful attraction and hiring of older workers can be attained through three components of the recruiting process including advertising, recruitment interviews and follow-up, and the nature of the work itself. They 
Ageism Climate 36

recommend that recruiting materials should include pictures of older workers, use language that conveys the value of experience to the organization, and be displayed in places where older workers would be reached, such as adult education centers. Moreover, during the recruitment interview, the researchers stress that the organization must convey a positive impression to the older applicant by explaining how older workers are supported and provided the necessary resources to be successful in the organization. Finally, during the final stages of the recruitment process, the researchers suggest that the organization should focus on the flexibility and type of work they would offer the older worker.

Retention of older workers is another line of research investigating the antecedents of age diversity. Researchers have identified several ways organizations can change their organizational context in order to utilize and retain older workers (Hedge et al., 2006; Rocco, Stein, \& Lee, 2003). Strategies like managerial training that combat age stereotypes, age norming, and ageist attitudes have been identified as a way to increase retention of older workers (Hedge et al., 2006; Rocco et al., 2003). Moreover, establishing organizational support resources for older workers, like developing processes and policies for reporting age discrimination claims and creating career counseling programs focused on long-term career management, have been proposed as additional strategies for retaining older workers (Hedge et al., 2006). Finally, researchers discuss strategies to design work alternatives that accommodate lifespan changes of older adults as another way to retain older workers (Hedge et al., 2006; Rocco et al., 2003). Creating flexible work alternatives like flexible work schedules, job sharing, job transfer and 
special assignments, and part-time work are discussed as ways to change the nature of the work in order to match the needs of workers through their lifespan (Hedge et al., 2006; Rocco et al., 2003). However, most of the recommended retention strategies have not been fully implemented and empirically evaluated, and therefore lack evidence-based support.

Although research examining the antecedents of age diversity is generally lacking, a significant amount of attention has been centered on the how age diversity affects individual and organizational outcomes. The majority of this research focuses on the affect of age diversity on important decision-making processes such as personnel selection, performance appraisal, training and development, and career opportunities. For example, in a simulated selection context, Cleveland, Festa, and Montgomery (1988) found that people's recommendations to hire older workers were less when there was a lower proportion of older workers in the applicant pool. In addition, in a performance appraisal context, evidence suggests that older workers receive lower performance ratings if they are older than the age norm associated with their career progression (Lawrence, 1988) and if they are older than others in their work group (Cleveland \& Shore, 1992). In regards to access to training and development, older workers also receive fewer training opportunities if they are older than their work group (Cleveland \& Shore, 1992) or their manager (Shore et al., 2003). Finally, in regard to career opportunities, older workers receive less opportunity for promotion if they are older than their manager (Shore et al., 2003) or older than their work group (Cleveland \& Shore, 1992). Consequently, age 
diversity research supports the negative effects of being an older worker in decisionmaking contexts especially when they are in the minority (Shore et al., 2009).

Age diversity researchers have proposed several theoretical explanations as to how age diversity affects individuals in the workplace. One of the most popular perspectives is the relational demography paradigm. Relational demography focuses on examining the interaction between individual demographic characteristics and the social context (Riordan \& Shore, 1997). The underlying assumption of relational demography is based on Similarity-Attraction Theory (Byrne, 1971) which argues that people use demographic characteristics to evaluate their similarity and dissimilarity with others in their organization, and this assessed level of similarity or dissimilarity affects workrelated attitudes and behaviors (Riordan \& Shore, 1997). It is argued that the greater the similarity between the individual and coworkers, the more positive the individual's work attitudes (Shore et al., 2003). In contrast, greater levels of dissimilarity are argued to have negative effects on work experiences and work attitudes (Shore et al., 2003). Agespecific relational demography research has generally supported the similarity/dissimilarity hypothesis (Shore \& Goldberg, 2005). For instance, research suggests that age dissimilarity results in less opportunity for development, lower manager-rated performance (Shore et al., 2003), less frequent technical communication within project groups (Zenger \& Lawrence, 1989), and negative effects on within-team perspective taking (Williams, Parker, \& Turner, 2005). Therefore, the relational demography research suggests that age diversity is a negative influence on individuals and teams in organizations. 
Ageism Climate 39

In contrast, some researchers have offered explanations and conditions under which dissimilarity might be beneficial (Riordan, Schaffer, \& Stewart, 2005). One perspective is referred to as the "value-in-diversity hypothesis" (Ely \& Thomas, 2001), and it asserts that information and decision-making may be enhanced by demographic heterogeneity (Riordan et al., 2005). In general, the research from this perspective has found support for the positive effects of diversity on personal characteristics such as tenure, experience, education, and knowledge, but much less of the research has found support for visible demographic characteristics like age, race, and gender (Riordan et al., 2005). Therefore, the results of this line of research seem to be inconsistent and depend on the personal characteristics level of visibility.

Norms have also been proposed as an alternative, but interrelated, explanation as to why age differences may affect an individual's workplace experience. The concept of career timetables, proposed by Lawrence (1988), may explain why some age differences have positive effects while others have negative effects. Lawrence suggests that norms exist about what level in an organization people should be at a given age. Therefore, people's evaluations of a worker are influenced by their assessment of whether the worker is "behind schedule," "ahead of schedule," or "on schedule." Lawrence (1988) found norms associated with career progress affect evaluations of an individual's job performance. Furthermore, people who are deemed to be "ahead of schedule" received higher performance ratings in comparison to those who are considered "behind schedule" (Lawrence, 1988). 
Ageism Climate 40

Perry and Finkelstein (1999) extended the idea of career timetables by proposing that a cognitive process, termed prototype matching, may be the process by which people make evaluations of workers according to their age. They argue for the existence of job age stereotypes and that people compare an individual's age relative to the age of the prototypical incumbent for the job. Favorable evaluations are derived from the match between the target's age and the age of a typical person in that job. Prototype matching research has mainly studied its effects in selection contexts (Shore \& Goldberg, 2003). For example, Perry, Kulik, and Bourhis (1996) found that older and younger applicants were evaluated similarly for old-type jobs, but older applicants were evaluated more negatively for young-type jobs. The career timetable and prototype matching perspectives provide important insights beyond similarity attraction theory into how organizational norms could affect the relationship between a worker's age and the evaluations made about that worker.

In summary, the age diversity literature has generally come to a similar conclusion as the age bias literature; people's age can affect their workplace experiences. Age diversity research differs from age bias research in that it takes a macro-level approach to examining the way age affects individual workers and organizations. However, this literature is limited by its narrow focus on older workers, and the limited empirical research examining the antecedents of age diversity. As Shore and colleagues (2009) note, "the research on age diversity is much less developed than that on race and gender, suggesting the need for new paradigms and new approaches to studying age in the work setting" (p. 5). A possible new approach to examining age diversity is through 
exploration of ageism climates, which is a focus of this dissertation. Ageism climates complement the extant age diversity research by providing the first measure to assess people's ageism climate perceptions and how these perceptions affect their work attitudes and well being.

Diversity climate. Diversity climate is an emerging line of research that is particularly relevant to my ageism climate measures. As previously discussed, organizational climate research examines how people experience and make sense of organizations (Schneider, 2000). Diversity climate is the examination of a worker's perceptions of an organization's diversity-related policies, practices, and procedures (Gelfand, Raver, Nishii, \& Schneider, 2005; Kossek \& Zonia, 1993). A positive diversity climate is generally thought to integrate all employees into the organization and, unhindered by group identity, to attain their full potential (Gelfand et al., 2005), resulting in positive attitudes toward an organization (Hicks-Clarke \& Iles, 2000; Nishii \& Raver, 2003).

Due to the relatively new introduction of diversity climate into the literature, very little research has investigated this construct. Of the limited diversity climate research that has been conducted, most has focused on the antecedents of diversity climate perceptions (Mor Barak, Cherin, \& Berkman, 1998). For example, Roberson and Stevens (2006) developed a typology examining diversity incidents that contribute to diversity climate perceptions. Six generic incident types emerged from their analyses including discrimination, representation, treatment by management, work relationships, respect between groups, and diversity climates. Other researchers have examined human resource 
policies and practices as well as gender and ethnic composition in the organization as possible antecedents to diversity climate perceptions (Kossek \& Zonia, 1993; Kossek, Markel, \& McHugh, 2003; McKay \& Avery, 2006; Mor Barak et al., 1998). Kossek and Zonia (1993) found group characteristics (i.e., ethnicity, gender, and level) rather than contextual organizational unit characteristics (i.e., gender and ethnic composition, resource support for women and ethnic minorities) were more strongly related to diversity climate. The researchers also found that Caucasian women and ethnic minorities valued efforts to promote diversity and held more favorable attitudes toward the qualifications of women and minorities compared to Caucasian men. Similarly, Mor Barak and colleagues found that Caucasian women and racial/ethnic minority men and women valued and felt more comfortable with diversity than white men. Both of these results suggest the existence of a self-serving bias effect. On the one hand, white men generally hold higher status positions in the workplace, and therefore, feel that the organizational systems are equitable. On the other hand, women and racial/ethnic minorities value diversity because of their desire to change the current organizational systems to be more equitable for all employees.

Recent diversity climate research is investigating the effect of the context external to the organization on the development of diversity climate perceptions (Pugh, Dietz, Brief, \& Wiley, 2008). McKay and Avery (2006), for example, argue that community demographic composition affects job acceptance decisions of minority candidates. Moreover, Pugh and colleagues (2008) also examined the effect of community racial composition on the formation of diversity climate perceptions. The researchers found that 
when few racial minorities live in the local community, workforce diversity becomes more salient, and this leads to negative perceptions of organizational diversity. Additionally, Brief, Umphress, Dietz, Burrows, Butz, and Scholten (2005) observed that community racial diversity moderated the relationship between group racial diversity and employee work attitudes. They found that increases in community racial diversity enhances the negative relationship between group racial diversity and job attitudes for majority group members.

Diversity climate researchers have also examined the effects of diversity climate on several important workplace outcomes including turnover, performance, and work attitudes (Hicks-Clarke \& Iles, 2000; McKay, Avery, Tonidandel, Morris, Hernandez, \& Hebl, 2007; McKay, Avery, \& Morris, 2008). One main focus of this research is to establish the "business case" of how diversity management and diversity climate impacts an organization's bottom line (McKay et al., 2007; McKay et al., 2008). For instance, McKay and colleagues (2007) found support for diversity climate moderating the relationship between racial/minority status and turnover. Furthermore, they found that a positive diversity climate led to increased retention of African American employees.

Moreover, research also supports that diversity climate moderates the relationship between race/ethnic status and sales performance (McKay et al., 2008). Indeed, McKay and colleagues (2008) found that disparities between white and ethnic/minority sales performance were smallest in retail stores where a positive diversity climate existed. In addition to retention and performance, researchers have also investigated the relationship between diversity climate and work and career attitudes. Hicks-Clarke and Iles (2000), 
for example, found that positive climates for diversity are significantly related to a wide range of work attitudes and career attitudes including organizational commitment, job satisfaction, career commitment, satisfaction with supervisor, career satisfaction, and career future satisfaction.

In summary, evidence suggests that diversity climate positively affects individuals and their organizations. Several consistent indicators of a positive diversity climate emerged from my literature review including inclusion, equitable treatment, and supportive organization policies for diverse workers. However, a limitation of this research is its narrow focus on gender and race diversity at the expense of studying other facets of diversity such as age. Nevertheless, the common themes I identified from the literature were applicable in the development of my ageism climate measures.

\section{Chapter Summary}

The thorough literature review provided in this chapter was a key step in the deductive approach used to create my measures of ageism climate. For instance, the extensive age bias literature provided common workplace stereotypes and a variety of age discriminatory behaviors that have been observed in both younger and older workers. In addition, the tripartite age bias framework (Finkelstein \& Farrell, 2007) was also used as a guide to develop items for the scale, which aligns my measure with contemporary age bias theory. Furthermore, the recognition that organizational structures, values, and technology may activate age biases that affect decision-making (Perry \& Finkelstein, 1999) suggests the existence of climates for ageism, which validates the need for ageism climate measures. 
The diversity and diversity climate research also contributed to the creation of the ageism climate measures. Specifically, the results from diversity climate research suggest that diversity climates affect individual and organizational outcomes, which validates the importance of measuring ageism climates. Furthermore, three common themes of a positive diversity climate were derived from my literature review, including inclusion, equitable treatment, and supportive organizational diversity policies. Item generation for ageism climates was dictated by these diversity climate themes.

The literature review also identified the gaps that will be addressed by creating ageism climate scales. For instance, the age bias literature seems to focus on stereotypes and discrimination, but less emphasis is placed on prejudice, the affective indicator of age bias. In addition, older workers are the main focus of age bias research, but little is known about age-related issues associated with younger workers. Finally, the diversity climate literature has focused on treating diversity climate as a unitary, global construct. However, different characteristics of diversity (e.g., age versus ethnicity or gender) may affect individual and organizational outcomes differently.

In summary, the literature reviewed in this chapter served as a useful reference in the creation of my ageism climates. The development of ageism climate measures complements and addresses some of the gaps in the age bias, diversity, and diversity climate literatures. Additional detail about the item generation process for the measures is described in the method section. Specifically, I provide a detailed description of how extant measures of age bias and diversity climate were utilized for item content. Additionally, to make my measure relevant to my sample population (i.e., registered 
Ageism Climate 46

nurses), I describe how interviews and comments captured from focus groups of practicing nurses were used to get a "real-world" perspective of how age affects nurses in the workplace. 
Ageism Climate 47

\section{Chapter 4: Core Self-Evaluations}

In the previous chapter, I reviewed the age bias and diversity literatures and described how these lines of research informed the development of my ageism climate measures. Ageism climates are argued to capture an individual's perceptions of how employees are treated in the workplace with regard to their age. Climate research supports the idea that psychological climates affect an individual's interpretation and sense-making in the workplace, which ultimately affects individual outcomes (Carr, Schmidt, Ford, \& DeShon, 2003; Parker, Baltes, Young, Huff, Altmann, Lacost, \& Roberts, 2003). However, little research investigates the relationship between personality and psychological climate. Moreover, since behavior is a function of both the environment and the individual, a comprehensive examination of workplace behavior should include both. Therefore, I addressed these issues by investigating how CSE affects the relationship between ageism climates and withdrawal intentions, work attitudes, and well-being.

This chapter is organized in the following fashion. First, I review the theory and conceptualization of core self-evaluations (CSE; Judge, Locke, \& Durham, 1997), a personality trait that captures people's fundamental self-regard and how they function in the world. Second, I briefly discuss CSE's correlates and outcomes. Third, I argue why CSE, as a personal characteristic, can be appropriately examined with ageism climates. Core Self-Evaluation (CSE)

The study of personality in the workplace has received greater attention in recent years and has become an important personal characteristic investigated in organizational 
research. Research has generally found that certain personality variables are related to important workplace outcomes including job performance (Barrick, Mount, \& Judge, 2001), performance motivation (Judge \& Ilies, 2001), and counterproductive work behaviors (Salgado, 2002). Therefore, empirical evidence suggests that people's personality traits do influence people's behaviors at work. However, until recently, less attention has been paid to how changes in personality through the lifespan can influence people through their work lives. For instance, emerging research investigating personality and aging is providing insight into how personality traits may change through the lifespan (Roberts, Wood, \& Viechtbauer, 2006). Additionally, research supports that people's perceptions and expectations of a target's personality are affected by the target's life stage (Truxillo, McCune, Bertolino, \& Fraccaroli, 2008). The implications of this research are that changes in personality through the lifespan could influence people's perceptions and behaviors in the workplace environment, and could also be a source of age stereotypes in the workplace (Truxillo et al., 2008).

Cognitive-affective personality system theory (Mischel \& Shoda, 1995) suggests that individuals differentially focus on different elements of the environment, how cues are cognitively and affectively categorized, and how the consequences of encoding interact with existing cognitions. Therefore, changes in personality through the lifespan could influence the processes associated with the cognitive-affective personality system resulting in changes in the cognitive appraisal processes of one's work environment, and subsequent reactions to these cognitive evaluations. Moreover, trait activation theory (Tett \& Burnett, 2003) provides a complementary perspective of how certain personality 
Ageism Climate 49

traits are activated by trait-relevant cues signaling from the environment that indicate the appropriateness to display people's propensity in that situation. Core self-evaluation (CSE; Judge, Locke, \& Durham, 1997) may be one personality trait that could influence how one appraises and reacts to different cues from the work environment. Consequently, I review the definition and theoretical conceptualization of CSE, the empirical research that has investigated its correlates, and the individual outcomes that CSE predicts.

Definition and conceptualization of CSE. Judge, Locke, and Durham (1997) introduced the concept of CSE as a dispositional model based on fundamental appraisals individuals make about themselves. They argued that CSEs provide one explanation for the link between dispositions and job satisfaction. CSE is defined as "fundamental premises that individuals hold about themselves and their functioning in the world" (Judge, Erez \& Bono, 1998, p. 168). Implied in this definition is that CSE encompasses both internal and external evaluations. Core internal evaluations are focused on appraisals made about one's worthiness, effectiveness, and capability (Judge, Locke, \& Durham, 1997; Judge, Locke, Durham, \& Kluger, 1998). These core internal appraisals are proposed to influence how one approaches and reacts to the world (Judge et al., 1997). Core external evaluations are the evaluations a person makes about the nature of people and how the world works (Judge et al., 1997). For example, those who consider themselves to be worthless or incapable would react to increased job responsibilities in a fundamentally different way than those who consider themselves to be worthy and capable. Likewise, people who consider the world to be inherently dangerous and unpredictable or consider people to be untrustworthy will experience a heightened 
anxiety in the face of increased job responsibility. In combination, these core internal and external evaluations are argued to be a central component of people's self-concept (Judge et al., 1998).

According to Judge et al. (1997), CSE is a higher-order latent construct that is indicated by traits that meet three criteria-(a) evaluation-focus, (b) fundamental, and (c) broad scope. Based on these criteria, four well-established traits were identified as indicators of the high-order latent concept of CSE. CSE is argued to be indicated by selfesteem, generalized self-efficacy, locus of control, and neuroticism. According to Judge et al. (1997) self-esteem is the broadest and most fundamental self-evaluation. Selfesteem is defined as the overall value one places on oneself as a person (Harter, 1990) and in the CSE model is conceptualized as the "self-worth" aspect of core evaluations (Judge et al., 1997). The second trait, generalized self-efficacy, is defined as a representation of people's perception of their ability to perform across a variety of situations, and it is distinct from task-specific self-efficacy (Gist \& Mitchell, 1992). Judge and colleagues argued that generalized self-efficacy is more appropriate to include as a trait of CSE because of its generality and its arguably close relationship with selfesteem (Tharenou, 1979). The third trait, locus of control, represents the perceived degree of power over one's life (Judge et al., 1998). People with internal locus of control believe in their own agency to be in command of their lives, whereas people with an external locus of control believe their life is directed by things outside of their power (Rotter, 1966). Although similar to general self-efficacy, locus of control is focused more on controlling outcomes and less concerned with the capacity to perform. Finally, 
neuroticism is the tendency to exhibit poor emotional adjustment (Goldberg, 1990). Highly neurotic people are likely to be insecure, guilty, and timid (Costa \& McCrae, 1988). Neuroticism is normally considered the converse of self-esteem (Judge et al., 1997), and it manifests itself in tendencies to be fearful of novel situations and to be susceptible to feelings of dependence and helplessness (Wiggins, 1996). Research supports CSE as a higher-order latent factor that explains the substantial associations among the four traits (Erez \& Judge, 2001; Judge, Erez, Bono, \& Thoresen, 2003). Thus, the theorized second-order latent structure of CSE seems to be supported by empirical research.

In general, what does it mean to have high CSE? Conceptually, people with high levels of self-esteem, general self-efficacy, and locus of control and low levels of neuroticism are described as being people who have a general positive self-concept or self-regard (Judge et al., 1998). Additionally, high CSE individuals will view the world with the belief that happiness and successful achievement are possible in their lives (Judge et al., 1998). Furthermore, Judge et al. (2003), describe a person with high levels of CSE as being, "someone who is well adjusted, positive, self-confident, efficacious, and believes in his or her own agency" (p. 304). Empirical research has consistently substantiated that people with high CSE are positively related to several favorable and important outcomes. In summary, the empirical evidence is quite compelling that high CSE has a positive influence in numerous contexts, and in the subsequent paragraphs I review the empirical robustness of CSE. 
Outcomes and correlates of CSE. Although the introduction of CSE was fairly recent, empirical support is accumulating for CSE as being a predictor of a variety of outcomes. As previously noted, the original impetus for the development of CSE was to provide theoretical support for dispositional traits as a cause of job satisfaction (Judge et al., 1997). In support of its initial purpose, several empirical studies have successfully shown CSE to be significantly and positively related to job satisfaction (Judge \& Bono, 2001; Judge et al., 2000; Judge et al., 1998). Moreover, CSE is also argued to be related to job performance (Judge et al., 1998), and results suggest that there is indeed a positive relationship between CSE and job performance (Judge et al., 2003; Judge et al., 1998).

Beyond being a moderate predictor of job satisfaction and job performance, CSE has displayed consistent relationships with a broad variety of work-related outcomes. For example, CSEs are an antecedent of job search intensity (Wanberg et al., 2005). Wanberg and colleagues (2005) found that people with high levels of CSEs were more persistent in their job search during unemployment than those with lower CSEs. Furthermore, people with higher levels of CSE obtain more objectively complex jobs (Judge, Bono, \& Locke, 2000), have increased goal commitment after being given negative feedback (Bono \& Colbert, 2005), and are better able to cope with organizational change (Judge, Thoresen, Pucik, \& Welbourne, 1999). Moreover, CSE has been found to be negatively related to burnout (Best, Stapleton, \& Downey, 2005), which extends the influence of CSEs into the occupational health and stress domain. In summary, those with high levels of CSEs seem thrive in the workplace. 
In addition to receiving empirical support within the workplace, CSE has also been shown to be directly related to broad outcomes outside of the work domain including capitalizing on one's advantages (Judge \& Hurst, 2007), life satisfaction (Judge et al., 1998; Tsaousis, Nikolaou, Serdaris, \& Judge, 2007), general happiness (Piccolo, Judge, Takahashi, Watanabe, \& Locke, 2005), and physical and psychological health (Tsaousis et al., 2007). From these studies it is easy to conclude that having high levels of CSE is related to positive outcomes across life domains.

Although CSE research has been mainly used in American samples, evidence is building for the construct's cross-cultural generalizability. For example, Judge, Van Vianen, and De Pater (2004) replicated CSEs positive relationship with job satisfaction in a cross-cultural validation study on Danish and Spanish samples. In addition, CSE was observed to have a positive effect on physical health functioning in a Greek sample (Tsaousis et al., 2007). Moreover, Piccolo et al. (2005) examined CSE in Japan and found that it was related to happiness. A recent study conducted by Liu, Wang, Piccolo, Zhan, and Shi (2008) found support for cross-cultural generalizability of CSE in a sample of Chinese workers. In sum, the results from these cross-cultural studies provide support for CSE's generalizability across cultures.

CSE as a moderator. In addition to serving as an antecedent, emerging research has studied CSE as a moderator. For example, Tsaousis, Nikolaou, Serdaris, and Judge (2007) looked at the moderating role of CSE between subjective well being (SWB) and physical and psychological health. The researchers found that people with high CSE and high levels of SWB (e.g., high PA, low NA, and high satisfaction with life) had greater 
Ageism Climate 54

physical health; however, this relationship surprisingly did not hold true for psychological health. A study conducted by Best et al. (2005) provides another example of CSE being examined as a moderator. The researchers analyzed whether the relationship between perceived organizational constraints and job burnout depended on the participants' level of CSE, but did not find significant support for the moderator relationship. Harris, Harvey, and Kacmar (2009) investigated whether CSE buffered the impact of workplace social stressors on people's job satisfaction, altruism, and turnover intentions. The researchers found that CSE buffered the effects of social stressors on job satisfaction and turnover intentions, but not altruism. Additionally, Kacmar, Collins, Harris, and Judge (2009) explored CSE's interactive relationships with perceptions of organizational politics and perceptions of leader effectiveness on job performance. The researchers found that those with higher levels of CSE received higher performance ratings in favorable situations (i.e., low organizational politics and high leader effectiveness). Although an emerging line of research examines CSE as a moderator, further research is needed in order to extend our knowledge about how people's level of CSE interacts with their work environment to affect workplace outcomes; thus, I investigate CSE's moderating role in the relationship between ageism climates and several work outcomes.

CSE and age. Conceptually, CSE may be appropriately examined in an agerelated context for at least two reasons. First, aging is a developmental process, and throughout people's life experiences their self-evaluations may affect the way they appraise and react to age-related experiences. For instance, people with high levels of 
CSE who face age discrimination experience may evaluate and react in a different way than those who have lower levels of CSE. Indeed, Best et al. (2005) cite a personal communication from T.A. Judge which stated "the dispositional nature of the core-selfevaluations construct is advantageous in its appraisal orientation (i.e., vs. behavioral), supporting its utility as an individual characteristic that helps shape subjective interpretations of contextual events" (p. 442). Second, CSE and chronological age are arguably integrated within one's self-concept. CSE has been described as a core element of the self-concept (Judge et al., 1997). Similarly, a person's age has also been identified as being a part of the self-concept (Barak, 1987). Moreover, in my master's thesis, I observed a significant relationship between people's perceived age and CSE, which suggests that a relationship exists between self-evaluations and perceptions of one's age (Cadiz, 2009). Therefore, considering the interplay between CSE and age, I argue that it is appropriate to investigate CSE in an age context, particularly its role as a moderator of the relationship between age constructs and outcomes.

In summary, empirical evidence supports the validity of CSE as an important construct in a number of relationships with a wide variety of variables across many contexts. In general, high levels of CSE seem to have a positive influence on people's cognitive appraisals of themselves and their environment resulting in several favorable outcomes across life domains. Consequently, it is logical to think that CSE may be an important personal characteristic that influences the way people assess, interpret, and react to their work environment. Research supports the CSE's interactive effect in certain situations in that CSE seems to buffer people from effects of negative situations (e.g., 
Harris et al., 2009) and enhance people's propensity to thrive in favorable conditions (e.g., Judge \& Hurst, 2008). Furthermore, the mounting evidence for CSE as an influential construct warrants continued research to expand CSE's nomological net including exploring its relationship in an age-related context, and more specifically, its relationship with ageism climates.

\section{Chapter Summary}

This chapter introduced CSE as a personal characteristic that is argued to influence the way people adapt to age-related experiences in their work environment. I discussed how CSE influences people's appraisals and reactions to their work environment. In the subsequent chapter, I develop the hypotheses used to guide my investigation of the relationships among CSE, ageism climates, and individual workplace outcomes. 


\section{Chapter 5: Model Outcomes and Hypotheses}

In the previous chapters I separately introduced individual and environmental factors that could influence people's experiences in the workplace. In this chapter, I integrate these personal and contextual characteristics into a model that predicts individual outcomes. Figure 1 provides a visual representation of my proposed conceptual model. First, the model illustrates that ageism climates have a direct relationship with job withdrawal, work attitudes, and well being. Second, the model depicts an interactional relationship between workplace age climate and CSE leading to the individual outcome variables. In other words, workplace age climate is directly related to job withdrawal, work attitudes and well-being, and this relationship is moderated by CSE.

I decided to explore three categories of individual outcome variables: job withdrawal, work attitudes, and well-being. First, I wanted to provide a comprehensive investigation of how personal and contextual variables affect multiple aspects of people's work experiences. Second, this type of examination provided the opportunity to see if there are any differential affects of my antecedents on each of the outcomes. Third, these categories of variables represent outcomes that have been previously linked to turnover and retention, which are concerns in the registered nurse workforce.

Specifically, organizational turnover intentions will represent the job withdrawal category because it is conceptualized as a type of job withdrawal (Hanisch \& Hulin, 1990) and it is applicable to workers across their work lives. Organizational commitment was selected to represent work attitudes because it is considered an important work 
attitude in the literature (Judge, Klinger, Simon, \& Wen Feng Yang, 2008). Finally, the occupational health psychology literature categorizes job engagement as a type of workplace well-being (Schaufeli, Taris, van Rhenen, 2008), and therefore job engagement will represent a well-being outcome. In the subsequent sections, I briefly introduce each outcome and develop my hypothesized relationships between ageism climate and CSE on that outcome.

Workplace Age Climate, CSE, and Organizational Turnover Intentions

Job withdrawal is defined as “employees' efforts to remove themselves from a specific organization and their work role" (Hanisch \& Hulin, 1991, p. 111). Organizational turnover intentions are considered to be turnover cognitions and have been conceptualized as being examples of job withdrawal (Hanisch \& Hulin, 1990). Furthermore, I operationalize job withdrawal as organizational turnover intentions because organizational turnover intentions are applicable across people's work lives, and the intention of this dissertation was to examine outcomes that affect people throughout their career span.

CSE and ageism climates may be two of many possible factors that that could influence organizational turnover intentions. Indeed, Cooper-Hakim and Viswesvaran (2005), in their meta-analytic review of the commitment literature, observed a significant correlation between affective commitment and turnover intentions. Moreover, organizational tenure has also been found to be significantly correlated with turnover intentions (Blau, 2007). Therefore, I control for these variables in my analyses to show 
workplace age climate and CSE's ability to account for incremental variance beyond common correlates of organizational turnover intentions.

Ageism climate and turnover intentions. Since my dissertation represents the initial investigation of how ageism climates affect people in the workplace, no extant empirical support for a relationship between ageism climate and organizational turnover intentions exists. However, general support for the positive effects of climate on decreasing job withdrawal is present in the literature (Carr, Schmidt, Ford, \& DeShon, 2003). In their meta-analytic review of the climate literature, Carr et al. (2003) found support for significant negative effect mean correlations between organizational climate and turnover intentions. Specifically, affective climate (i.e., climates associated with people involvement, interpersonal, or social relations) had a mean correlation with turnover intentions of -.28 , cognitive climate (i.e., climates associated with psychological involvement, self-knowledge, and development) had a mean correlation with turnover intentions of -..07, and instrumental climate (i.e., task involvement and work processes) had a mean correlation of -.33. Arguably, workplace age climate would be categorized as an affective climate under the Carr et al. (2003) taxonomy because it is climate perceptions associated with the interpersonal treatment of workers according to their age. Therefore, this indirect empirical evidence suggests I would find a negative relationship between ageism climates and organizational turnover intentions.

Conservation of Resource theory (Hobfoll, 1989) would consider positive ageism climates to be a positive conditional resource that could have a positive effect on people's workplace experiences resulting in lower turnover intentions. Specifically, age supportive 
climates would reflect a workplace where workers of all ages are provided equal opportunities to utilize organizational resources, resulting in personal resource gains such as improvement in their job competence. These gains in personal resources leave people in a better position to allocate more resources (i.e., greater effort) to increase their likelihood of workplace success and decreased thoughts of leaving the organization.

Hypothesis 1: After controlling for organizational tenure and affective commitment, ageism climates will be positively related to organizational turnover intentions.

CSE as a moderator of ageism climate-turnover intentions relationships. In addition to having a direct influence on job withdrawal, workplace age climate may interact with CSE to affect turnover intentions. An emerging line of research investigates the interaction between CSE and situational factors on a variety of incomes including job performance (Kacmar, Collins, Harris, \& Judge, 2009), future income (Judge \& Hurst, 2007), and turnover intentions (Harris, Harvey, \& Kacmar, 2009). Kacmar and colleagues found that people's levels of CSE interacted with perceptions of organizational politics and leader effectiveness to affect supervisor performance ratings. Specifically, those with higher CSEs received higher job performance ratings in favorable situations (i.e., low organizational politics and high leader effectiveness). Judge and Hurst (2007) found that those with higher levels of CSE were able to capitalize on early advantage circumstances, which was operationalized as the educational and occupational attainment of one's parents. Specifically, the researchers observed that people with high CSE were able to attain greater income levels when their parents had higher occupational prestige and had 
completed higher levels of education. Harris et al. (2009) examined whether workplace social stressors interacted with CSE to affect turnover intentions. They observed that CSE buffered the negative effects of social stressors in that people with higher levels of CSE had lower turnover intentions even when facing social stressors. From these results, it can be concluded that people with higher levels of CSE flourish in favorable environments and that CSE can shield people from the negative impacts of unfavorable circumstances.

Theoretically, from a COR perspective (Hobfoll, 1989), CSE seems to act as a positive personal resource that can be allocated to prevent or buffer threats to one's resources when faced with adverse circumstances. Furthermore, higher levels of CSE seem to allow people to invest in gaining additional resources resulting in positive individual outcomes. Moreover, from a trait activation perspective, high CSE individuals seem to positively react to situations that are likely to maintain positive self-relevant cognitions and affect (Kacmar et al., 2009). Positive age climates are conditional resources that provide favorable situations (e.g., access to important workplace resources, support) that activate high CSE individuals' self-regulatory processes to invest personal resources for resource gains that result in an increased likelihood of being successful in the workplace. Thus, I hypothesize that the resource gains and successes reaped from resource investment would result in lower turnover intentions.

Hypothesis 2: After controlling for organizational tenure and affective commitment, CSE will moderate the relationship between ageism climates and turnover intentions such that the ageism climate-turnover intentions relationship 
Ageism Climate 62

will be positive and stronger when people's level of CSE are higher than when CSE levels are lower.

\section{Ageism Climates, CSE, and Organizational Commitment}

Work attitudes represent a broad content area that investigates people's beliefs about their jobs, their work organizations, and their careers (Barnes-Farrell \& Matthews, 2007). Organizational commitment is one of the most studied work attitudes in organizational research (Judge et al., 2009). Mowaday, Porter, and Steers (1982) describe organizational commitment as including acceptance and belief in an organization's goals and values, a willingness to exert effort for the organization, and a desire to remain in the organization. Meyer and Allen (1991) identified three types of organizational commitment - affective, continuance, and normative. I specifically focused on affective commitment because one focus of this dissertation was to investigate potential ways to retain nurses in the workforce, and affective commitment has been found to have the most robust relationship with turnover intentions compared to continuance and normative commitments (Cooper-Hakim \& Viswesvaran, 2005).

Affective commitment is defined as having an emotional attachment to, identification with, and involvement in an organization (Meyer and Allen, 1991). Meyer and Allen (1991) argue that affective commitment is influenced by changes in comfort and competence-related work experience. I expect ageism climates to be related to people's affective commitment because ageism climates are a reflection of people's evaluation of an organization's age-supportiveness. Therefore, a more supportive environment should increase the likelihood of people being more comfortable in the 
workplace and should result in greater emotional attachment to the organization. Moreover, although research examining the influence of people's personality on commitment is limited (Erdheim, Wang, \& Zickar, 2006), CSE could be a personality trait that influences people's attachment to their organization. In fact, the propensities associated with CSE may be activated by ageism climates to enhance people's attachment and affiliation to their organization. In the subsequent sections, I will investigate the relationship between ageism climates and organizational commitment and how CSE may moderate this relationship.

To provide a more stringent analysis of organizational commitment as an outcome, I will control for variables that have been observed as correlates of affective organizational commitment. Specifically, based on a quantitative literature review of commitment, organizational tenure and chronological age have an established empirical relationship with affective organizational commitment (Meyer, Stanly, Herscovich, \& Topolnytsky, 2003).

Ageism climates and organizational commitment. In general, results from climate research suggest that people's psychological climate influences people's work attitudes (Parker et al., 2003). Specifically, Parker et al. (2003) found in their quantitative summary of psychological climate research a mean correlation of .22 between psychological climate and the category labeled other job attitudes, including organizational commitment and job involvement. Although several types of psychological climate were collapsed into an overall measure of psychological climate in this meta-analysis, the results from this examination suggest a relationship between 
ageism climates and organizational commitment. Furthermore, Hicks-Clarke and Iles (2000) observed, in a sample of private and public sector organizations, that positive climates for diversity are positively related to organizational commitment, providing another indirect form of evidence suggesting that ageism climates may have positive relationships with organizational commitment.

A positive relationship between ageism climates and organizational commitment makes theoretical sense. Age supportive climates represent work contexts where people of different ages are given equal access to development opportunities to be effective and successful in their jobs. In other words, people may interpret the organization as providing them the necessary resources to be competent and successful in the organization. Thus, this type of supportive environment could elicit positive feelings toward and increased attachment to the organization. Moreover, a positive workplace age climate may also reflect a context where management encourages workers to pursue challenging development experiences regardless of their career stage, increasing the individual's sense of value to the organization, and therefore, increased affiliation and identification with the organization.

Hypothesis 3: After controlling for chronological age and organizational tenure, ageism climates will be negatively related to affective organizational commitment.

CSE as a moderator of the ageism climate-affective commitment relationship. The relationship between ageism climates and organizational commitment may be influenced by personality factors like CSE. As previously argued, ageism climate perceptions reflect 
an environment that provides access to organizational resources to all employees, which could increase people's attachment to and identification with the organization. However, trait activation theory (Tett \& Burnett, 2003) would suggest this type of work environment may provide a trait-appropriate situational cue that would trigger people's propensities to act in a certain way in reaction to this situation. The propensities activated by this situation could enhance the effects of a favorable age-supportive environment. Previous research supports the idea that CSE may be a personality trait that could be activated by a favorable work environment. Kacmar and colleagues, for instance, found that those with higher levels of CSE receive higher job performance ratings in favorable situations (Kacmar et al., 2009). Therefore, those with high positive self-regard and beliefs in their capabilities (i.e., high levels of CSE) may view the equal access to desired organizational resources (like career development) as an opportunity to enact their propensities to strive for work success, allowing them to maintain a self-consistent positive work status and positive self-regard. The affective commitment in those with higher levels of CSE would be enhanced because they would be able to take advantage of their opportunities. They would therefore feel greater emotional attachment to their organization because they would attribute this success to the organization providing a work environment that allows them to express their tendencies.

Hypothesis 4: After controlling for chronological age and organizational tenure, CSE will moderate the relationship between ageism climates and organizational commitment such that the ageism climate—organizational commitment 
Ageism Climate 66

relationship will be negative and stronger when people's level of CSE are higher than when CSE levels are lower.

Ageism Climates, CSE, and Work Engagement

Workplace well-being is a broad term used to describe people's psychological response to the workplace. Work engagement is an emerging concept that is described as a "positive, fulfilling, affective motivational state of work-related well-being" (Bakker, Schaufeli, Leiter, \& Taris, 2008, p. 187) and is considered a type of workplace wellbeing. Schaufeli and Bakker (2001) define engagement as a construct characterized by vigor, dedication, and absorption. Vigor reflects high levels of energy, mental resilience, willingness to invest effort, and persistence. Dedication is the perception of significance, enthusiasm, pride, and challenge in one's job. Absorption is the idea of being deeply engrossed in one's job (Schaufeli \& Bakker, 2001). Although work engagement suffers from a lack of consensus as to its conceptualization, most researchers agree that engagement is characterized by high levels of energy and strong identification with one's job (Bakker et al., 2008). The most popular measure of work engagement is the Utrecht Work Engagement Scale (UWES; Schaufeli, Salanova, Gonzalez-Roma, \& Bakker, 2002), which is based on Schaufeli \& Bakker's (2001) conceptualization of work engagement. Therefore, following the trend in the literature, I will approach work engagement from Schaufeli and Bakker's conceptualization in that work engagement is an independent, distinct construct that is indicated by vigor, dedication, and absorption.

The research examining work engagement has effectively established the value of having engaged employees (Bakker et al., 2008). For instance, work engagement is 
related to higher levels of in-role and extra-role job performance (Bakker, Demerouti, \& Verbeke 2004), customer service climate (Salanova, Agut, \& Peiro, 2005), and daily financial returns (Xanthopoulou, Bakker, Demerouti, \& Schaufeli, 2009). Moreover, work engagement has also been linked to greater levels of personal growth and development (Bakker et al., 2008). Therefore, work engagement has both individual and organizational implications.

Emerging research by Xanthopoulou and colleagues (Xanthopoulou et al., 2009, Xanthopoulou, Bakker, Demerouti, \& Schaufeli, 2007, Xanthopoulou, Bakker, Heuven, \& Schaufeli, 2008) examines the influence of both job and personal resources on work engagement. These researchers observed support for the combined positive influence of personal characteristics like self-efficacy, optimism, self-esteem, and job resources such as autonomy, coaching, team climate, and colleague support on greater work engagement (Xanthopoulou et al., 2009, Xanthopoulou et al., 2007, Xanthopoulou et al., 2008). In other words, allocating higher levels of personal resources allow people to become more engaged in their job, and a supportive environment adds additional resources to their resource pool which in turn leads to more engagement in their work. My dissertation extends this research by investigating the influence of a personal characteristic (CSE) and job resources (ageism climates) not previously examined with work engagement.

To conduct a more stringent analysis of CSE and ageism climate's effect on work engagement, I account for a variable that has been previously found to have a relationship with work engagement. Specifically, chronological age was observed to have a positive correlation with work engagement in a sample of Norwegian nurses (Bégat, Ellefsen, \& 
Severinnsson, 2005). Therefore, chronological age served as a control variable in all of my analyses involving work engagement as an outcome.

Ageism climate and work engagement. Theoretically, ageism climates are conditional resources and should be related to work engagement because they provide environments where workers have equal access to career development resources regardless of people's career stage. Access to development opportunities facilitates people's ability to gain the necessary personal resources to become more competent and effective in their work and may promote people's willingness to allocate their effort and ability so they are energized about, dedicated to, and absorbed in their work. Indeed, Bakker et al. (2008) argue that job resources can, “...play an extrinsic motivational role because they are instrumental in achieving work goals" (p. 191). Moreover, research has found that colleague support has a positive influence on work engagement (Xanthopoulou et al., 2008). A positive ageism climate could reflect an individual's perception that all people are treated as valuable members of the organization. This perception may manifest from workers experiencing encouragement and support from their colleagues regardless of their career stage. Finally, a positive ageism climate could reflect people's perceptions that they have equal access to mentoring and coaching experiences from their manager or supervisor regardless of their career stage; consequently, they would feel they have the outside support to facilitate engagement in their work. In fact, daily coaching from managers has been found to increase worker engagement (Xanthopoulou et al., 2009). Accordingly, I expected a positive relationship between ageism climates and work engagement. 
Ageism Climate 69

Hypothesis 5: After controlling for chronological age, ageism climates will be negatively related to work engagement.

CSE as a moderator of the ageism climate-engagement relationship. Research supports the combined positive influence of job resources (i.e., coworker support, team climate) and personal resources (i.e., self-esteem, self-efficacy, optimism) on work engagement (Xanthopoulou et al., 2009, Xanthopoulou et al., 2007, Xanthopoulou et al., 2008). Ageism climates, acting as job resources, and CSE, acting as a personal resource, could interact to have an enhanced positive effect on work engagement. In general, positive ageism climates reflect a less constrained work environment that should provide equal access to organizational resources facilitating increased work engagement. Increased access to organizational resources would augment the personal resources provided by people's level of CSE increasing their overall resources to allocate to becoming more engaged at work. More specifically, a positive ageism climate would provide a favorable context for people with high levels of CSE because it would activate their tendency to pursue their intrinsically motivated self-concordant work goals (Judge, Bono, Erez, \& Locke, 2005). This activated intrinsic motivation to achieve selfconcordant work goals could result in a greater likelihood of increased vigor, dedication, and absorption in one's work because the person is focused on something that is personally meaningful and valuable. Moreover, a positive ageism climate could provide people access to organizational resources like increased training opportunities, promotions, and challenging work assignments all of which could activate high CSE people's propensity to persist in the face of difficult tasks (Erez \& Judge, 2001) and their 
propensity to seek and thrive in advantageous situations (Judge \& Hurst, 2007).

Persistence on complex tasks and exploiting opportunities in advantageous situations would resonate with people with high CSE. Accordingly, during their pursuit of these challenging activities and successful achievement of their goals, they would feel greater levels of work engagement.

Hypothesis 6: After controlling for chronological age, CSE will moderate the relationship between ageism climates and work engagement such that the ageism climatework engagement relationship will be negative and stronger when people's levels of CSE are higher than when they are lower.

I argued that ageism climates are related to several individual outcomes, and people's level of CSE may moderate these relationships. In general, I proposed that ageism climates are conditional/situational resources that affect people's organizational turnover intentions, organizational commitment, and work engagement. Moreover, I argued that those with high levels of CSE may be activated by a positive ageism climate to follow their propensity to thrive in advantageous situations (Judge \& Hurst, 2007). Table 1 provides a summary of the hypotheses examined in this dissertation. In the next chapter, I describe the development of my workplace age climate measures and my research methods. 


\section{Chapter 6: Method}

This chapter is organized in the following way. First, I describe the process used to develop the conceptual foundation and content for my ageism climate measures.

Second, I discuss the data collection procedure and participants involved in my research. Finally, I provide a detailed description of the variables involved in the study and the role each variable played in my analyses.

Ageism Climate Measures Development

A main contribution of this dissertation is to create ageism climate measures and build evidence for the construct validity of these measures. To ensure that I followed a comprehensive process for scale development and validation, I used an established framework outlined by Hinkin (1998). I followed the first five of the six steps outlined by Hinkin: Item generation, questionnaire administration, initial item reduction, confirmatory factor analysis, and convergent/discriminant validity. Hinkin's final validation step, replication, is left for future research. Before I discuss the item generation step of my ageism climate measures, I describe the three primary sources for the conceptual and content development of the ageism climate measures.

Formulation of ageism climates. Three personal experiences triggered my conceptualization of ageism climates. The first stemmed from my involvement in nurse focus groups for the Oregon Nurse Retention Project. In these focus groups, nurses described several instances of inter-generational conflict between older and younger nurses. For instance, some nurses discussed the existence of a "hazing" process for younger nurses and a general feeling that younger nurses lack the "work ethic" to be an 
effective nurse. Additionally, comments were made about older nurses being perceived as less knowledgeable about new techniques and technology and unwilling to listen to younger nurses when they offer ideas as to how the older nurse could implement new techniques and technology into their practice.

The second experience involved two phone interviews with nurses who were on the two ends of the age spectrum. I interviewed a nurse in her 60s who had over 35 years of experience and another nurse that was in her mid-20s with less than five years of experience. Both interviews focused on how each nurse's age affects her work and interactions with coworkers and managers. The younger nurse reported that she felt that the older nurses treated her like she was of a lower status because of her lack of experience. Moreover, the older nurse felt that her access to new technology training was lacking and made her feel incompetent. The responses from the nurses further validated my idea that many nurses of all ages feel that their age affects how they are treated in the workplace.

A final catalyst for my pursuit of an age climate measure came from an interesting finding from my master's thesis. I observed a significant negative correlation between chronological age and experienced age discrimination, which suggested that younger nurses reported more experiences of age discrimination in the workplace. The accumulation of these three experiences solidified my interest in investigating age-related workplace climate and its effect on individuals.

Literature review. As described in Chapter 3, the conceptual development of my ageism climate measures was derived from a thorough review of the theory and research 
in the age bias, age diversity, and diversity climate literatures. From this review of the literature, I discovered gaps in the literature that could be addressed by the creation of ageism climate measures. These gaps include addressing the psychological climate associated with an organization's treatment of workers regarding their age and the treatment of younger workers. Additionally, I used common themes within each literature to guide measure development. For instance, a common theme identified from the age bias literature was the importance of age stereotypes as a mechanism that affects people's workplace experiences. Additionally, from the diversity climate literature, I identified the common themes of inclusion, equitable treatment, and supportive organization policies for diverse worker. Finally, I used the literature review to critically analyze and extract content from extant measures used in each respective literature. In the subsequent paragraphs, I identify the strengths and limitations of these existing scales and explain how the extant measures were used to generate items for the ageism climate scales. Age bias and diversity climate. Several measures have been introduced in age bias and ageism research. Initial measures of ageism or age-related attitudes assessed commonly held opinions about older people and were focused on the cognitive aspect of age bias (Faboni, Saltstone, \& Hughes, 1990; Rupp, Vodanovich, \& Credé, 2005). For instance, the Old People Questionnaire (Tuckman \& Lorge, 1953) and the Attitudes Toward Old People Scale (Kogan, 1961) are two initial measures assessing age bias that focused on assessing general opinions about older people and were strictly focused on evaluating the cognitive component of age bias and do not include affective and behavioral components of age bias. 
The Faboni Scale of Ageism (FSA; Faboni et al., 1990) is a measure that attempts to capture the cognitive, affective, and behavioral components of age bias: Antilocution (antagonism and antipathy catalyzed by stereotypes about older people), Avoidance (avoiding social contact with older people), and Discrimination (discriminatory thoughts about the political rights, segregation, and activities of older persons). A recent study by Rupp et al. (2005) supported the multi-dimensional nature of the FSA, although the structure of the three factors was different from what was initially proposed by Faboni and colleagues (Rupp et al., 2005). Rupp and colleagues proposed that the three factors were better labeled as stereotypes, separation, and affective attitudes, and are a more accurate representation of the scale's factor structure. The strength of the FSA scale is that it incorporates cognitive and affective attitudes, but it is limited because it focuses on general attitudes about older people without a specific context and it has not been used in the workplace literature. Arguably, different contexts, such as the workplace versus at home, could elicit different age-related attitudes.

The ageism scales discussed above did not have a workplace focus, which is a context of interest in this dissertation. Cleveland, Festa, and Montgomery (1988) created a seven-item measure that has been commonly used to assess workplace age bias. Similar to other scales, the focus of this scale is on general age bias, but the raters are asked to make their assessments of people at work. The internal consistency of the scale has been reported to be at or below the .70 acceptability level (Cleveland et al., 1988; Perry, Kulik, \& Bourhis, 1996), which limits the measure's usefulness. Additionally, this measure does 
not capture people's perceptions of the organizational climate about the treatment of people regarding their age, which is the goal of my ageism climate measures.

Goldberg, Perry, and Finkelstein (2006) developed an ageism scale that is strictly focused on organizational ageism. The researchers aimed to get people's perceptions of an organization's attitudes toward older workers in a recruitment context. The six-item scale asks participants to rate their level of agreement with statements describing workplace stereotypes of older workers in regards to whether they believe organization members subscribe to these views. The researchers conducted an exploratory factor analysis and found that a one-factor solution provided the best fitting model. The strength of the scale is that it focuses specifically on the organizational context. However, the measure is too narrowly focused in that it only assesses older worker treatment in a recruitment context and excludes the treatment of younger workers.

In summary, a common theme across extant age bias scales is the use of older worker stereotypes as an indicator of age bias, a concept that guided the development of my measure. Additionally, a recent advancement in these scales is the transition from solely measuring cognitive elements of age bias (i.e., stereotypes) to also including affective elements of age bias, another concept I integrated into my measures. Finally, I have identified limitations in these scales that I addressed in developing my ageism climate measures. For instance, these scales focus strictly on older adults, ignoring the existence of negative attitudes toward younger adults. Moreover, most of the scales examine general attitudes or bias about older people and fail to recognize the contextual 
(i.e., the workplace) influences on an individual's feelings. Therefore, my ageism climate scales focused on addressing these limitations.

Diversity climate scales. As discussed above, diversity climate research is an emerging line of research in the diversity literature. Diversity climate scales have approached the measurement of diversity climate both as a multi-dimensional construct (e.g., Kossek \& Zonia, 1993; Mor Barak, Cherin, \& Berkman, 1998) and as a single dimension (e.g., McKay, Avery, \& Morris, 2008; Pugh, Dietz, Brief, \& Wiley, 2008). I critically analyze several diversity climate scales below.

Kossek and Zonia (1993) developed a four-factor measure of diversity climate that included the following dimensions: efforts to promote diversity, attitudes toward qualifications of racioethnic minorities, attitudes toward qualifications of women, and department support of racioethnic minorities and women. The researchers found support for the dimensionality of their scale through an exploratory factor analysis. A limitation of this scale for my purposes is its exclusion of age diversity. However, an important concept is its identification of support for diverse employees as an antecedent to diversity climate.

Mor Barak, Cherin, and Berkman (1998) developed the Diversity Perceptions Scale (DPS), which has two general dimensions - organizational and personal. The organizational dimension included an organizational fairness factor and an organizational inclusion factor, whereas the personal dimension included a personal diversity value factor and a personal comfort factor. The researchers found that the four-factor structure held up when they conducted a principal components analysis with varimax rotation. The 
scale's strength is the recognition of organizational-level practices that influence an individual's overall diversity climate perceptions. However, a limitation is that it addresses diversity in general, and not age diversity specifically. For example, if a participant rates "strongly agree" on the item, "I feel I have been treated differently here because of my race, sex, religion, or age," it could reflect differential treatment due to one, some, or all of the diversity characteristics mentioned.

Hicks-Clark and Ilies (2000) developed the positive climate for diversity scale. The researchers argue that diversity climate includes two dimensions: policy support for diversity and equity recognition. The policy support for diversity was measured by asking about people's perceptions of whether their organization's human resource policies included equal opportunity policies, mentoring, flexible working hours, childcare, and a career break. The equity scale included perceptions that justice exists in the organization, the organization recognizes the need for diversity, and the organization supports diversity. A limitation of this measure is that the researchers did not investigate the factor structure of their construct; rather, they treated each measure as an individual predictor of specific individual outcomes.

Recent research using diversity climate measures have treated diversity climate as a unitary construct encompassing several components of diversity. For example, McKay et al. (2007) used a nine-item scale that was adapted from the organizational dimension of Mor Barak and colleagues' (1998) diversity climate scale. The researchers reported a Cronbach's alpha of .90 , but did not provide any additional analysis as to the measure's factor structure. Moreover, McKay et al. (2008) used a four-item measure to assess 
diversity climate. Three of the items were from the McKay et al. (2007) scale, and one item was adapted by collapsing several items into a single item assessing equitable treatment. The researchers found support for a one-factor structure using principal components factor analysis. Pugh, Dietz, Brief, \& Wiley (2008) also approached diversity climate as a unitary construct with their four-item measure which was based on three existing measures (Kossek et al., 2003; McKay et al., 2007; Mor Barak et al., 1998). The researchers conducted a confirmatory factor analysis and found that a one-factor model provided an excellent fit to the data (i.e., $\mathrm{CFI}=1.0, \mathrm{TLI}=.99$, and $\mathrm{RMSEA}=.04$ ). Overall, the measures following a unitary approach to diversity climate have observed acceptable psychometric properties and shared several common conceptualizations identified by the multi-dimensional measures. However, these scales are limited by their broad treatment of diversity as a single concept rather than recognizing that different characteristics and attributes (e.g., age, gender, ethnicity) may differentially affect people's perceptions and experiences in the workplace.

In summary, several similar conceptualizations of diversity have emerged in the diversity climate literature. The common themes of inclusion, equitable treatment, and support of diverse workers are consistently used to indicate a positive climate for diversity. A general limitation of the diversity climate scales is that they do not explicitly measure age diversity. However, the scales do identify content areas related to organizational policies, practices, and procedures that were helpful in the development of my age climate scale. Moreover, this research specifically focuses on diversity in the workplace, which increases the applicability of these common themes to examine the 
differential treatment of diverse workers according to their age. Therefore, I integrated these common themes in creating ageism climate measures.

Step 1: Item generation. Up to this point, I discussed the conceptual development of my ageism climate measures, which proceeds Hinkin's (1998) six-step scale development process. However, in this section, I describe the item generation process utilized for my ageism climate measures, which is Hinkin's (1998) first step of scale development. A deductive approach was used to create my ageism climate measures using theory and research from the age bias and diversity climate literatures. First, I utilized the common age stereotypes (Postuhuma \& Campion, 2009) and the Organizational Ageism Scale (Goldberg et al., 2006) as the primary sources for item generation from the age bias literature. Second, the common themes observed from my review of the diversity climate research, described above, were also used to create items and conceptually categorize the items generated. Finally, I attempted to address the limitations identified in my critical evaluation of extant ageism and diversity climate measures, which included the lack of attention paid to younger workers, the limited focus of measuring age-related attitudes in a workplace context, and the lack of measuring affective age attitudes (i.e., prejudice). After I generated the items for the measure I had two experts in I/O Psychology review the items. Having experts review the measure added to the thoroughness of the process. Please see Table 2 for the list of scale items and a brief description of how they are related to the common workplace age-related stereotypes identified by Posthuma and Campion (2009) and to the themes derived from my review of the diversity literature. 
To make the measure more manageable to administer in the field, the brevity of the scale was imperative and necessitated the collapse of conceptually or logically similar themes into single items. For example, the common older worker stereotypes of poor performance, resistance to change, lower ability to learn, having shorter tenure, and being more costly are associated with the perceived value of an employee. Moreover, to make the items relevant to my nurse sample, most of the item stems specifically referred to the treatment of nurses. Consequently, I attempted to capture the combination of these common older worker stereotypes with the following item "In my organization, older nurses are viewed as less valuable than younger nurses." Furthermore, the perceived value of an employee may affect people's perceptions of the employee's return on investment to the organization. Accordingly, I created the following item to address this idea, "My organization views investments in older workers as unlikely to yield a return." Finally, the perceived value and perceived return on investment of an employee may manifest itself in the amount of resource investment in the employee in the form of career development opportunities. Hence, I created the following item, "Older nurses are not given as much access to career development resources (i.e. training) as compared to younger nurses."

The themes of equitable distribution of resources, inclusion, and support derived from my review of the diversity climate research also influenced the creation of items. For instance, the equitable distribution of resources or access to opportunities is a subject that pervades the diversity literature. Therefore, I created two items that focused on investment in workers due to their age and access to career development resources as a 
way to integrate this theme into my scale. Furthermore, inclusion in the workplace was commonly discussed as a positive influence on perceptions of diversity, and therefore I attempted to directly assess this idea with the following item, "People of certain ages are often not well integrated into the organization." Moreover, the diversity literature discusses support of diverse workers as a crucial factor to create positive perceptions of diversity. Accordingly, I attempted capture this important concept with the item, "In my organization, older nurses do not get as much support as they might need."

To extend the age bias literature, I wanted to examine the effects of age-related attitudes toward younger workers. I decided to use the same items that I had created for older workers to assess the climate for younger workers. The logic behind this decision is that there is empirical evidence supporting the idea that younger workers may face similar age-related experiences as older workers, such as the difficulty in obtaining organizational resources (Steiner, Bertolino, Fraccaroli, \& Truxillo, 2007). Likewise, the stereotypes held about younger workers may influence the way they are treated in organizations. Indeed, research has found that younger workers are seen as less trustworthy (Loretto et al., 2000) and less loyal to organizations (Coy, Conlin, \& Thorton, 2002). Arguably, these stereotypes reflect a general perception that younger workers may not stay with an organization long term, and in turn, could lead members of organizations to perceive younger workers as providing lower returns on investment, being less valuable, and not worthy of career development resources. Therefore, the three items that were created about older workers addressing themes of organizational value, return on investment, and career development are also applicable to younger workers. 
Ageism Climate 82

Moreover, the general themes identified in the diversity research broadly address how to create an overall positive diversity climate for all workers including both older and younger workers. Hence, an item assessing support is just as applicable for younger workers as it is for older workers.

According to Rupp, Vodanovich, and Credé (2006), most of the current ageism scales do not incorporate the affective component of age bias. I approached the assessment of people's general feelings toward a person due to their age through developing a statement that captures people's general regard (i.e., like or dislike) toward an individual. After consideration, I created the following item, "Sometimes a person's age affects how they are viewed in my organization." Arguably, this item assesses the affective component of age bias because it asks people to think about whether age plays a factor in how people feel about particular person with regard to their age.

In summary, ageism climates assess three types of age climate-older worker (4 items), younger worker (4 items), and general (2 items) ageism climate. I utilized a deductive approach to create the 10 items for the measures. The deductive approach was an appropriate method of item generation because there is established theory in regards to age bias and diversity climate. If this method is followed properly, it should assure the content validity of the measure (Hinkin, 1998). Both the age bias and diversity literatures played important roles in guiding the development of each scale item. Complementing the literature review were responses from two interviews and comments from nurses in focus groups suggest that an age climate exists and affects coworker interactions and may be a source of negative experiences in the workplace. The measure addresses limitations 
of extant measures such as capturing the treatment of younger workers, focusing on people's perceptions in the workplace, and capturing affective perceptions of age-related workplace treatment. The combination of my personal experiences and critical review of extant research increases my confidence that the measures provide a brief, but comprehensive assessment of ageism climates.

\section{Oregon Nurse Retention Project (ONRP)}

Step 2: Questionnaire administration. Hinkin's (1998) second scale development step is to administer a questionnaire to a sample representative of the population of interest. In this case, since the initial conceptualization of the construct was based on my experiences with nurses, I administered a survey to nurses as an implementation of this step. The archival data used for my dissertation was previously collected as part of a larger project called the Oregon Nurse Retention Project (ONRP). ONRP was collaborative project with the Oregon Nurse Association (ONA), the professional association for Oregon Nurses, and was funded by a grant from the Northwest Health Foundation. ONRP focused on identifying key factors of nurse turnover and providing greater understanding of how nurses' working conditions may affect retention (Sinclair, Mohr, Davidson, Sears, Deese, Wright, Waitsman, \& Cadiz, 2009). A multi-method approach was used to collect information for the study including conducting focus groups, reviewing staffing request reports provided by ONA, and collecting surveys. Survey data collection was conducted in three phases: a baseline survey, 12 weekly surveys, and a follow-up survey. The data for my dissertation are from the baseline and follow-up surveys, and therefore, is archival data because the data were collected prior to 
my dissertation proposal. Even though I was heavily involved in the data collection process, I had little control over it and was restricted by the number of items that I was allowed to have on the survey. Therefore, this placed a limitation as to how much content could be assessed with my ageism climate measures.

As an ONRP research team member, I was actively involved in several aspects of the project. I attended team research meetings that spanned about 18 months which included providing input on the conceptual framework used as a guide for what variables were collected, helping to generate items for creating new measures, and helping to resolve project implementation and survey administration issues. I was also involved with reviewing and analyzing archival data from staffing request documents which were used to develop staffing sufficiency and staffing mix items for the survey. Moreover, I also helped to conduct several focus group discussions, which were used to get feedback and suggestions as to the content and relevance of our survey items for practicing nurses. Finally, one of my main contributions to ONRP was managing the Time 1 survey administration. As the lead for the Time 1 survey administration, I was responsible for managing the online database, sending email invitations and follow up reminders to the potential participants, and providing technical assistance to participants that were having difficulty filling out or submitting the survey. At the completion of the Time 1 survey administration, I helped hand-write thank you post cards to participants.

In addition to performing several functions as an ONRP research team member, I was involved with several projects focused on disseminating our research findings including writing a summary of my research for the final technical report, working on 
Ageism Climate 85

posters and presentations that have been presented at annual profession conferences, and using data from the Time 1 survey to complete my master's thesis. Overall, the ONRP project provided a great opportunity to be involved with a comprehensive, mixed-method research project on nurses, a population that I am interested in continuing to research in the future. In the subsequent sections, I describe the data collection procedure, participants, measures, and analytic strategy used to validate the ageism climate measures and test my hypotheses.

\section{Procedure}

Participant recruitment was conducted by the Oregon Nurses Association (ONA). During the recruitment process, prospective participants were directed to the ONA website for registration to participate in the study. In the registration process, participants' names, contact information, and basic demographic information were collected. ONA assigned a confidential code to each of the participants before sending any information to the research team, thus keeping the participant's identity confidential. As a further step to keep participant responses confidential, ONA was not provided specific survey response information.

During the recruitment process, participants were given the option of filling out either an online survey or paper survey that was mailed to their home. About $86 \%$ of the nurses chose to participate through the online survey. Two reminder emails-one week and three weeks after the initial email invitation-were sent to participants who had not yet completed the survey. The same reminder process was used for the follow-up survey. No follow-up process was used for those who indicated they preferred a paper survey. 
Participants were offered an incentive of $\$ 20$ to fill out the baseline survey (Time 1) and $\$ 10$ to fill out the follow-up survey (Time 2). The Appendix displays items, instructions, and response format for the scales that I used from the baseline and follow-up surveys.

\section{Participants}

There were 657 surveys distributed at Time 1 and 424 responses were received, resulting in a response rate of $64.5 \%$. For Time 2 , the same numbers of surveys were distributed as in Time 1. I received 349 responses, which is a response rate of $53.1 \%$. The matched data from Time 1 and Time 2 resulted in a total sample of 339 participants and an overall response rate of $51.6 \%$. The participants were mainly female (93\%) and Caucasian $(92 \%)$. The average age of the participants was 45.86 years old $(S D=11.30)$, and the ages ranged from 22 to 70 . Because age is a major focus of this dissertation I broke out the sample by decade to provide some additional descriptive information. I found that $11 \%$ of the participants are under $30,20 \%$ are between 30 and $39,24 \%$ are between 40 and $49,37 \%$ are between 50 and 59, and $9 \%$ are 60 and older. Over $76 \%$ of the sample held a bachelors degree or higher. Sixty percent of the participants worked full-time, and $82 \%$ worked in a hospital or acute care setting. The average professional tenure was approximately 18 years $(S D=12.14)$, organizational tenure was 11 years ( $S D$ $=9.29)$, and job tenure was 7 years $(S D=7.17)$.

\section{Measures}

The measures used in the study are described below. The variables have been organized into four sections: control variables, convergent and discriminant validity variables, antecedents, and outcome variables. 


\section{Control Variables}

The variables listed below were considered as control variables in the regression analyses because they either were identified in extant research as a well-established correlate of the outcome variables or theoretical considerations merit their inclusion. For instance, a nurse's practice setting (i.e., rural versus urban) and the medium in which the nurse took the survey (i.e., paper versus online) were considered potential control variables because there could be meaningful differences between people variables that should be accounted for in my analyses. Organizational tenure and chronological age were used as control variables in the regression analyses due their established relationships with turnover intentions (Blau, 2007; Hedge, Borman, \& Lammlein, 2006) and affective organizational commitment (Meyer, Stanly, Herscovich, \& Topolnytsky, 2003). Finally, affective organizational commitment was a control variable in the turnover intentions analysis because it has been observed to be significantly related to turnover intentions (Cooper-Hakim \& Viswesvaran, 2005). However, affective commitment was also an outcome variable so I discuss this variable in the outcome section.

Paper versus online. This variable indicates whether the participant took the webbased $(86 \%)$ or paper survey.

Rural versus urban. This variable was created from the city or town where participants indicated they practiced. Cities with populations greater than 50,000 people were categorized as an urban setting. Based on this categorization, $62 \%$ of the participants worked in an urban setting. 
Chronological age. Chronological age was measured with one item asking the person's age in years. The mean age in the sample is 45.86 years $(S D=11.30)$.

Organizational tenure. Organizational tenure was measured with one item asking how long the participant has worked for their current organization $(M=11$ years, $S D=$ 9.13).

\section{Convergent and Discriminant Validity Variables}

Several variables were included based on whether they had a strong theoretical relationship with the ageism climate measures (i.e., convergent validity) or a weak or no relationship was expected with the ageism climate measures (i.e., discriminant validity). Various sources of support were included as convergent validity variables because ageism climates are conceptually related to people's perceptions of whether their organization is supportive of workers across the age continuum. Moreover, incivility, age discrimination, and general discrimination were included because these negative workplace experiences could be theoretically related to people's climate perceptions of age diversity in the workplace. Finally, experienced workplace violence was identified as a variable that would have a weak relationship with ageism climates because experienced workplace violence is more situation-specific and is independent from a person's age. Convergent and discriminant validity was investigated by examining the correlation between these variables and the ageism climate measures. The response scale used to assess the perceived organizational support, coworker support, and manager support scales was a 5-point Likert-type that ranged from Strongly Disagree to Strongly Agree, and response the scale used to assess incivility, experienced age discrimination and 
Ageism Climate 89

experienced general discrimination was a 5-point frequency scale that ranged from Never to Very Often.

Perceived organizational support. Perceived organizational support was measured with four items from the original 36-item Survey of Perceived Organizational Support (Eisenberger, Huntington, Hutchinson, \& Sowa, 1986). The four items selected for this study were some of the highest loading items from the original measure. The use of a reduced scale is warranted because the original scale has unidimensionality and high internal reliability (Rhoades \& Eisenberger, 2002). In fact, Witt (1992) observed a Cronbach's alpha of .74 using a three-item version of the measure. A sample item from the reduced form of the measure is, "The organization I work for really cares about my well-being." The observed alpha for this measure is .81.

Coworker support. I measured coworker support with four items adapted from the Survey of Perceived Organizational Support (Eisenberger et al., 1986). A sample item of the measure is, "My coworkers really care about my well-being." The observed alpha for this measure is .86 .

Manager support. I measured manager support with four items adapted from the Survey of Perceived Organizational Support (Eisenberger et al., 1986). A sample item from the measure is, "My manager really cares about my well-being." The observed alpha for this measure is .92 .

Incivility. Incivility towards the respondent was measured with an adapted version of the Workplace Incivility Scale (WIS; Cortina, Magley, Williams, \& Langhout, 2001). The items from the original scale were adapted to focus on common sources of incivility 
in the nursing workplace including coworkers and supervisors. Four items for each source were used to assess frequency of the uncivil events that occurred over the past 30 days. I used the coworker and manager incivility scales for the convergent and discriminant validity investigation. An item from the scale is, "Coworkers [Supervisors] made demeaning or derogatory remarks about you." The alpha for the coworker and manager measures are .87 and .86 , respectively.

Experienced workplace violence. Experienced workplace violence was measured with four items created for the ONRP study. A sample item from this measure is, "I was physically assaulted by patients or their family members." The alpha for this measure was .88 .

Experienced age discrimination. Experienced age discrimination was measured with one item adapted from the Expanded Nurse Stress Scale (French, Lenton, Walters, \& Eyles, 2000). The item is, "I was discriminated against due to my age."

Experienced discrimination. Experienced discrimination was measured with five items adapted from the Expanded Nurse Stress Scale (French et al., 2000). An example item from this measure is, "I was discriminated against because of race or ethnicity." Other items included in this scale assess discrimination based on sexual harassment, sexual orientation, gender, and religion. The alpha for this scale was .73.

\section{Antecedents}

The variables included in this section were hypothesized as the predictors of the identified outcomes. These variables were included in all of the regression analyses and the ageism climate variables were the focus of several construct validity analyses. A 5- 
Ageism Climate 91

point agreement response scale was used that ranged from Strongly Disagree to Strongly Agree.

Core self-evaluations. CSE was measured with the 12-item core self-evaluations scale (CSES) developed by Judge, Erez, Bono, and Thoresen (2003). A sample item from the scale is, "I am confident I get the success I deserve in life." The alpha for this scale was .82.

Ageism climates. Ageism climates were measured with the 10 -item scale that was developed for this dissertation and described in detail above. The construct contains three dimensions of ageism climate including ageism climates associated with older and younger workers and a general ageism climate. Four items assess older worker ageism climate. An example item for this scale is "In my organization, older nurses are viewed as less valuable than younger nurses." In addition, four items assess younger worker ageism climate. An example item for this scale is "My organization views investments in younger nurses as unlikely to yield a return." Two items were used to assess people's perceptions of a general ageism climate. An example item for this scale is "Sometimes a person's age affects how they are viewed in my organization." The complete list of items is given in Table 2 . The alpha for the older worker ageism climate was .88 , the alpha for the younger worker ageism climate was .76, and the alpha for the general ageism climate was .83. Additional psychometric characteristics are described in the Results chapter.

\section{Outcomes}

The variables below were identified as the important workplace outcomes that would be affected by ageism climates and CSE. These variables were used in the 
criterion-related validity analyses, which involved testing the hypotheses using regression analysis. A five-point agreement response scale was used ranging from Strongly Disagree to Strongly Agree.

Organizational turnover intentions. An adapted three-item version of Hom, Griffeth, and Sellaro's (1984) organizational turnover intentions measure was used to collect turnover intentions. A sample item from this measure is, "I am planning to search for a new job outside this organization during the next 12 months." Time 1 and 2 alphas for the scale were .92 and .91 , respectively.

Affective organizational commitment. Organizational commitment was operationalized as affective organizational commitment. Affective commitment was measured with four items from Meyer, Allen, and Smith's (1993) original six-item scale. A sample item is, "This organization has a great deal of personal meaning for me." The observed alpha for the measure at Time 1 and Time 2 was .93 and .92 , respectively.

Work engagement. Work engagement was measured with the Utrecht Work Engagement Scale-9 (UWES-9), a nine-item scale developed by Schaufeli, Bakker, and Salanova (2006). Work engagement was collected at Time 1 and Time 2. A sample item is, "I was immersed in my work." The alpha for this scale was observed to be .92 at both Times 1 and 2, respectively. 
Ageism Climate 93

\section{Chapter 7: Results}

In this chapter, I describe my study's results. First, I review the results of the correlation analysis, which examined the relationships among all of the study variables. Second, I report the results of my scale validation analysis including the confirmatory factor analysis, measurement equivalent analysis, and the investigation of discriminant and convergent validity. Finally, I describe the results of my criterion-related validity analysis, which involved testing the hypothesized relationships between the ageism climates and several workplace outcomes.

\section{Correlation Analysis}

Means, standard deviations, and intercorrelations are displayed in Table 3. Gender was not correlated with any of the variables included in this study. Moreover, survey medium (i.e., paper versus online) was not related to any of the study variables except for the age of the participant, in that the older the participant the greater likelihood the participant selected the paper survey option $(r=.11, p<.05)$. The location worked (i.e., rural vs. urban) is related to age and tenure with younger and less tenured nurses working in more urban settings $(r=-.18, p<.01 ; r=-.12, p<.05)$. Additionally, those who work in rural settings report being more engaged at work, both at Time $1(r=-.14, p<.01)$ and Time $2(r=-.14, p<.05)$. As expected, chronological age and organizational tenure are significantly related $(r=.51, p<.01)$, and age is also positively related to engagement at Time $2(r=.12, p<.05)$. In addition, chronological age is negatively related to coworker support $(r=-.11, p<.05)$ and manager incivility $(r=.16, p<.01)$. Organizational tenure had a significant positive relationship with older worker climate $(r=.34, p<.01)$ and 
general age climate $(r=.22, p<.01)$ indicating that those with longer organizational tenure reported more ageist older and general climates. Additionally, organizational tenure is negatively related to perceived organizational support $(r=-.12, p<.05)$ and positively related to manager incivility. In short, the observed relationships suggest that location, chronological age, and organizational tenure are related to several key study variables, and therefore will be utilized as control variables.

Of particular interest are the relationships among the age climate measures, CSE, and the outcome variables. CSE is significantly related to all of the outcome variables. CSE has moderately strong, positive relationships with engagement collected at Time 1 ( $r$ $=.38, p<.01)$ and Time $2(r=.30, p<.01)$. Additionally, CSE is positively correlated with affective organizational commitment collected at Time $1(r=.14, p<.05)$ and Time $2(r=.13, p<.05)$. However, this relationship is not as strong as the relationship observed with engagement. As expected, CSE is negatively related to organizational turnover intentions at Time $1(r=-.26, p<.01)$ and Time $2(r=-.20, p<.01)$. This suggests that those high in CSE are generally more engaged at work, have greater affective commitment, and lower intent to turn over.

Similar to CSE, all of the age climate measures were significantly related to the outcome variables, except for older worker climate with engagement at Time $1(r=-.07$, $n s)$. Older worker climate, however, is significantly related to Time 2 engagement $(r=-$ $.12, p<.05)$. Older worker climate is also significantly related to affective commitment at Time $1(r=-.24, p<.01)$ and Time $2(r=-.22, p<.01)$ as well as significantly related to turnover intentions at Time $1(r=.22, p<.01)$ and Time $2(r=.24, p<.01)$. Younger 
worker climate has a significant negative relationship with Time 1 engagement $(r=-.12$, $p<.05)$, Time 2 engagement $(r=-.14, p<.05)$, Time 1 affective commitment $(r=-.29, p$ $<.01)$, and Time 2 affective commitment $(r=-.33, p<.01)$. In addition, younger worker climate has a significant positive relationship with turnover intentions at Time $1(r=.25$, $p<.01)$ and Time $2(r=.26, p<.01)$. General age climate had a similar pattern of relationships as the other two age climate scales; significant negative relationship with engagement at Time $1(r=-.17, p<.01)$ and Time $2(r=-.15, p<.01)$; significant negative relationship with affective commitment at Time $1(r=-.14, p<.01)$ and Time 2 $(r=-.14, p<.01)$; and a significant positive relationship with turnover intentions at Time $1(r=.25, p<.01)$ and Time $2(r=.25, p<.01)$. In general, the correlations with the outcome variables are in the proposed direction and are significant, which provides initial support for my hypotheses.

Finally, I examined the inter-correlations among the age climate measures to gather initial support for the multi-dimensionality of ageism climate. Young worker climate has a significant positive relationship with both older worker climate $(r=.20, p<$ $.01)$ and general age climate $(r=.48, p<.01)$. Older worker climate and general age climate also share a significant positive relationship $(r=.60, p<.01)$. Although the relationship between young and older worker climate is not as strong as expected, the results provide initial support that the age climate measures are related to one another. More importantly, the results also indicate that older and younger worker climates are not the same.

Exploratory Factor Analysis and Item Reduction (Hinkin's Step 3) 
Ageism Climate 96

Up to this point, I have addressed the item generation and questionnaire administration steps (i.e., Steps 1 and 2) of Hinkin's (1998) scale development process. The third step in the scale development process is described as the initial item reduction phase and involves analyzing inter-item correlations, calculating internal reliability statistics, and conducting an exploratory factor analysis. The subsequent sections discuss the results for each of these analyses.

Inter-item correlations. Inter-item correlations are indicators of the relationship among individual items within a measure and it is assumed that positive and medium to strong average inter-correlations indicate the items are drawn from an appropriate content domain (Hinkin, 1998). The correlations within each respective ageism climate measure were .39 and above. Cohen (1988) suggests that correlations above .30 indicate a moderate relationship and those above .50 as being a large relationship. Therefore, the inter-item correlations suggest that each ageism climate captures a similar content domain. Moreover, when I examined the relationships among the items across three ageism climate measures, I observed that the younger worker items generally had weak relationships with the older worker climate items. The exception is the younger worker climate item that is associated with younger workers not getting enough support they might need which had small to moderate relationships with all of the older worker climate items. The older climate items relationship with general ageism climate items ranged from .35 to .52 which indicates that the items are moderately related. A similar result was observed when looking at the younger worker climate and the general ageism climate in that the relationships ranged from .24 to 50 . Therefore, the results suggest 
that the older and younger worker climate items are capturing different content domains whereas the general ageism climate items share moderately strong relationships with the older and younger worker ageism climate items. The inter-item correlations are displayed in Table 4.

Internal reliability analysis. Hinkin (1998) suggests examining the internal reliability of the measures as a sub-procedure of the third step of his scale validation process. I decided to calculate Cronbach's alpha to represent the internal reliability for each ageism climate measure. The Cronbach's alphas for younger worker, older worker, and general ageism climates were $.76, .88$, and .83 , respectively. Each of these alphas is above the generally accepted .70 cutoff criteria for acceptable internal consistency, which provides support for the internal reliability of the ageism climate measures.

Exploratory factor analysis. Hinkin (1998) also recommends conducting an exploratory factor analysis (EFA) as a sub-procedure in the third step of the scale development process. The 10 ageism climate items were included in a principal components analysis (PCA) using an oblimin rotation (i.e., an oblique rotation) because this type of rotation allows the factors to be correlated and this is appropriate because I observed that the climate measures were significantly related in the correlation analysis described above. The results suggested that there were two factors, which were determined by identifying the factors with Eigenvalues greater than 1 and examining where the break in the slope of the graphed Eigenvalues occurs. The first factor explained $43 \%$ of the variance and the second factor explained about $22 \%$ of the variance, which means that these two factors combined to account for close to $65 \%$ of the variance. I 
examined the extracted factor loadings in the pattern matrix and this suggested that one of the factors included the older worker climate and general age climate items, and the second factor included the younger worker climate items. The factor loadings within each factor were above .61 except for the general ageism climate items. Moreover, standard errors are not calculated in a PCA so I was unable to determine whether these factor loadings are significantly different from zero. Interestingly, I also observed that the two proposed general ageism items also had factor loadings of .40 on the younger worker climate factor, which suggests that these items may cross-load on the older worker and younger worker ageism climate scales. The factor loading matrix for the final solution is presented in Table 5. In summary, although I proposed that there were three factors being assessed by my ageism climate measures, the EFA suggested that there were only two factors of ageism climate being assessed and the general ageism climate items crossloaded on both factors. Further examination of the factor structure is required and is discussed in the confirmatory factor analysis section below.

\section{Confirmatory Factor Analysis (Hinkin's Step 4)}

I used confirmatory factor analysis (CFA) to investigate how well the proposed three-factor structure of ageism climate fit the data, which is Hinkin's (1998) fourth step of his scale development process. First, I investigated whether the proposed three-factor structure was the best fitting model compared to two variations of a two-factor model and a one-factor model. I used chi-square difference tests to determine whether the threefactor model fit the data significantly better than two variations of a two-factor model and 
a one-factor model. Table 6 summarizes the results from this analysis. The proposed three-factor model fit the data significantly better than the one-factor model $(\Delta d f=3$, $\left.\Delta \chi^{2}=465.64, p<.01\right)$. In addition, the three-factor model fit the data significantly better than the two-factor model where I combined the general age climate measure with the older worker climate measure and left the second factor as younger worker climate $(\Delta d f$ $\left.=2, \Delta \chi^{2}=185.01, p<.01\right)$. The three-factor model also fit the data significantly better than the model where I combined the general age climate measure with the younger worker climate measure and left the second factor as older worker climate $\left(\Delta d f=2, \Delta \chi^{2}\right.$ $=197.57, p<.01)$. Therefore, the three-factor model fit the data best in comparison to other potential models.

Additionally, I examined multiple fit statistics including CFI, RMSEA, and SRMR. Generally, a model is considered to have acceptable fit if the CFI is close to .95, RMSEA is below .08, and SRMR is close to .05 (Hu \& Bentler, 1999). Upon investigation, the fit statistics suggested that the proposed three-factor model had unacceptable fit to the data, $\mathrm{CFI}=.92, \mathrm{SRMR}=.07$, and $\mathrm{RMSEA}=.11$. Due to this lack of fit to the data, I examined the modification indices, and found that correlating item error coefficients would significantly improve the fit. In general, correlating error terms is considered an acceptable practice if there is reason to believe that common measurement error exists between the items being correlated. With this in mind, I decided to correlate the errors between two items from the older worker climate scale. This was done because the items have the same item stem "in my organization," which could mean they share some error variance simply due to their item stem. The updated model fit the data 
significantly better than the original three-factor model $\left(\Delta d f=1, \Delta \chi^{2}=15.99, p<.01\right)$ and the model also had improved fit statistics CFI $=.94$, SRMR $=.07$, and RMSEA $=$ .10 , but the fit statistics remained above the cut-off guidelines for acceptable fit (Hu \& Bentler, 1999).

Because the model did not have an acceptable fit to the data, I decided to investigate further. First, I examined the content of each item in detail and identified two items in the younger worker climate scale that may not be theoretically appropriate for younger workers compared to older workers, "My organization views investments in younger nurses as unlikely to yield a return" and "In my organization, younger nurses are viewed as less valuable than older nurses." Arguably, since these items were based on older worker stereotypes, they are not necessarily applicable to younger workers.

Therefore, I decided to remove these two items from the young worker scale, leaving the ageism climate measures with a total of eight items - four items assessing older worker climate, two items assessing young worker climate, and two items representing general age climate. The fit statistics for this updated model indicated a better fit to the data $\left(\chi^{2}=\right.$ $60.78, \mathrm{p}<.01, \mathrm{~N}=344, \mathrm{CFI}=.96, \mathrm{SRMR}=.05, \mathrm{RMSEA}=.10)$, but the RMSEA was still above acceptable fit. However, RMSEA is affected by sample size and the number of parameters to be estimated, where smaller sample sizes and less freely estimated parameters could affect the calculation of RMSEA potentially making it a less effective statistic to assess model fit in this situation (T. Bodner, personal communication, May 24, 2010). Moreover, some would argue that a decision about the fit of a model should not be made on a single statistic alone (Hu \& Bentler, 1999). The CFI and SRMR both indicate 
that the model fits the data well, and I have provided a graphical depiction of this model in Figure 2. Therefore, one could conclude that the modified model provides an acceptable fit to the data. However, I decided to further investigate to confirm that the measure was indeed a robust construct that could be confidently used in future research.

Theoretically, the initial mediocre fit of the model to the data could be a reflection of the construct functioning differently depending on the age of the participant responding to the item. For instance, a younger worker may be better able to assess the treatment of younger workers, whereas older workers may be able to assess the treatment of older workers due to personal experience. To explore the possibility of construct bias, I conducted multi-group CFA looking at the measurement equivalence of the older worker climate between participants who are younger than 40 and those that are 40 or older. Forty was set as the cut-off point because those 40 or older are protected under the Age Discrimination in Employment Act of 1967. Please note that since the general age climate and the reduced younger worker climate measures only have two items, I am unable to run a multi-group CFA because the model would be under-identified. Therefore, the measurement equivalence analysis was focused on the older worker climate measure.

The measurement equivalence analysis involved two steps. First, I ran the multigroup CFA with all of the parameters unconstrained and freely estimated. Second, I ran the model with the factor loadings for each item constrained to be equal across the older and younger groups. This is a standard procedure to assess measurement equivalence or construct bias as discussed by Kline (2005). To examine whether a significant difference 
exists between groups, a chi-squared difference test is performed by comparing the chisquare statistic from the constrained and unconstrained models. The chi-square difference test indicated that the constrained model fit the data significantly worse than the unconstrained model, suggesting that the older worker climate measure functions differently between the two age groups. The result of this analysis is displayed on Table 7.

To eliminate the possibility that individual items are causing the significant difference between the groups, I decided to run the measurement equivalence process in a different way. Instead of constraining all of the factor loadings for all of the items to be the same across the two groups, I constrained one item at a time. The result of this analysis is also displayed in Table 7. When Item 2 was constrained ('My organization views investments in older workers as unlikely to yield a return."), the chi-square change was significantly worse compared to the unconstrained model, $\Delta \mathrm{df}=1, \Delta \chi^{2}=289.91$. Additionally, when Item 4 was constrained ("In my organization, older nurses do not get as much support as they might need."), there was a significant change in chi-square that indicated the model fit significantly worse compared to the unconstrained model, $\Delta \mathrm{df}=$ $1, \Delta \chi^{2}=11.13$. The results from this analysis suggest that more than one item is driving the observed measurement non-equivalence across the two age groups, and therefore, any further analysis should be run separately for each age group to account for the construct bias observed for the older worker climate measure.

Since I was unable to run a multi-group CFA on the general age and younger worker climate scales, I decided to examine the pattern of correlations for each item 
within the measure with potential covariates and outcome variables across the two age groups. Similar correlation patterns across the age groups would suggest that the general climate items function similarly across the age groups. Please see Table 8 for the tabulated correlations for this investigation. In the general age climate measure, the direction of the relationships across the outcomes and covariates were similar. Moreover, I used a process analogous to meta-analytic procedures to compare the magnitude of the correlations between the two age groups. Specifically, Fisher Z transformation was used to convert each correlation into an appropriate effect size statistic to compare the two age groups (Hedges \& Olkin, 1985). Z-score differences between the age groups were calculated accounting for the different sample sizes in each age group. A significantly difference between the age groups was indicated by a z-difference score greater than 1.96 or less than -1.96 . The only significantly different relationship between the under 40 and 40 and over groups was the relationship between the second item of the general age climate scale and age discrimination $(\mathrm{z}=2.22, p<.01)$. Taking these results into consideration, I conclude that the general age climate scale generally functions the same across the age groups.

In addition, I conducted the same investigation described above for the two younger worker climate items. Table 9 displays the results of the examination. In general, the patterns of the relationships with potential covariates and the outcome variables across the two age groups were similar. I only observed one relationship where the direction of the relationship is in the opposite direction when comparing the two age groups. The relationship between the younger worker climate item pertaining to a 
younger nurse's value compared to older nurses value and experienced discrimination has a positive relationship $(r=.32, p<.01)$ in nurses under 40 and a negative relationship $(r$ $=-.09, n s)$ in nurses 40 and older. In addition, the correlations are significantly different from each other $(\mathrm{z}=3.40, p<.01)$. I also observed three relationships where the direction of the relationship was the same, but the magnitude of the relationship between the two age groups differed significantly. These significant differences were observed for the younger climate item pertaining to the value placed on younger nurses. The negative relationship between this item and affective commitment collected at Time 2 for those under $40(r=-.36, p<.01)$ was significantly stronger compared to those 40 and older $(r=$ $-.09, n s)$, indicated by the significant $z$-score difference $(z=2.43, p<.01)$. A difference was also observed for affective commitment collected at Time 1 where the relationship between the younger worker value item and commitment for those under $40(r=-.35, p<$ $.01)$ had a stronger relationship compared to those 40 and older $(r=-.14, p<.05)$, but this difference was not significant $(z=1.85, n s)$. In addition, the negative relationship between the younger worker value item and perceived organizational support for those under $40(r=-.41, p<.01)$ was significantly stronger compared to participants 40 and older $(r=-.14, p<.05)$ indicated by the significant $z$-score difference $(z=2.26, p<.01)$. The results of this investigation suggest that the younger worker ageism climate measure is affected by the age of the participant. Moreover, two of the significant differences involve one of the outcomes of interest (e.g., affective organizational commitment). Therefore, the regression analyses involving younger worker ageism climate will be 
examined by running the regressions for under 40 and 40 and older participants separately.

In summary, I have concluded that construct bias exists with regard to a participant's age in the older and younger worker climate measures, which meant that all of the subsequent regression analyses testing my hypotheses were run separately for each respective age group (i.e., under 40 and 40 or older) for these two age climate scales. However, regression analyses were run using the entire sample using the general age climate scale because the patterns of correlations and strength of the relationships were similar across the age groups, which suggests that construct bias does not exist for the general age climate scale.

\section{Convergent and Discriminant Validity Analysis (Hinkin's Step 5)}

In addition to examining the ageism climate's factor structure, I also investigated the convergent and discriminant validity, which is described as the fifth step in Hinkin's (1998) scale development process. This step involved analyzing correlations between the ageism climates and constructs that it should be theoretically related to and with those that it should have little or no relationship. Based on the results from the measurement equivalence analysis, I ran the convergent and discriminant validity analysis with three separate variations of the sample: nurses under 40 years old, nurses 40 years and older, and the combined sample. In addition, it is also important to note that I recoded the ageism climate measures so that a high score means a positive climate and a lower score would reflect a negative climate. Please see Table 10 for a summary of the analysis. Convergent validity 
I analyzed three categories of variables that are conceptually related to the ageism climates: perceived support, experienced incivility, and experienced discrimination. In the perceived support category, I investigated the relationships among the ageism climate measures and organizational, manager, and coworker support. Perceived support was expected to be negatively related to ageism climates because those who do not feel supported at work would have a greater likelihood of having negative climate perceptions. In the 40 and older and combined samples, almost all of the ageism climate measures had significant negative relationships with the different sources of support except for the relationship between coworker support and younger worker climate in the combined sample $(r=-.11, p=.05)$, which was close to being significant. In other words, the higher the ratings were for the ageism climates, the lower the participant's perceptions of support from their organization, managers, and coworkers. However, in the under 40 sample, I observed unexpected relationships between the support variables and older worker climate. The relationship between older worker climate and perceived organizational support $(\mathrm{POS} ; r=-.02, n s)$ and manager support $(r=.07, n s)$ were not significant in the under 40 sample. In fact, significant differences were found when comparing the under 40 and 40 and older sample correlations between older worker climate and POS $(z=3.88, p<.01)$ and older worker climate and manager support $(z=$ $3.76, p<.01)$. Furthermore, I observed a significant positive relationship with coworker support $(r=.20, p<.05)$, which was in the opposite direction expected and significantly different from the correlation observed in the 40 and older sample $(z=3.59, p<.01)$. In other words, for those under 40, a more ageist climate for older workers was associated 
with greater coworker support. Therefore, the relationships among the ageism climate variables and support variables among younger workers were different from the over 40 and combined samples. Note that these findings may broadly suggest that diversity climate may not be a unitary construct as conceptualized by some researchers (McKay, Avery, \& Morris, 2008).

Additionally, interpersonal conflicts at work (incivility) were expected to have a positive relationship with the ageism climate measures because uncivil workplace interactions with coworkers and managers could reflect a more ageist climate. Significant positive relationships between manager incivility and the ageism climate measures were observed across the samples except for older worker climate rated by participants under $40(r=.06, n s)$, but this correlation is not significantly different from the correlation between older worker climate and manager incivility rated by those over $40(z=1.93$, $n s)$. The relationship between coworker incivility and the ageism climate measures was not as uniform compared to the manager incivility relationships. A significant positive relationship between older worker climate and coworker incivility was observed in the 40 and older sample $(r=.33, p<.01)$ and combined sample $(r=.27, p<01)$. However, a significant relationship was not found between coworker incivility and older worker climate in the under 40 sample $(r=-.02, n s)$ and this correlation is significantly different from what was observed in the 40 and older sample $(z=2.93, p<.01)$. Significant positive relationships between coworker incivility and general age climate were observed in the 40 and older sample $(r=.37, p<.01)$ and combined sample $(r=.33, p<.01)$, but not in the under 40 sample $(r=.19, n s)$. However, the difference in the correlations 
between the under 40 sample and the 40 and older sample was not significant $(\mathrm{z}=1.65$, $n s)$. I also found that younger worker climate had a significant positive relationship with coworker incivility only in the combined sample $(r=.12, p<.05)$, but not in the under 40 sample $(r=.18, n s)$ and 40 and older sample $(r=.10, n s)$. Therefore, in general, the observed relationships between the incivility variables and older worker and general age climate were as expected, where those who experience greater levels of incivility from their coworkers and managers perceive an increased level of ageism climate. Although support was found for a positive relationship between young worker climate and manager incivility, I observed no support for a significant positive relationship between young worker climate and coworker incivility.

Finally, I examined the relationship between ageism climate measures and two experienced discrimination variables (i.e., age discrimination and general discrimination). Theoretically, if someone has experienced workplace discrimination this should result in assessing the climate as more ageist. Therefore, I expected that all of the age climate measures would be positively related to experienced general and age discrimination, but the observed relationships were not uniform. Older worker climate and general age climate were found to have significant positive relationships with both age discrimination and general discrimination in the older and combined samples. In the under 40 sample, however, a negative significant relationship was observed between age discrimination and older worker climate $(r=-.22, p<.05)$ indicating that younger nurses who perceived a more ageist older worker climate reported less personal experiences of age discrimination. Furthermore, no significant relationship was observed between younger 
worker climate and age discrimination across the three sample variations. In fact, younger worker climate was only significantly related with general discrimination in the under 40 sample $(r=.29, p<.01)$. Therefore, older worker climate and general age climate confirmed expectations with regard to their positive relationship with the experienced discrimination variables, whereas younger age climate did not. This provides support that relational demography, specifically similarity attraction theory (Byrne, 1971), may be affecting age climate perceptions and measuring age climate in terms of multiple dimensions provides additional important information.

In summary, convergent validity was generally supported across the samples for older worker and general age climates. The relationships between younger worker climate and the convergent validity variables differed from the other two climate variables. Specifically, limited to no support was observed between younger worker climate and coworker support and incivility as well as with age and general discrimination. This suggests that there are multiple dimensions of ageism climate and that relational demography is important to consider as affecting assessments of ageism climate. Moreover, I observed differences in the convergent validity analysis across the samples, which was expected since evidence of measurement non-equivalence was indicated across age groups from the multi-group CFA.

Discriminant validity

I expected that the ageism climate scales would have a weak or no relationship with experienced workplace violence. Younger age climate did not have a significant relationship with experienced workplace violence across the three sample variations, but I 
observed significant relationships between experienced workplace violence and older worker climate and general age climate. Specifically, in the combined sample, I found weak, significant positive relationships between experienced violence and older worker climate $(r=.14, p<.05)$ and general age climate $(r=.17, p<.01)$. Moreover, a weak, significant negative relationship between general age climate and experienced violence was observed in the over 40 sample $(r=.16, \mathrm{p}<.05)$. Therefore, the results indicate that older worker and general age climate have a weak positive relationship with experienced workplace violence, but younger worker climate does not. There was general support for discriminant validity with regard to the ageism climate-experienced workplace violence relationship because the magnitude of the relationships are weak (accounting for less than $3 \%$ of the variance in these variables), and given the size of the sample, I did not expect to get a zero correlation.

\section{Summary of convergent and discriminant validity analyses}

The results of convergent and discriminant validity analysis generally supported expectations, with a notable pattern of exceptions in the convergent validity analysis that have interesting implications. In contrast, the pattern of relationships was different for younger worker climate and for younger workers rating older worker climate. This result suggests that different age groups view the age climate variables differently, which may be affected by perceptions associated with relational demography. In addition, the differential relationships observed across the ageism climate measures suggest that the current way of conceptualizing diversity climate as a unitary measure may not be appropriate (e.g., McKay et al., 2008), and emphasize the importance of measuring 
multiple dimensions of ageism climate to capture additional important information. The subsequent section reports the results from the regression analyses that tested proposed hypotheses.

\section{Regression Analyses}

Hierarchical multiple regression was used to test all of my hypotheses. Since the outcome variables were collected at two time points, I decided to run each regression analysis twice. The first set of analyses investigated age diversity and CSE's effects on the Time 2 outcome variables. The subsequent set of regressions were run the same way except the outcome variables were those collected at Time 1. This approach was used because ageism climate was collected at Time 2 and the relationship with the Time 2 outcomes may be inflated due to the fact that the variables were collected at the same time. Examining the relationship between ageism climates (collected at Time 2) and the Time 1 outcomes, provides a more conservative test of the relationship because it reduces concerns regarding the potentially inflated relationship from common method variance because there was a six-month temporal separation between data collection points. Additionally, since the older and younger worker climate measures were non-equivalent with regard to a participant's age, I ran each of the regression analyses splitting the sample into two groups, nurses under 40 years old $(\mathrm{N}=104)$ and nurses 40 years and older $(\mathrm{N}=239)$. However, to investigate the effects of general age climate on the outcomes, I ran the regression analysis with the combined sample $(\mathrm{N}=350)$ since measurement non-equivalence was not observed for this measure. 
Prior to running the regression analysis, I ran one-way ANOVAs to examine the potential differential effect of the rural versus urban location of where the nurse practices on the antecedents and outcome variables of interest. Because I will be running regression analyses involving three variations of the sample-nurses under 40 , nurse 40 and older, and the combined sample — I ran three separate ANOVAs with each sample variation, respectively. Arguably, hospitals in rural areas may function differently from those in urban locations, which would suggest that this variable would need to be controlled for in the regression analyses. Indeed, the results from the one-way ANOVAs suggested that there is a significant effect of work location on work engagement collected at both Time $1(F(1,335)=7.13, p<.01)$ and Time $2(F(1,339)=6.59, p<.05)$ in the combined sample. Moreover, this significant effect was also observed in the 40 and older sample for Time 1 engagement $(F(1,230)=5.03, p<.05)$. Therefore, urban versus rural will be used as a control variable in the regression analyses investigating work engagement as an outcome, but will not be used as a control variable in the other regression analyses in order to save degrees of freedom.

Additionally, I investigated whether the medium in which a participant filled out a survey effects how a participant responded to the survey. I ran a one-way ANOVA investigating whether there were significant differences between participants who filled out paper versus the web-based versions of the survey (although the surveys had the exact same content) on the outcome variables. The results of the analysis suggested that there were no significant differences with regard to participation medium across the sample variations on any of the outcome variables collected at Time 2. Similar non-significant 
differences were observed for the outcome variables collected at Time 1 . Therefore, the survey medium variable will not be used as a control variable in the regression analyses.

Finally, I conducted a response and non-response analysis to evaluate the potential bias of those who responded at Time 1, but did not respond at Time 2 . Rogelberg and Stanton (2007) reviewed and discussed several non-response bias techniques and proposed the nonresponse bias impact assessment strategy (N-BIAS). The researchers argued that assessing the bias associated with non-response is similar to a test validation strategy in that they recommend the implementation of multiple strategies to build evidence that non-response is not biasing results. However, most of the strategies outlined by Rogelberg and Stanton either required upfront planning prior to the survey administration in order to implement the technique or required following up with respondents, which was not feasible. Therefore, I conducted what was described as an archival analysis, which involved examining information about respondents/nonrespondents that are available in an archived database to assess if there are any significant differences that could potentially bias my results.

First, the analysis required coding the missing data set for each item involved in the study through assigning a zero for missing values and a one for items where a response was received. I found that the range of missing values across the items was 6 to 14 , which equates to non-responses representing only $2 \%$ to $4 \%$ of total responses. The second step in this analysis was to run one-way ANOVAs for each study variable using response and non-response as the category of comparison. The ANOVA for turnover intentions at Time lindicated that there was a significant difference between Time 1 only 
respondents and Time 1 and 2 respondents $(F(1,410)=9.29, \mathrm{p}<.01)$. Indeed, I observed that there was a significant mean difference between Time 1 turnover intentions for those who only responded to Time $1(\mathrm{M}=2.66)$ and those who responded to Time 1 and Time $2(M=2.21)$. This analysis suggests that those who did not respond to both surveys had higher turnover intentions, which logically makes sense because those who had high intentions to leave at Time 1 may have actually left between the data collections, or at a minimum, they could have become more disengaged and therefore chose not to fill out the survey a second time. When I examined the other variables involved in my analyses including chronological age, organizational tenure, POS, coworker support, manager support, coworker incivility, manager incivility, perceived violence, age discrimination, general discrimination, urban versus rural, and CSE, there were no other identified significant differences between these two groups. In sum, there generally does not seem to be any major differences between those who responded at Time 2 and those that did not, except on turnover intentions, which is logical because these respondents may have left the profession or moved jobs and we were unable to get in contact with them at Time 2. Therefore, I feel confident that non-response bias will have minimal effect on my regression analyses.

\section{Hypotheses 1 and 2: Time 2 Turnover Intentions Analysis}

I tested Hypothesis 1, that ageism climates have a positive relationship with organizational turnover intentions, and Hypothesis 2, that CSE would moderate the relationship between the ageism climates and turnover intentions, using hierarchical multiple regression analysis. The hierarchical multiple regression analysis involved three 
steps. The control variables (chronological age, organizational tenure, and affective organizational commitment) were entered as a block in the first step. The main effects of CSE and age climate were entered in the second step. The interaction (product) terms involving CSE and the age climate variables were entered in the third step. Prior to running the analysis, I created three interaction variables involving the three ageism climate measures and CSE. In order to reduce multicollinearity, I standardized the ageism climate measures and CSE variables before creating the interaction terms. The regression analysis was run three separate times to investigate the relationships in the under 40 sample, the 40 and older sample, and the combined sample.

Hypotheses 1 and 2: Time 2 turnover intentions (under 40). In the under 40 sample, the third step of the analysis resulted in a significant change in $R^{2}\left(\Delta R^{2}=.09, F(3\right.$, $85)=3.72, p<.05)$, which indicates that the interaction terms account for $9 \%$ of additional variance in turnover intentions beyond the control variables and main effects. The results of this analysis are displayed in Table 11. The regression coefficients for the main effect of younger worker climate $(\beta=.03, n s)$, older worker climate $(\beta=-.23, n s)$, and general age climate $(\beta=.06, n s)$ on turnover intentions were not significant, thus Hypothesis 1 was not supported. However, CSE moderated the relationship between younger worker climate $(\beta=-.52, p<.01)$ and general age climate $(\beta=.43, p<.01)$ and turnover intentions. To examine the nature of these interactions, I plotted the equation one standard deviation above (high) and one standard deviation below the mean (low) to represent the levels of the age climate variables and CSE (see Figures 3 and 4). 
The interaction between younger climate and CSE on turnover intentions was in the opposite direction from what I hypothesized. Based on examining the simple slopes in the figures, organization turnover intentions are lower in a less ageist younger worker climate $(M=2.73)$ compared to a more ageist younger worker climate $(M=3.69)$ in those with lower levels of CSE. However, turnover intentions is lower for those with higher levels of CSE in a more ageist younger worker climate $(M=2.77)$ compared to a less ageist younger worker climate $(M=3.62)$. The results suggest that CSE buffers the adverse effects of a negative younger worker climate and a positive younger worker climate benefits those with lower levels of CSE. Since the direction of the effect was different than I hypothesized, Hypothesis 2 was not supported.

The interaction between general age climate and CSE on turnover intentions also resulted in an effect that was in the opposite direction of the interaction just described. Organization turnover intentions are lower in those with higher levels of CSE in a less ageist general climate $(\mathrm{M}=2.67)$ compared to a more ageist general age climate $(\mathrm{M}=$ 3.72). However, in those with lower levels of CSE, turnover intentions increase in a more ageist general ageism climate $(\mathrm{M}=2.84)$ compared with a less ageist general ageism climate $(\mathrm{M}=3.58)$. This observed interaction supports Hypothesis 2 , which predicted CSE would enhance the effects of a positive age climate on turnover intentions.

Hypotheses 1 and 2: Time 2 turnover intentions (40 and older). In the 40 and older sample, the third step in the regression equation resulted in a significant change in $R^{2}\left(\Delta R^{2}=.03, F(3,208)=2.87, p<.05\right)$, which indicates that the interaction terms account for $3 \%$ of additional variance in turnover intentions beyond the control variables 
and main effects. The results of the regression analyses are summarized in Table 11 .

Older worker climate $(\beta=.30, p<.01)$ and younger worker climate $(\beta=.14, p<.05)$ had significant main effects on turnover intentions, which provides support for Hypothesis 1. In other words, a less ageist age-group specific workplace climate is related to lower organizational turnover intentions. Notably, CSE also had a significant main effect on turnover intentions $(\beta=-.19, p<.01)$, which suggests that higher levels of CSE are also related to lower turnover intentions. Additionally, I found a significant interaction between older worker climate and CSE on turnover intentions $(\beta=-.19, p<.05)$. I plotted the equation to aid in the interpretation of the interaction (see Figure 5). Based on examining the simple slopes, organization turnover intentions are lower for those with lower levels of CSE and when the older worker climate is less ageist $(M=2.90)$ compared to when older worker climate is more ageist $(M=3.96)$. However, although turnover intentions increases in those with higher levels of CSE when comparing a more ageist older worker climate $(\mathrm{M}=3.16)$ with a less ageist older worker climate $(\mathrm{M}=$ 2.91); the magnitude of the positive slope appeared to be less than what was observed for low CSEs. This result does not support Hypothesis 2 because I proposed that those with higher levels of CSE would have significantly lower turnover intentions in a less ageist age climate compared to a more ageist age climate.

Hypotheses 1 and 2: Time 2 turnover intentions (combined sample). In the combined sample, the third step in the analysis did not result in a significant change in $R^{2}$ $\left(\Delta R^{2}=.01, F(1,310)=2.78, n s\right)$, but the second step $\operatorname{did}\left(\Delta R^{2}=.04, F(2,311)=7.31, p<\right.$ .05). This indicates that CSE and general age climate account for an additional $4 \%$ 
turnover intentions variance beyond the control variables. General ageism climate had a significant regression coefficient $(\beta=.12, p<.05)$ with turnover intentions, which supports Hypothesis 1. Therefore, a more ageist general age climate is associated with greater turnover intentions. In addition, CSE had a main effect on turnover intentions $(\beta=$ $-.15, p<.01)$. Table 17 summarizes the results of the regression analysis.

Hypotheses 1 and 2: Time 2 turnover intentions analysis summary. To summarize, I found partial support for Hypothesis 1 in that the ageism climate measures had significant positivve relationships with Time 2 turnover intentions in the 40 and older sample and the combined sample, but these main effects were not observed in the under 40 sample. However, the main effects for the under 40 sample were qualified by the significant interactions between younger and general age climate and CSE on turnover intentions. Moreover, I found a significant interaction between older worker climate and CSE on turnover intentions in the 40 and older sample. Only one of the significant interactions supported the relationship proposed in Hypothesis 2; in fact, some of the results were in a direction opposite of that hypothesized. Thus, Hypothesis 2 was minimally supported.

\section{Hypotheses 1 and 2: Time 1 Turnover Intentions Analysis}

In an attempt to validate the results described above for Time 2 turnover intentions, I conducted a more conservative supplemental analysis with turnover intentions collected at Time 1 as the outcome variable. This analysis is more conservative because there was a temporal separation between the collection of the ageism climate measures and the outcome variable, thus it potentially reduces inflation due to data being 
collected during the same survey administration. To aid in cross-analysis comparisons, I created Table 19 which displays the beta coefficients across the three samples and includes turnover intentions collected at both time points.

In comparing the Time 1 and Time 2 analyses I found two notable similarities. First, in the under 40 sample, the significant regression coefficients for the interaction terms between younger and general age climate and CSE were similar to what I observed in the Time 2 analysis. In addition, the nature of the interactions is similar to the Time 2 analysis, and therefore, will not be described in further detail (see Figures 6 and 8). Second, in the combined sample, there were no significant main effects or interactions involving general age climate which replicated the results from the Time 2 analysis.

In contrast, there was one main difference observed when comparing the Time 1 turnover intentions analysis compared to the Time 2 turnover intentions analysis. In the under 40 sample, I observed the emergence of an additional significant interaction. I found that there was a significant interaction between older worker climate and CSE $(\beta=$ $-.32, \mathrm{p}<.05)$ on Time 1 organizational turnover intentions. The nature of this interaction is similar to the interaction between younger worker climate and CSE in that organization turnover intentions are lower in those with lower levels of CSE when the older worker climate is less ageist $(M=3.31)$ than when older worker climate is more ageist $(M=$ 3.43). However, turnover intentions increases in those with higher levels of CSE when comparing a less ageist older worker climate $(M=2.37)$ with a more ageist older worker climate $(M=3.73)$. A graphed representation of this relationship is displayed in Figure 7. 
Tables 12 and 18 summarize the results of the Time 1 turnover intentions regression analyses.

In summary, when comparing the results across turnover intentions collected at Time 1 versus Time 2, similar patterns emerged for the significant predictors on turnover intentions across the three age climate measures for the under 40 sample. The only difference was the emergence of a significant interaction between older worker climate and CSE on Time 1 turnover intentions. In contrast, the main effects of older and younger worker climates disappeared with Time 1 turnover intentions as the outcome compared to Time 2 turnover intentions in the 40 and older sample. This suggests that common method variance could have inflated the relationship at Time 2 because the climate measures were also collected at Time 2.

Hypothesis 3 and 4: Time 2 Affective Organizational Commitment Analysis

I tested Hypothesis 3, that ageism climates have negative relationships with affective organizational commitment, and Hypothesis 4, that CSE would moderate the relationship between ageism climate and commitment, using hierarchical multiple regression analysis. The hierarchical multiple regression analysis involved three steps. The control variables, chronological age and organizational tenure, were entered as a block in the first step. The main effects, CSE and age climate variables, were entered in the second step. The interaction terms involving CSE and the age climate variables were entered in the third step. The same standardized variables and interaction terms created for the turnover intentions analysis were used in this analysis. Likewise, as in the 
turnover intentions analysis, the regression analysis was run three separate times to investigate the relationships in the under 40 , the 40 and older, and the combined samples. Hypotheses 3 and 4: Time 2 organizational commitment (under 40). In the under 40 sample, the third step in the regression analysis did not result in a significant change in $\mathrm{R}^{2}\left(\Delta \mathrm{R}^{2}=.03, F(3,87)=.99, n s\right)$, suggesting that the interaction terms did not account for significant incremental variance. However, the second step in the regression analysis resulted in a significant change in $\mathrm{R}^{2}\left(\Delta \mathrm{R}^{2}=.20, F(4,90)=5.50, p<.01\right)$, indicating that the ageism climate variables and CSE accounted for an additional $20 \%$ of variance in organizational commitment beyond the control variables. I found that younger worker climate had a significant negative relationship with affective organizational commitment $(\beta=-.30, p<.05)$, thus providing partial support for Hypothesis 3. Therefore, people have greater affective organizational commitment in a less ageist younger worker climate. Although not hypothesized, CSE was also observed to be a significant predictor of affective organizational commitment $(\beta=.28, p<.01)$, which indicates that people with higher levels of CSE have greater affective organizational commitment. However, I did not find any significant interactions with CSE as a moderator. Therefore, Hypothesis 4 was not supported.

Hypotheses 3 and 4: Time 2 organizational commitment (40 and older). In the 40 and older sample, the third step in the regression analysis did not result in a significant change in $\mathrm{R}^{2}\left(\Delta R^{2}=.01, \Delta F(3,210)=1.00, n s\right)$, suggesting that the interaction terms did not account for significant incremental variance. However, the second step in the regression equation resulted in a significant change in $\mathrm{R}^{2}\left(\Delta R^{2}=.14, \Delta F(4,213)=8.40, p\right.$ 
$<.01$ ), indicating that the ageism climate variables and CSE accounted for an additional $14 \%$ of variance in organizational commitment beyond the control variables. Older worker and younger worker climates had significant negative relationships with organizational commitment, respectively $(\beta=-.22, p<.05 ; \beta=-.17, p<.05)$. In other words, less ageist older and younger worker climates are related to greater affective organizational commitment. Therefore, Hypothesis 3 was partially supported. Similar to the under 40 sample, no significant interactions with CSE as the moderator were observed. Therefore, Hypothesis 4 was not supported. The results of the 40 and older analyses are summarized in Table 13.

Hypotheses 3 and 4: Time 2 organizational commitment (combined sample).In the combined sample, the third step in the regression equation did not result in a significant change in $\mathrm{R}^{2}\left(\Delta R^{2}=.00, \Delta F(1,313)=.38, n s\right)$, suggesting that the interaction terms did not account for significant incremental variance. However, the second step in the regression equation resulted in a significant change in $\mathrm{R}^{2}\left(\Delta R^{2}=.09, \Delta F(2,314)=14.93\right.$, $p<.01$ ), indicating that the ageism climate variables and CSE accounted for an addition $9 \%$ of variance in organizational commitment beyond the control variables. General age climate had a significant negative relationship with affective organizational commitment $(\beta=-.27, p<.01)$. This result provides support for Hypothesis 3. I did not find a significant interaction between general age climate and CSE, which means that Hypothesis 4 was not supported. The results of this analysis are summarized in Table 17.

Hypotheses 3 and 4: Time 2 affective organizational commitment analysis summary. In summary, the results suggest that the ageism climate measures have 
significant negative relationships with affective organizational commitment across the different analyses, which provides support for Hypothesis 3. None of the age climate measures had a significant interaction with CSE on affective organizational commitment. Thus, Hypothesis 4 was not supported.

Hypothesis 3 and 4: Time 1 Affective Organizational Commitment Analysis

In an attempt to validate the results observed for affective organizational commitment collected at Time 2, I conducted a more conservative analysis using affective organizational commitment collected at Time 1 as the outcome variable. To aid in cross-analysis comparisons, I created Table 19, which displays the beta coefficients across the three sample variations and includes affective organizational commitment collected at both time points.

In comparing the Time 1 and Time 2 analyses I found two notable similarities. First, in the 40 and older sample, the significant regression coefficients for main effects of younger and older worker climate on Time 1 commitment were similar to what I observed in the Time 2 analysis. Second, in the combined sample, I observed significant negative regression coefficients for general age climate on Time 1 , which replicated the results from the Time 2 analysis.

In contrast, there were two main differences observed when comparing the Time 1 and Time 2 organization commitment analyses; both differences involve the under 40 sample. First, the observed main effect of younger worker climate on Time 2 commitment disappeared in the Time 1 analysis. Second, I observed the emergence of two significant interactions. There was a significant interaction between younger worker 
climate and $\operatorname{CSE}(\beta=.43, \mathrm{p}<.05)$ on Time 1 commitment and general age climate and $\operatorname{CSE}(\beta=-.52, \mathrm{p}<.01)$ on Time 1 commitment. To examine the nature of these interaction relationships, I created Figures 9 and 10. In Figure 9, I found that commitment increases in those with lower levels of CSE in a less ageist younger worker climate $(\mathrm{M}=$ 3.64) than in a more ageist younger worker climate $(M=2.54)$. However, organizational commitment decreases in those with higher levels of CSE when comparing a more ageist younger worker climate $(M=3.41)$ with a less ageist younger worker climate $(M=3.20)$, which was different from what I hypothesized. In Figure 10, I observed that organization commitment increases in those with higher levels of CSE when the general ageism climate is less ageist $(M=3.90)$ than when general ageism climate is rated as more ageist $(M=2.72)$. However, organizational commitment decreases in those with lower levels of CSE when comparing lower general age climate $(\mathrm{M}=3.46)$ with higher general age climate $(M=2.73)$, which is similar to what I hypothesized.

In summary, the results were very similar comparing the Time 1 and Time 2 affective commitment analysis in the combined sample and the 40 and older sample. At both time points, the ageism climate measures had significant positive relationships with affective organizational commitment in the combined sample and the 40 and older sample, which supports Hypothesis 3. In contrast, in the under 40 sample, the results differed between the time points. Specifically, in the Time 1 analysis, two significant interactions emerged, one involving younger worker climate and $\operatorname{CSE}(\beta=.43, p<.05)$ and the other involving general age climate and $\operatorname{CSE}(\beta=-.52, p<.01)$. However, since 
Ageism Climate 125

the general age climate by CSE interaction was the only significant interaction that supported Hypothesis 4, this suggests only partial support for Hypothesis 4.

Hypothesis 5 and 6: Time 2 Work Engagement Analysis

I tested Hypothesis 5, that ageism climates have negative relationships with work engagement, and Hypothesis 6, that CSE would moderate the relationship between ageism climate and engagement, using hierarchical regression. The regression analysis involved three steps. The control variables, chronological age and organizational tenure, were entered as a block in the first step. The main effects, CSE and age climate variables, were entered in the second step. The interaction terms involving CSE and the age climate variables were entered in the third step. I used the same standardized variables and interaction terms created for previous analyses. Likewise, as done in the previous analyses, the regression analysis was run three separate times to investigate the relationships in the under 40 sample, the 40 and older sample, and the entire sample.

Hypothesis 5 and 6: Time 2 work engagement (under 40). In the under 40 sample, no step of the regression analysis resulted in a significant change in $R^{2}$ (Step 1: $\Delta R^{2}=.04$, $F(2,93)=1.80, n s ;$ Step 2: $\Delta R^{2}=.08, F(4,89)=1.94, n s ;$ Step 3: $\Delta R^{2}=.05, F(3,86)=$ $1.60, n s)$, which indicates that it is not appropriate for me to investigate any individual relationships. Results of this analysis are displayed in Table 15. Therefore, Hypotheses 5 and 6 were not supported in the under 40 sample.

Hypothesis 5 and 6: Time 2 work engagement (40 and older). In the 40 and older sample, the third step of the regression analysis did not result in a change in $R^{2}\left(\Delta R^{2}=.00\right.$, $\Delta F(3,211)=.20, n s)$, indicating that the interaction terms did not account for significant 
incremental variance in work engagement. However, the second step in the regression equation resulted in a significant change in $R^{2}\left(\Delta R^{2}=.15, \Delta F(4,214)=9.84, p<.01\right)$, which suggests that the main effects accounted for an additional $15 \%$ of variance in work engagement beyond the control variables. Specifically, older worker climate has a significant negative relationship with work engagement $(\beta=-.18, p<.05)$, which provides partial support for Hypothesis 5. CSE also had a significant positive relationship with engagement $(\beta=.31, p<.01)$. In other words, a less ageist older worker climate is related to increased work engagement. No significant interactions were observed which means that Hypothesis 6 is not supported. The results of the regression analysis are summarized in Table 15.

Hypothesis 5 and 6: Time 2 work engagement (combined sample). In the combined sample, the third step in the analysis did not result in a significant change in $R^{2}$ $\left(\Delta R^{2}=.00, \Delta F(1,313)=1.52, n s\right)$, indicating that the interaction terms did not account for incremental variance in work engagement. However, the second step of the regression analysis resulted in a significant change in $R^{2}\left(\Delta R^{2}=.12, \Delta F(2,314)=21.22, p<.01\right)$, which suggests that the general age climate and CSE account for an additional 12\% of variance in work engagement beyond the control variables. Specifically, general ageism climate had a significant negative relationship with work engagement $(\beta=-.13, p<.05)$, thus supporting Hypothesis 5. In other words, a positive general age climate is related to increased work engagement. Hypothesis 6 was not supported because I observed no significant interaction. The results for this analysis are displayed in Table 17. 
Hypothesis 5 and 6: Time 2 work engagement analysis summary. In summary, there were no significant interactions observed in this analysis suggesting that Hypothesis 6 was not supported. However, I did find partial support for Hypothesis 5 across the three separate analyses. Older worker climate was observed to have a significant relationship with work engagement in the 40 and older sample, and general age climate had a significant relationship with work engagement in the combined sample. To validate these results, I ran a follow up analysis with work engagement collected at Time 1 as the outcome variable.

\section{Hypothesis 5 and 6: Time 1 Work Engagement Analysis}

Similar to the previous regression analyses, I conducted a more conservative supplemental analysis entering work engagement collected at Time 1 as the outcome variable. To aid in cross-analysis comparisons, I have created Table 19 which displays the beta coefficients across the three sample variations and includes affective organizational commitment collected at both time points.

When comparing the Time 1 and Time 2 analyses, I found two notable similarities and one main difference. First, in the 40 and older sample, I did not find significant main effects or interactions between the ageism climate measures and work engagement, which replicated the results from the Time 2 analysis. Second, I observed a significant main effect between general age climate and Time 1 engagement, which also replicates the results in the Time 2 analysis. However, there was one main difference between the Time 1 and Time 2 work engagement analyses. In the 40 and older sample, the observed main effect of older worker climate on Time 2 engagement disappeared in the Time 1 analysis. 
In summary, I found similar results comparing the Time 1 analysis with the Time 2 analysis, with the exception of the disappearance of the main effect between older worker climate on Time 1 engagement in the 40 and older sample. This may indicate that common method variance could have inflated the relationship at Time 2 because the climate measures were also collected at Time 2. However, the significant main effect of general ageism climate on engagement was replicated in the combined sample, providing partial support for Hypothesis 5. Moreover, similar to the Time 2 analysis, no significant interactions were observed; thus, there was no support for Hypothesis 6. Overall, the results suggest that general age climate is the only ageism climate variable with a consistent relationship with work engagement.

\section{Regression Analyses: Summary}

In short, I observed several significant relationships among the ageism climate measures and the outcome variables across data collection points, which provided partial support for my hypotheses. In addition, I observed many differential relationships between different ageism climate measures and the outcomes across the different samples. Specifically, in the under 40 sample, I observed several interactions between the different ageism climate measures and CSE on turnover intentions and organizational commitment. Furthermore, in the 40 and older sample, I observed several main effects of both younger and older climate on turnover intentions and commitment. Finally, in the combined sample, I observed main effects between general age climate and commitment and work engagement. Indeed, general age climate had the only consistent relationship with work engagement. Overall, the results from the regression analyses provide support 
for ageism climate's effects on important workplace outcomes, and that many of these effects depend on the age group examined, which provides additional evidence for the importance of measuring multiple dimensions of ageism climate. A summary of these results is displayed in Table 19.

\section{Post Hoc and Supplemental Analyses}

Several post hoc and supplemental analyses were run to provide additional insight and to complement the analyses that I described above. These analyses include conducting a post hoc power analysis, a missing data analysis, investigating whether my results could have been by chance, examining how ageism climate is perceived across generations, and determining whether the ageism climate measures could be aggregated to the hospital level of analysis.

Post Hoc Power Analysis

A post hoc power analysis was conducted to evaluate the level of power for each of my regression analyses. Power estimates were obtained using the statistical program G*Power 3 (Faul, Erdfelder, Lang, \& Buchner, 2007). The program is able to account for interaction terms, and therefore, all of the reported power analysis includes all of the predictors investigated for each regression analysis. I examined the power associated with my observed total $\mathrm{R}^{2}$ for each sample variation (e.g., under 40, 40 and older, and combined samples) across the three outcomes. I observed that the power for all of these analyses was above .86 . Therefore, the post hoc power analysis suggests that I had acceptable levels of power to detect the observed changes in $\mathrm{R}^{2}$ across all of my regression analyses. A summary of this analysis is displayed in Table 20. 


\section{Missing Data Analysis}

Systematic missing data could potentially bias research results (Howell, 2008). Therefore, I investigated whether the missing data in my data set had a systematic pattern of missingness. Rubin (1976) defined a taxonomy of missingness that has become the standard for any discussion of this topic. This taxonomy depends on the reasons why data are missing. If the fact that data are missing does not depend upon any values, for any of the variables, then data are said to be missing completely at random (MCAR). If the probability of missing data on a variable is not a function of its own value after controlling for other variables in the design, then the data are missing at random (MAR). Missing data that does not meet the MCAR or MAR classifications are classified as missing not at random (MNAR) and this means some model lies behind the missing data which would result in biased parameter estimates.

The first step I took to explore missingness was to determine how much missing data existed in my data set. I investigated respondent compliance across the study items and variables. Compliance was calculated by taking the total number of complete responses for an item or variable and dividing by the total potential responses and multiplying this value by 100 in order to transform it into a percent. I found that missing data only made up between $2-4 \%$ of all item responses and the frequency of missing data at the variable level and the range of missing values was between $2-6 \%$. Therefore, the amount of missing data in my data set was relatively small.

Furthermore, missing data were examined as a function of each predictor and outcome. Specifically, I flagged all missing data points for each variable by dummy 
coding the missing data points as 0 and items with responses as 1 . Then, I conducted a one-way ANOVA for each of the dummy-coded variables examining whether a pattern of differences emerged between participants with and without missing data across study variables. No significant differences were found on demographic and study-specific variables (i.e., gender, age, occupational tenure, urban versus rural work location, paper versus online survey completion). In addition, no significant differences between missing and non-missing data were observed among variables that would have been included in the same regression analysis with one exception. I found that the ageism climates for those missing data for Time 1 engagement were significantly lower than those without missing data.

In sum, the results generally indicate no systematic patterns of missingness in my data, and therefore, I would consider the missing values either missing completely at random (MCAR) or, at a minimum, missing at random (MAR). In either case, using listwise or casewise deletion would result in unbiased parameter estimates (Howell, 2008). The disadvantage of listwise deletion is the loss of statistical power, but the post hoc power analysis described above suggested that my analyses did not suffer from insufficient power.

\section{Results by chance analysis}

Two potential methods are used to examine whether observed results could be due to chance. The simple way is to multiply the number of tests by the alpha level to get the expected number of false rejections of the null hypothesis. The second way is to calculate the probability of rejecting at least 1 true null hypothesis. Both methods assume that the 
null hypotheses are true and they assume the tests are independent of one another. In reality, neither of these assumptions is true, which makes any results cautionary. For example, these analyses have two different interpretations with regard to my observed significant results being greater than by chance. Specifically, the total expected false rejections for all of my analyses were 4.2 and I observed 20 significant relationships, therefore the number of observed significant relationships is much greater than what would be expected by chance. However, the probability of rejecting one true null hypothesis for all of my analyses was $99 \%$, which suggests a high likelihood that at least one of my significant results may have been due to chance. In sum, this analysis raises the concern that some of my observed significant relationships could potentially have occurred by chance and future research could address this concern through replicating my results.

\section{Ageism Climates as a Function of Generation}

In the above analyses, I split the sample at age 40 based on legal definitions of who is protected under the Age Discrimination and Employment Act of 1967. However, there are several ways that the participants could be categorized according to their age including identifying people by generation and categorizing people according to the age group they feel they are compared to others in the workplace.

Research examining generation differences in the workplace has been gaining in popularity, which is exemplified by a recent article by Twenge, Campbell, Hoffman, and Lance (2010) where the researchers examined differences in work values across four generations. Using a cross sequential research design, which allowed the researchers to 
isolate generational differences from age differences, the researchers found significant differences across the generations on leisure values, work centrality, extrinsic values, altruistic values, and social values.

Based on these findings, I thought it would be useful to explore whether people's perceptions of ageism climates differs by generation. Although this is limited to a crosssectional dataset, which makes it impossible to separate age differences from generation differences, it could still provide initial evidence that differences exist. Therefore, I used the generation names and categories from Twenge et al. (2010) to code my dataset and these categories include Silent $(1925-1945)=83-63$, Baby Boomers $(1946-1964)=62-$ 44, Generation X $(1965-1981)=43-27$, and Generation Me $(1982-1999)=26$ and under. I ran a one-way ANOVA to examine whether there were significant differences across the generations on the three ageism climate measures. I found that only significant differences exist across the generations on the older worker ageism climate measure $(F(3$, $330)=9.64, p<.01)$. Generation $\mathrm{Me}(\mathrm{M}=16.63)$ and Generation $\mathrm{X}(\mathrm{M}=15.57)$ perceive the older worker climate more positively than the Baby Boomer $(\mathrm{M}=13.79)$ and Silent $(M=13.07)$ generations. In sum, the results suggest that the Generations $X$ and Me seemed to perceive that there was a more favorable climate for older nurses compared to the Baby Boomer and Silent generations (i.e., the grass is greener for others).

In addition to examining differences across generations, I investigated whether people's workplace age group identification (i.e., relative age) could affect people's perceptions of ageism climates. Relative age is a measure that captures respondents 
answers to a question about whether they feel older, the same, or younger than most other people in their workplace (Cleveland \& Shore, 1992). Cleveland and Shore (1992) observed that perceived relative age was negatively related to perceived organizational support and manager-rated frequency of career counseling. Furthermore, they also found that perceived relative age accounted for incremental variance in perceived organizational support and manager-rated frequency of career counseling over and above chronological age. Therefore, relative age could account for differences in people's perceptions of ageism climates.

I ran a one-way ANOVA to examine whether there were significant differences across the relative age identifications on the three ageism climate measures. Similar to the generations analysis, I found that only significant differences exist across the relative age designations on the older worker ageism climate measure $(F(2,326)=5.08, p<.01)$. Specifically, those who consider themselves younger than their coworkers rate older worker ageism climate higher $(\mathrm{M}=3.85)$ than those who consider themselves neither younger nor older $(M=3.61)$ and those who consider themselves older $(M=3.46)$. In sum, the results suggest that those who consider themselves as younger than their coworkers perceived a more favorable climate for older nurses compared to those who consider themselves as neither younger nor older and those who consider themselves older, which is a similar result to the generations analysis.

Post Hoc 55 and Older and 40 to 54 Analyses

No consensus exists regarding what age designates a person as being an "older worker" in workplace aging research, but a significant number of researchers have 
designated 55 and older as the old category on their surveys (Finkelstein \& Farrell, 2007). Since I used the legal definition of older as defined by ADEA, I investigated whether my results would change if I was to categorize those who are 55 and older as the "old" group in my regression analysis.

Differences were observed with regard to the results of the regression analyses designating the 55 and older participants as the old group compared to the analyses that designated 40 and older as the old group. The main difference is that younger worker ageism climate was not significantly related to turnover intentions and affective commitment when examining 55 and older as the old group. This result mirrors the findings from the under 40 group in my original analyses in that the ageism climate associated with one's age group is the only climate that affects people's turnover intentions and commitment.

This result also brings out the question as to whether ageism climates affect those who are between the ages of 40 and 55. In other words, the group that is between 40 and 55 may not identify with being older or younger, and therefore, the effects of ageism climate on this group may be completely different from those who are under 40 and those who are 55 and older. In fact, when I ran the analysis investigating people aged 40-54, I observed some interesting results across the outcome variables. Older worker ageism climate was the only significant ageism climate related to turnover intentions and engagement whereas younger worker ageism climate was the only ageism climate with a marginally significant relationship with affective commitment. These differential results across the outcomes may be attributed to the fact that the group between 40 and 54 may 
identify with being middle-aged or mid-career, a designation that is not generally examined in workplace age research.

\section{Hospital-Level Aggregation of Ageism Climates}

In this section, I describe the supplemental analysis examining whether the ageism climates could be aggregated to the hospital level of analysis. The investigation involved several steps. The first step in this analysis was to build a nested data set through obtaining the hospital affiliation for each nurse participant. I was able to successfully retrieve this information from ONA and match it with my dataset. ONA was able to extract the hospital affiliation data from their membership database. After the matching process, I ended up with a sample of 340 nurses representing 28 hospitals. However, in order to examine within-group agreement, at least two participants are required to represent a hospital. Therefore, I removed 10 hospitals from my analysis because only one nurse participated, which left me with a sample of 330 nurses representing 18 hospitals.

Now that I had a nested data set, I was able to take several steps to examine whether the ageism climates could be appropriately examined at the hospital-level of analysis, and ultimately, whether age diversity at the hospital-level of analysis affects individual outcomes. My first step was to determine whether there was enough agreement between nurses within the same hospital to appropriately aggregate to the higher level of analysis. In other words, does a collective perception of ageism climate exist within a hospital? Evidence for agreement is generally established by calculating within group 
agreement (i.e., $\mathrm{R}_{\mathrm{wg}(\mathrm{j})}$ ) and intra-class correlations (ICC) statistics. The tabulated results from the analyses are displayed in Table 21.

I decided to calculate within-group agreement using the $\mathrm{R}_{\mathrm{wg}(\mathrm{j})}$ statistic (James, Demarre, \& Wolf, 1993). The $\mathrm{R}_{\mathrm{wg}(\mathrm{j})}$ statistic is more appropriate than the $\mathrm{R}_{\mathrm{wg}}$ because participants are providing a response to multiple parallel items for a given construct (James et al., 1993). The mean $\mathrm{R}_{\mathrm{wg}(\mathrm{j})}$ values across the hospitals for older worker, younger worker, and general age climate are $.73, .83$, and .54 , respectively. Generally, an $\mathrm{R}_{\mathrm{wg}(\mathrm{j})}$ value that is greater than .70, would indicate that there is high level of agreement within hospitals. Therefore, the older worker and younger worker climate scales have what is considered to be high level of agreement within hospitals.

However, high levels of within group agreement may be a function of all of the nurses rating the age climate measures similarly regardless of their hospital affiliation. Accounting for this possibility, I decided to calculate intraclass correlations (ICCs) as an additional method to assess the appropriateness of aggregating the age climate measures to a higher level of analysis. To calculate the ICCs for each respective climate measure, I ran an intercepts-only model analysis in SPSS and entered each climate measure as the dependent variable. The value of ICC as an estimate of agreement is that it compares within and between group variations, and therefore, a high ICC value would not only be associated with small within group variance, but also indicates meaningful variation among groups (James, 1982). The ICC values for older worker, younger worker, and general age climate are $.05, .01$, and .00 , respectively. The results of this analysis suggest that there is low inter-rater agreement within hospitals and low variation among hospitals 
with regard to the three age climate measures. Therefore, based on my low ICC values, I concluded that it would be more meaningful to keep the examination of the ageism climate measures at the individual level of analysis, which means the measure reflects a nurse's psychological climate.

In summary, although the within-group analysis showed promising results, the results of the ICC analysis indicated that it is not appropriate to examine the ageism climate measures at the hospital level of analysis. Furthermore, the results also suggest that it would be inappropriate to move forward with utilizing hierarchical linear modeling (HLM) to investigate whether ageism climate has a significant cross-level effect on individual outcomes. Therefore, I did not perform any additional analyses examining the age climate measures at the hospital level of analysis. 


\section{Chapter 8: Discussion}

This dissertation focused on the development of measures of ageism climate. I found evidence of a younger worker ageism climate as well as an older worker ageism climate, and that these ageism climate variables function differently among older and younger workers. I also investigated whether ageism climates and CSE affect workplace intentions, attitudes, and well-being in a field sample of registered nurses. Specifically, I found ageism climates affect turnover intentions, affective organizational commitment, and work engagement. Finally, I found that CSE moderated some of the relationships between the ageism climate measures and the outcomes.

In the subsequent sections, I first discuss the implications from the construction validation process for the ageism climate scales and make recommendations for future directions to develop this measure. Second, I review the relationships among the ageism climate measures, CSE, and the outcome variables. Specifically, I provide theoretical explanations for my significant results as well as potential explanations for why I did not find support for other expected relationships. Then, I discuss the theoretical and practical implications. I conclude with a discussion of the study's potential limitations and suggestions for future research.

\section{Construct Validation of Ageism Climate}

One main contribution of my dissertation was to develop a workplace ageism climate scale and build evidence for its construct validity through following a comprehensive scale development and validation process. This process included examining the internal structure of the ageism climate measures as well as their 
relationship with other the constructs. In the subsequent sections, I discuss the results of the workplace age climate item analysis, factor structure, and the relationship with variables within workplace age climate's nomological net. I conclude the section with a discussion about the implications of these results on the further development of the workplace age climate measures.

Ageism Climate Item Analysis and Factor Structure

Initial analyses investigating the reliability and intercorrelations among the three dimensions were promising. The three measures had Cronbach's alphas above .70, and the three dimensions had significant positive intercorrelations, suggesting that the measures share some conceptual overlap, but are distinct. However, further investigation into the factor structure of the ageism climate was disappointing, at least within the full sample.

Confirmatory factor analysis (CFA) was used to investigate the factor structure of the ageism climate scale, and the initial findings from the CFA suggested that the a priori three-factor structure did not provide an acceptable fit to the data. This result catalyzed an in-depth investigation into the underlying causes of the poorly fitting model. I removed two younger worker climate items because they were originally derived from the older worker stereotypes literature, and therefore, the items did not seem to be applicable in the assessment of younger worker treatment. After removing these items, the updated model fit the data significantly better, but the model still had a RMSEA fit statistic that did not meet the cut-off criteria for acceptable fit. 
The disappointing results from the CFA prompted additional investigation into other potential reasons for why the proposed factor structure did not fit the data well. Ultimately, through measurement equivalence analysis and item-level correlation analysis, I discovered evidence of construct bias in the younger and older worker climate measures. Specifically, I found the meaning of older worker and younger worker climate depends on the age of the person making the ratings. In contrast, item-level correlation analysis for the general ageism climate measure indicated that this measure did not have construct bias, suggesting that the assessment of general ageism climate does not depend on the age of the respondent.

At least three implications can be derived from the analysis of the factor structure. First, although the a priori three-factor model of ageism climate did not fit the data at an acceptable level, the three-factor model did fit the data significantly better than a twofactor or one-factor solution. Moreover, post hoc modifications of the workplace climate construct (i.e., removal of two younger worker climate items and correlating error terms of two items) did significantly improve the fit of the three-factor model, but the RMSEA fit statistic remained above the cut-off criterion for acceptable fit. Potentially, an acceptably-fitting model could be achieved through further item generation and measurement development. This would mean that future ageism climate research could treat ageism climate as a latent variable, reflecting three different dimensions of an organization's age climate, and structural equation modeling could be used to test complex relationships involving the latent ageism climate variable. However, in its 
current form, ageism climate may be more appropriately treated as three separate measures reflecting younger worker, older worker, and general age climates.

Second, my results suggest that age-group specific climate measures have different meanings depending on the age of the respondent. This has important implications for the conceptualization of age climate and its meaning among different age groups. One explanation for measurement non-equivalence is that age climate evaluations are affected by people's age-group identification. People may perceive treatment of those in a similar age group from an in-group perspective whereas evaluations of those considered in a different age group would be an out-group assessment. For instance, a younger worker making an assessment about younger worker climate would be assessing the treatment of workers like herself whereas making an assessment of older worker climate would be making an assessment about the treatment of "other" workers. Therefore, these findings provide support for the relational demography paradigm in that people use demographic characteristics to evaluate their similarity and dissimilarity with others in how they are being treated by the organization, and this assessed level of similarity or dissimilarity affects their work-related attitudes and behaviors (Riordan \& Shore, 1997). Specifically, these similarity/dissimilarity assessments may be best explained using social identity theory (SIT; Tajfel \& Turner, 1979), a common explanatory framework used in relational demography research. SIT is based on the assumption that social (i.e., group) membership is a part of an individual's self-definition, that individuals need to achieve a positive self-image, and that positive identity is derived from favorable comparisons made between one's in-group and relevant out-groups 
(Tajfel \& Turner, 1979). Arguably, nurses’ social memberships may be derived from their identification as a younger or older nurse. Such identification may stem from changes in nurse training and education over time, which could lead to differences in expectations with regard to nursing practices and how nurses should be treated. Identification as a younger nurse could also stem from the fact that younger nurses are more likely to feel overwhelmed and stressed (Symes et al., 2005), which could result in seeking support and comfort from other younger nurses who are going through a similar experience, thus solidifying their identification with younger nurses. Finally, it is well recognized that hierarchical and power structures exist within the nurse culture (Bradbury-Jones, Sambrook, \& Irvine, 2007), which could result in groups that traditionally have less power (i.e., younger nurses) to band together in order to try to gain power in the workplace. Furthermore, the lack of power may also be a function of the graying of the nurse workforce which means that there are fewer young nurses in proportion to other-aged nurses in the workplace. The combination of when a nurse is trained, shared experiences associated with career stage, and a nurse's position in the power hierarchy could lead to a greater identification with one's age group since this identification is strongly associated with these factors. Moreover, such identification could be derived from socialization processes at work (e.g., Bauer, Bodner, Erdogan, Truxillo, \& Tucker, 2007) and the way, for instance, younger workers are treated by older colleagues and vice-versa. Therefore, the treatment of nurses in one's identified social group could be more salient and meaningful because favorable or unfavorable treatment affects one's self-image. Accounting for this self-identification explanation, it is not 
surprising that the age-group specific climate measures were observed to function differently across age groups. This is an important finding which suggests the faceted nature of diversity climate, which runs counter to current unitary conceptualization used in some diversity research (e.g., McKay, Avery, \& Morris, 2008; Pugh, Dietz, Brief, \& Wiley, 2008).

Third, item-level correlation analysis did not indicate construct bias due to age for the general age climate measure. This finding suggests that people's assessments of an organization's general age climate may be more universal than the age-targeted climate measures. The implication for this finding is that the general climate measure could be used in research focused on evaluating a broader sense of an organization's age climate rather than the specific treatment of certain age groups. However, these age-group specific measures were found to be distinct, and therefore, should be used to capture a more complete picture of worker treatment across the lifespan. Moreover, in the subsequent section I discuss how convergent and discriminant validity analyses further suggest that age-group measures act as important predictors of key outcomes.

\section{Convergent and Discriminant Validity}

Convergent and discriminant validity were examined as an additional step of the ageism climate construct validation process. Two particularly insightful findings emerged from this analysis.

First, I found that younger worker climate rated by younger workers, and older worker climate rated by older workers, were generally related to support, incivility, and experienced discrimination. In other words, age-specific worker climates had significant 
negative relationships with two of the workplace support variables (i.e., organizational, supervisor), and they had significant positive relationships with incivility (manager and coworker) and discrimination (age and general). Moreover, the positive relationship among ageism climate, incivility, and discrimination suggests that people may attribute interpersonal conflict and discriminatory behavior to their age, and therefore, to a negative age climate. Overall, because perceptions of ageism climate were related to both positive and negative interpersonal workplace interactions and experienced discrimination, this suggests that people's age climate perceptions may be derived from the social and interpersonal workplace context.

Second, when I examined younger workers rating older worker climate and older workers rating younger worker climate, an interesting pattern emerged. This was not unexpected in light of the measurement equivalence analysis results. For example, nurses under 40 with low coworker support and who experienced age discrimination rated the older worker climate as being less ageist. Thus, nurses under 40 may see older and younger worker climates as mutually exclusive where favorable treatment of older nurses leaves younger nurses exposed to unfavorable treatment.

In contrast, a very different result was found for older nurses rating younger worker climate. For instance, those who rated younger climate as less ageist reported receiving greater POS, manager support, and decreased incivility with their manager. In other words, older nurses may view older and younger age climate as complementary such that positive treatment of younger and older workers reflects an overall positive 
Ageism Climate 146

work environment. Overall, these results further illustrate that age-group specific climate may mean different things to people in different age groups.

\section{Summary of Reliability and Validity Analyses}

In short, although the results from the convergent and discriminant validity analysis were generally promising, the results of the factor analyses lead me to conclude that additional measurement development is needed in order to fully capture the ageism climate domain. I have identified several recommendations to further develop and improve the ageism climate measures.

First, the item reduction process left the younger worker climate measure with only two items to capture the entire younger worker climate domain. Therefore, a more extensive item generation process is needed in order to increase the number of items and confidence that the items in the measure are capturing the entire conceptual domain. Since research examining younger worker treatment is limited, one potential way to generate items for the younger climate measure would be to collect critical incidents from younger workers through focus groups, interviews, and surveys. This would identify relevant content to assess a climate associated with the treatment of younger workers. In addition, recent reviews that have identified positive and negative stereotypes of younger workers (e.g., Posthuma \& Campion, 2009) could provide item content.

Second, although some additional item generation has already begun, further item generation is needed to develop more items for the older worker and general age climate measures. This process should include exploration into the age bias and diversity climate literatures. For example, fairness of organizational decisions (Mor Barak, Cherin, \& 
Berkman, 1998) may broaden the content domain captured by the ageism climate measures. For instance, an item reflecting decision fairness might be, "Organizational decisions made about people are sometimes affected by a person's age." Additional items could also be generated through further examination of the literature, critical incidents, and collaboration with age bias and diversity climate subject matter experts.

A third enhancement would be to create parallel positively-worded scales so there would be measures that would reflect positive age and negative age climate. The current scale only captures negative workplace climate, but not positive climate, which may be two very different things. That is, the negatively worded items may mean something different than positively worded items; positive age climate may not simply be the opposite of negative age climate, but could be capturing different things related to age climate.

\section{Ageism Climate and the Outcomes}

Investigating criterion-related validity was an additional step in my process of validating the ageism climate measures. Specifically, I tested my hypotheses through examination of ageism climate's effects on turnover intentions, organizational commitment, and work engagement. In the subsequent sections, I will review and discuss the relationships between each age climate measure and the outcomes, providing a theoretical explanation for the significant and nonsignificant findings. Given that I found construct bias in the younger worker and older worker climate measures, I ran each analysis involving these measures by splitting the sample into two samples, those under 40 years old and those 40 years and older. However, since the general ageism climate 
measure was not found to have construct bias, I investigated its relationship with the outcomes in the combined sample, which best reflects the analysis that I originally proposed to run in this dissertation. Therefore, I have organized the discussion of these analyses by briefly reviewing the results involving the combined sample and then discussing the results from the split sample investigations. I have created Table 17, which summarizes the results from the analyses used to test all of the hypotheses to aid in the discussion and interpretation of the results.

\section{General Age Climate in the Combined Sample}

In the combined sample, the general age climate measure had significant main effects on the outcomes, but no significant interaction was observed between general age climate and CSE on the outcomes. General ageism climate's relationship with turnover intentions was the only relationship with the outcome variables that was not significant. Therefore, from this analysis, general ageism climate does not affect people's intentions to stay with an organization.

However, a less ageist general ageism climate resulted in increased emotional attachment to the organization. From a conservation of resources perspective (Hobfoll, 1989), a favorable general ageism climate is a conditional resource that provides a workplace environment that supports equitable treatment of people regardless of their age. In turn, people who experience this favorable age climate would have a greater likelihood of being comfortable at work and be afforded competence-related work experiences, which are argued to increase affective organizational commitment (Meyer \& Allen, 1991). 
Moreover, general ageism climate had the most consistent relationship with work engagement compared to the age-specific climates. Potentially, a favorable general age climate frees personal resources to be allocated to being energized and absorbed in one's work, which may have been otherwise used to cope with a negative age climate. Although the analysis of the overall sample was my original focus, the analyses involving the split samples (under 40; 40 and over) provide a more insightful investigation of ageism climates and their effects on individual outcomes. The subsequent sections discuss these examinations in further detail.

\section{General Age Climate in the Split Samples}

In the split sample analysis, general ageism climate did not have a main effect on turnover intentions, organizational commitment, and work engagement. However, I observed significant interaction relationships between general age climate and CSE on turnover intentions and commitment in the under 40 sample. Specifically, in younger nurses with higher CSE, a positive relationship was observed between general age climate and turnover intentions. In addition, a negative relationship was observed between general age climate and organizational commitment in younger nurses with higher CSE. Therefore, CSE enhances the positive effects of a positive general age climate with regard to turnover intentions and organizational commitment in younger nurses. Researchers have suggested that high CSE individuals seem to positively react to situations that are likely to maintain positive self-relevant cognitions and affect (Kacmar et al., 2009). Arguably, from a trait activation theory perspective (Tett \& Burnett, 2003), a favorable general age climate provides a trait-relevant cue that activates high CSE 
individuals' tendencies to thrive in advantageous circumstances (Judge \& Hurst, 2007), which results in greater workplace success, lower turnover intentions, and greater organizational commitment.

Interestingly, no significant relationships were observed between general ageism climate and the outcomes in the older nurse sample. This finding suggests that general ageism climate does not affect older nurses to the same extent as younger workers with regard to intentions to stay and commitment to the organization. Alternatively, general ageism climate may not be as important to older nurses because they are the dominant age group with regards to numbers and because they hold higher positions of power in the hierarchy (Bradbury-Jones, Sambrook, \& Irvine, 2007). Indeed, Mor Barak, Cherin, and Berkman (1998) observed that the group that had the greatest representation and power positions in the organization (Caucasian men) perceived the organizational diversity climate as more fair and inclusive in comparison to Caucasian women and ethnic minority men and women. Therefore, being in a powerful group could affect climate perceptions. Moreover, these differential relationships provide further evidence for the importance of measuring multiple dimensions of ageism climate in order to gather additional information about the effects of age-related treatment in the workplace.

\section{Younger Worker Climate and the Outcomes}

In general, I found that younger worker ageism climate affects turnover intentions and affective organizational commitment. However, the relationship between younger worker climate and turnover intentions depended on the age group being examined. Specifically, I found a significant positive relationship between younger worker climate 
and turnover intentions in the younger nurses, but not in the older nurses. In other words, a less ageist younger worker climate may be a positive situational resource that positively affects younger nurses' workplace experiences through providing a less toxic work environment, thus increasing younger nurses' desire to stay at the organization. Furthermore, I found that a less ageist younger worker climate positively affects people's emotional attraction to the organization across the two age group samples. Arguably, this favorable climate results in increased comfort and competence-related work experiences, which are proposed to increase affective organizational commitment (Meyer \& Allen, 1991). Hicks-Clarke and Iles (2000) also observed that positive climates for diversity were positively related to organizational commitment. Overall, the observed main effects echo the meta-analytic findings of Carr, Schmidt, Ford, and DeShon (2003) where positive climates were observed to be negatively related to turnover intentions and positively related to commitment, but this is the first time that these relationships have been established with an age climate construct.

Additionally, I observed that CSE moderated the relationship between younger worker climate and turnover intentions and commitment, but only in the under 40 sample. Specifically, CSE buffered the adverse effects of an ageist younger worker climate because a positive relationship was observed between younger worker climate and turnover intentions in younger nurses with higher levels of CSE. Harris, Harvey, and Kacmar (2009) found a similar buffering effect of CSE on the negative effects of social stressors with regard to turnover intentions. Conceptually, those with higher levels of CSE have a positive outlook and self-regard (Judge, Locke, \& Durham, 1997), which 
serve as coping resources to mitigate the negative effects of a less favorable organizational context (Harris et al., 2009). Arguably, an ageist younger worker climate elicits a weak situation (Mischel, 1977) because their organization's age-related policies are lacking or are not explicit enough to enforce compliance. The weak situation allows those with high levels of CSE to freely express their propensity to persist in the face of challenges (Erez \& Judge, 2001) through allocating their coping resources to overcome the negative effects of a biased climate against younger nurses. Potentially, coping with the negative climate would involve focusing on the positive attributes of the organization. This may enhance positive feelings and attachment to the organization, thus increasing affective commitment and decreasing their intentions to leave.

Finally, younger worker ageism climate did not have a significant effect on work engagement across age-group samples. This result was unexpected because there is empirical evidence for the positive effect of job resources, such as team climate, on work engagement (Xanthopoulou, Bakker, Demerouti, \& Schaufeli, 2009). Perhaps nurses remain highly engaged in their work despite an ageist younger worker climate, because they are highly committed to their role of helping people, and they recognize that being disengaged in their work may put their patients' health in jeopardy. Alternatively, since the items were negatively worded, respondents may not have viewed ageism climate as a job resource, but rather as a contextual obstacle, and organizational obstacles may not reside on the same conceptual continuum as a job resources.

Overall, these results support the effect that younger worker climate has on important workplace outcomes. Some of the relationships depended on the age group 
being examined, which has implications for relational demography research and stresses the importance of treating age climate as a multi-faceted construct. Both of these theoretical implications will be discussed in further detail later in this chapter.

\section{Older Worker Climate and the Outcomes}

In general, older worker climate had significant effects on turnover intentions, organizational commitment, and work engagement. However, these effects differed depending on the age group being analyzed. For example, older workers are more likely to stay when the older worker climate is less ageist, but this relationship was not observed in younger workers. Perhaps those who are 40 and older view a less ageist older worker climate as a positive job resource that results in positive workplace experiences, which increases their intentions to stay. In fact, both older and younger worker climates affect older nurses' intentions to stay and affective commitment, which implies these two climates are viewed as complementary and reflect a generally positive organization climate that is appealing to older nurses. In contrast, those who are under 40 may view a positive older worker climate as competing with younger workers receiving job resources, and therefore, older worker climate is not seen as a positive resource for younger workers. Indeed, in the under 40 sample, even though the beta coefficients were not significant for older worker climate, they were in the opposite direction with the outcomes, which provides some evidence for the competing climates explanation.

Similar to the younger worker climate findings, the relationship between older worker climate and turnover intentions was moderated by CSE. However, the interaction relationship that occurred in both age group samples (under 40 and 40 and older) was 
different from the interaction observed for younger worker climate where the interaction only occurred in the under 40 sample. For those with high levels of CSE, the nature of the older worker climate and CSE interaction was similar to what I observed in the younger worker climate analysis in that CSE buffered the adverse effects of a negative older worker climate on turnover intentions. As proposed above, an ageist older worker climate activates those with high levels of CSE to allocate their self-regulatory personal resources to overcome the negative effects of a biased climate against older workers. In contrast, in those who are under 40, a less ageist older worker climate resulted in an increase in turnover intentions for those who have higher levels of CSE.

Overall, these results support the effect that older worker climate has on important workplace outcomes. Some of the relationships depended on the age group being examined. The different interaction relationship observed for older worker climate between the age groups has implications for similarity attraction theory (Byrne, 1971), and also provides additional evidence for the competing climates explanation described above. These theoretical implications will be discussed later in this chapter.

\section{Summary of Hypothesis Testing}

In short, several interesting findings emerged from my hypothesis testing. First, general ageism climate was found to be related to people's organizational commitment and work engagement in the combined sample. Second, younger and older worker climates are related to people's turnover intentions and organizational commitment across the split samples. Third, younger worker and older worker climate are related to turnover intentions and organizational commitment in nurses who are 40 and older, but this pattern 
was generally not observed in nurses under 40. Fourth, in nurses under 40, CSE buffers the negative effects of a negative younger worker and older worker climate on turnover intentions and commitment, but CSE only buffers the effects of a negative older worker climate on turnover intentions in those 40 and older. Fifth, in nurses under 40, CSE enhances the positive effects of a favorable general age climate on turnover intentions and commitment. Finally, the combination of conservation of resource theory (Hobfoll, 1989) and trait activation theory (Tett \& Burnett, 2003) provide reasonable explanations for the observed relationships.

\section{Theoretical Implications}

The results of my dissertation have several theoretical implications. First, I developed the idea of ageism climate, conceptualized as younger worker climate, older worker climate, and general age climate. This contributes to the age bias and diversity climate literatures as being the first psychological climate construct that strictly focuses on people's perceptions of age-related treatment in the workplace. Moreover, I also developed three measures to assess the dimensions of ageism climate, providing a multifaceted way to evaluate an organization's age-related treatment of their employees. However, the development of this measure is still in its preliminary stages, and further development and validation of the measure is needed. In fact, I identified several potential enhancements that could be made to the measure, both by focusing on generating additional items rooted in the age bias and diversity climate literatures and by including subject matter experts in the item generation and validation process. Additionally, creating a positively-focused measure of age-supportive climate could 
complement the current more negatively-focused ageism climate measures. This dissertation was the initial examination into ageism climates, but more work is needed. However, the results show promise for the effect of ageism climates on important workplace outcomes.

Second, I found that ageism climates affect important work outcomes. My theoretical explanation for these results was rooted in conservation of resources (Hobfoll, 1989) and trait activation theories. Therefore, this dissertation has implications for the theoretical integration of these theories. However, an additional explanation for these results could be due to age stereotypes being internalized throughout people's lifespan which develop into negative self-stereotypes once people reach older age (Levy, 2003). Therefore, negative age stereotypes may become self-fulfilling and result in decreased performance because they become negative self-stereotypes. An ageist workplace climate allows negative age stereotypes to persist, which could decrease people's performance if they have internalized negative associations with their age.

Third, I observed that age-group specific climate measures (i.e., younger and older worker climate) are unique from general age climate, provide incremental prediction over general age climate, and have differential relationships with workplace outcomes compared to general age climate. This result contributes to the ongoing debate surrounding the conceptual distinction between molar and specific climate constructs, and specifically contributes to the diversity climate literature by providing evidence for the need to include age-group specific climates when researching the effects of age in the workplace. Moreover, it significantly challenges the appropriateness of treating diversity 
climate as a general concept that encompasses several characteristics where individuals may differ, which is currently a popular way of conceptualizing diversity climate in the literature (McKay et al, 2008; Pugh et al., 2008). In other words, people may identify with certain characteristics more than others (i.e., age versus gender versus ethnicity), making that characteristic more personally relevant; thus, negative workplace experiences associated with that personally salient characteristic could have a greater effect on the person's perceptions of diversity climate and the reaction to workplace experiences attributed to that characteristic. Additionally, attribute-specific diversity climates, such as ageism climates, may have different effects on individual and organization outcomes than other diversity climates associated with other personal characteristics. Therefore, this result challenges the way current diversity climate researchers broadly conceptualize diversity attributes as a single construct (e.g., McKay et al., 2008; Pugh et al., 2008).

Fourth, I introduced a younger worker climate measure to the literature, which is the first time to my knowledge that a climate measure has assessed people's perceptions of the treatment of younger workers. Very little research examines the treatment of younger workers and how people's perceptions of the treatment of younger workers affect work attitudes, work withdrawal, and well being. Therefore, the younger worker climate measure advances the literature by providing some initial evidence of how the perceived treatment of younger workers affects younger workers in the workplace.

Fifth, when I examined younger workers rating older worker climate and older workers rating younger worker climate, a pattern of relationships emerged that has implications for the relational demography literature (Tsui \& O’Reilly, 1989). 
Specifically, I found support that younger workers view older and younger worker climates as mutually exclusive environments where favorable treatment of older workers results in less favorable workplace experiences for the younger worker, including receiving less support from coworkers and having more experiences of discrimination. In other words, younger nurses appear to view older nurses as dissimilar to them, and favorable treatment of older nurses is potentially attributed to perceived negative effects on their workplace experiences. Therefore, this result supports the similarity-attraction paradigm (Byrne, 1971) because greater perceived levels of dissimilarity are argued to have negative effects on work experiences (Shore et al., 2003).

In contrast, I observed that older nurses view older and younger age climates as being complementary because older nurses who rated younger and older worker climate as positive also reported positive perceptions of support and less experiences of incivility. From a similarity-attraction perspective (Byrne, 1971), older nurses may broadly evaluate similarity from the perspective that they are all nurses (i.e., the same professional identity), and therefore, the favorable treatment of young and old nurses is beneficial to their workplace experience. In short, these results suggest that similarity-dissimilarity evaluations may change as a function of age, which has not been previously discussed in the workplace relational demography literature.

Sixth, this dissertation took an interactionalist approach (Tett \& Burnett, 2003) to examining how people's reactions to their work environment are affected by both the person and the organizational context, which contributes to the literature by providing a comprehensive approach to studying the impact of ageism climates. CSE moderated 
several relationships between ageism climates and the outcomes, and interestingly, the nature of these interaction relationships depended on the ageism climate measure examined. Specifically, CSE buffered the adverse effects of a negative age-group specific climate (i.e., younger or older worker climate), whereas CSE enhanced the positive effects of a positive general age climate. The difference in the relationships could stem from the different ageism climates eliciting different CSE-relevant cues. For instance, negative age-group climates signal a weak, but challenging situation that cues those with high levels of CSE to allocate personal resources to cope with the negative situation (a potential threat to resources) to fulfill their tendency to persist in the face of a challenge (Erez \& Judge, 2001). In contrast, a general age climate provides a different situational cue that indicates an advantageous environment, which activates high CSE individuals' propensity to thrive in favorable situations (Judge \& Hurst, 2007).

Finally, although not the primary focus of this dissertation, this study expanded the investigation of the nomological network for CSE, which is emerging as an important personality variable in organizational research. For example, CSE was found to be significantly related to work engagement, which is the first time to my knowledge that this relationship has been established. In addition, I found that a significant relationship between CSE and turnover intentions and organizational commitment depended on the age group being examined. For example, CSE was only a significant predictor of turnover intentions in the 40 and older sample. However, CSE was only a significant predictor of affective organizational commitment in the under 40 sample. These relationships indicate that CSE has differential validity with certain workplace outcomes 
Ageism Climate 160

depending on a person's age, which is the first time that these differential age effects have been identified in the literature.

\section{Practical Implications}

Several practical implications can be derived from this dissertation. Currently, the nursing workforce is projected to face dramatic shortages, (Buerhaus, Donelan, Ulrich, Norman, \& Dittus, 2006), and therefore, the ability to retain nurses has broad societal implications with regard to the healthcare system's ability to administer quality health care through maintaining proper nurse staffing. The findings from this dissertation could potentially alleviate some concerns about shortages in the nurse workforce, if healthcare organizations, and nurse executives specifically, are willing to undertake improving their age climates. I found that younger worker ageism climate perceptions affect younger nurses' intentions to stay and affective commitment. Younger nurses have higher rates of turnover intentions and actual turnover compared to older nurses (Aiken et al., 2001), and therefore, improving an organization's younger worker ageism climate could lead to increased retention of younger nurses. Additionally, I observed that both younger and older ageism climates affect older nurses' intentions to stay and affective commitment. Improving an organization's ageism climates (i.e., older, younger, and general) could be a potential way to retain older nurses, thus addressing nursing shortage concerns with regard to older nurses retiring.

Three strategies that nurse executives could implement to improve the ageism climate in their organizations include developing a mentoring program, ensuring that all staff have access to career development, and creating and enforcing strong policies to 
prevent "hazing" and negative behaviors toward younger nurses. Indeed, mentoring programs that match younger and older nurses have been successfully implemented to reduce experienced nurses "eating their young" through their negative treatment of young nurses (Green \& Puetzer, 2002). Mentoring programs could also be a way to address accommodating potential physical limitations of older nurses as the nursing workforce ages. Additionally, research has found that older workers seek less career development when they face negative age stereotypes in the workplace (Maurer, Barbeite, Weiss, \& Lippstreu , 2008), which means that if ageist stereotypes are removed from the workplace, older workers may engage in more career development activities increasing their likelihood of avoiding becoming obsolete. Finally, horizontal violence against younger nurses has been identified as a major problem in the nursing profession (Stanley, Martin, Michel, Welton, \& Nemeth, 2007) and nurse executives need to implement and strongly enforce a non-bullying policy to reduce the incidence of workplace bullying (Salin, 2003).

Furthermore, ageism climates could be added as additional factors assessed in obtaining Magnet accreditation, which would be another nurse-specific practical implication. Magnet status is an accreditation achieved by a hospital that meets over 65 stringent quantitative and qualitative standards developed by the American Nurses Credentialing Center (ANCC) associated with creating an environment that achieves excellence in nursing management, philosophy, and nursing practice (Stone, MooneyKane, Larson, Pastor, Zwanziger , \& Dick, 2007). In fact, hospitals achieving Magnet 
status have an increased level of retention in comparison to non-Magnet hospitals (Stone et al., 2007).

The results of my dissertation could also broadly affect organizational policy, training, organizational socialization, career development participation, recruitment, and age discrimination litigation. First, from an organizational policy perspective, the results support the idea that creating positive ageism climates positively influences turnover intentions, organizational commitment, and work engagement. Therefore, it is important for human resource professionals to assess whether their organization has a positive or negative ageism climate. Specifically, the three ageism climate measures can be used to evaluate people's perceptions of the organization's age-related treatment of its employees in order to diagnose ageism concerns. General age climate could be used to diagnose broader issues of an organization's age-related treatment of workers whereas the agegroup specific measures could provide detailed information about what age-groups are having issues in the workplace. These measures allow organizations to take a more targeted strategy for their age-supportive policy development and implementation strategy to have the greatest impact on employee retention, commitment, and engagement. Improving the retention of older workers would help organizations retain the knowledge, experience, and expertise that could enhance an organization's competitiveness. Moreover, retaining and engaging younger workers through agesupportive policies increases the likelihood of cultivating employees who could be the future leaders of the organization. 
Second, building positive ageism climates may require organizations to implement interventions such as age diversity training. In fact, strategies like managerial training that combat age stereotypes, age norming, and ageist attitudes have been identified as a way to increase retention of older workers (Hedge et al., 2006; Rocco et al., 2003). Although diversity training has been criticized for resulting in little observed learning (Rynes \& Rosen, 1995), some researchers have identified and integrated the best practices from the diversity training and education literatures which could improve the effectiveness of diversity training as an intervention (King, Dawson, Kravitz, \& Gulick, in press; King, Gulick, \& Avery, in press). To emphasize the importance of the age supportive climate to the organization, the training intervention could be integrated into the new employee orientation ensuring that age-related practices, policies, and procedures are emphasized immediately upon organizational entry. In addition, the age-supportive intervention should be emphasized throughout an organization's management and leadership development process in order to instill in the future leaders how important uniform implementation of age-supportive policies are to the organization's employee retention strategy.

Third, the results from this dissertation have implications for organizational socialization processes. Bauer et al. (2007) found that social acceptance mediated the effects of an organization's socialization tactics on socialization outcomes including job satisfaction, organizational commitment, job performance, intentions to remain, and turnover. Arguably, a positive workplace climate would reflect a workplace with greater social acceptance, which would result in positive effects on the above important 
socialization outcomes. Moreover, an organization that can build strong ageism climates would have an easier time propagating this age-supportive treatment throughout their organization because it could be passed from insiders to newcomers through naturally occurring socialization processes. In fact, mentoring programs, an organizational socialization tactic, are being designed and implemented in hospitals to address the concerns surrounding experienced nurses "eating their young" through their negative treatment of young nurses (Green \& Puetzer, 2002).

Fourth, developing an age-supportive workplace climate could increase employees' participation in career development and training activities. Maurer, Barbeite, Weiss, and Lippstreu (2008) found that negative stereotypes adversely affect people's career development self-efficacy and their likelihood to participate in career development activities. Therefore, organizations that address workplace age bias by implementing agesensitive policies and practices could be rewarded through having a better trained workforce because workers will feel supported to seek training and development at all career stages.

Fifth, strong age-supportive policies and climate may build an organization's reputation for equitable treatment of workers across the career span, thus increasing the organization's attractiveness and effectiveness in recruiting talented workers of all ages. As the workforce ages and becomes more diverse, the ability to appeal to a broader age range of applicants through a positive age-supportive reputation could increase the likelihood of attracting higher quality applicants, making the organization more competitive (Doverspike, Taylor, Shultz, \& McKay, 2000). Doverspike and colleagues 
discuss the importance of being able to attract older workers to organizations and outline multiple strategies that organizations can use to successfully recruit more mature workers including creating accommodating and flexible workplaces, which could be included as a part of an age-supportive policy.

Finally, given that the number of age discrimination claims being filed is increasing, age discrimination litigation is an important issue in organizations (McCann $\&$ Giles, 2002). A positive age-supportive climate could reduce the likelihood of facing age discrimination claims, which helps an organization avoid costly litigation and negative perceptions of the organization. The legal focus of an age discrimination case involves a comparison between the treatment of older and younger workers (Maurer \& Rafuse, 2001). An organization with a strong climate of equitable treatment of older and younger workers may have a lower likelihood of losing an age discrimination case or potentially of even having a claim filed. In fact, I observed that a positively rated agegroup specific climate was related to fewer experiences of discrimination.

\section{Potential Limitations and Suggestions for Future Research}

As with all research, this study could be improved or expanded on in several ways in future studies. The following section outlines potential limitations and several additional considerations for future research.

First, I was unable to implement an iterative process of item generation and item trimming because the data were already collected for the original ageism climate measures. Additionally, the original measure was designed to be short because of the extreme length of the existing survey. Specifically, this posed a limitation in that the 
original measure contained 10 items to assess three dimensions of ageism climate. Therefore, item trimming was difficult since any reduction in the measures would result in even fewer items that were supposed to represent the content domain of ageism climate. In fact, during the item trimming process, I had to reduce the younger worker climate to two items, which calls into question how well the younger worker climate measure actually captures the entire domain of younger worker treatment in a workplace context. However, the current study appropriately serves as a preliminary investigation into a multi-stage development of the ageism climate measures. I look forward to additional research to refine and revise the ageism climate measures in order to truly capture the ageism climate domain. For example, a content area that I think needs to be addressed specifically for the younger worker ageism climate measure is the idea of agefocused aggressive behaviors such as hazing and incivility. In the nurse workforce specifically, the existence of a climate of "nurses eating their young" or horizontal violence has been identified as a major problem in the nursing profession (Stanley, Martin, Michel, Welton, \& Nemeth, 2007). However, lateral violence, also referred to as workplace bullying, exists across age groups, professions, and workplaces (Salin, 2003), making the addition of this content area more generalizable. Additionally, incivility, a more subtle aggressive behavior, has been argued to be a form of sex and race discrimination (Cortina, 2008). Arguably, incivility could also be a form of age discriminatory behavior, and age discrimination is associated with the age bias framework that I used to conceptually develop the ageism climates. Therefore, all of the 
ageism climate measures could benefit from the addition of items tapping age-focused aggressive behaviors.

In addition, I have identified perceived fairness of age-related treatment of workers to be another potential content area that could be captured by the general ageism climate measure. In fact, data are being collected in Italy on an updated version of the scale that has two additional general age climate items that attempt to implicitly capture fairness. The additional items included in the data collection are "Organizational decisions made about people are sometimes affected by a person's age," and "Sometimes people's age affects how they are treated in my organization."

Second, the ageism climates focus on the negative treatment of workers with regard to their age. However, some of my explanations for my results incorporate how an age supportive environment may increase people's likelihood of success and commitment due to increased access to resources. However, I do not measure an age-supportive climate directly, but rather assume that an age supportive environment is on the opposite pole of an age climate continuum. Ageism climate and age supportive climate may or may not share the same continuum and could be two completely different constructs. Therefore, future research should develop an age supportive climate measure and investigate whether ageism climate and age supportive climates are different constructs or the opposite poles of one construct.

Second, as noted, these results question the appropriateness of treating diversity climate as a general concept, which is currently a popular way of conceptualizing diversity climate in the literature (McKay, Avery, \& Morris, 2008; Pugh, Dietz, Brief, \& 
Wiley, 2008). However, I was unable to test whether age diversity climate is distinct from or provides incremental prediction over general diversity climate, because a measure of general diversity climate was not included in the dataset. Future research should investigate this possibility by collecting general diversity climate as well as the three ageism climate measures. Arguably, attribute-specific diversity climates, such as ageism climate, may have different effects on individual and organization outcomes than other diversity climates associated with other personal characteristics. Therefore, further examination is needed to determine whether attribute-specific diversity climates are distinct. In other words, ageism climates should be examined with ethnicity-related climates, gender-related climates, and other attribute-specific climates to build evidence for discriminant validity of ageism climates. Furthermore, future research should investigate if these climates have differential relationships with individual and organizational outcomes. For instance, future research should expand the investigation into how the treatment of younger workers affects other individual and organizational outcomes such as job performance, job satisfaction, and psychological health.

Third, different patterns of relationships emerged across age groups between the age-group specific age climate variables and several of the convergent validity variables. For instance, those who were under 40 and rated older worker climate as positive also reported that they received less coworker support and experienced more age discrimination. Future research investigating the role of interpersonal support and conflict in evaluating age climate would be beneficial to further development of the age climate measures. For instance, future research could examine how support or interpersonal 
conflict affect age climate perceptions and whether support or interpersonal conflict may buffer or enhance the effects of ageism climates. Additionally, these types of relationships imply that some sort of self-other evaluation is being made when people respond to the age climate items. However, I did not have the opportunity to follow up with the participants to investigate these relationships further. Potentially, future research could investigate this self-other explanation through interviews in which participants could be asked to explain their responses. In addition, future research should investigate the potential effects of self-other assessments of treatment on an individual's workplace attitudes and behaviors. For instance, the use of age-group identity measures would be beneficial to examine how age-identity affects people's age climate perceptions. Finally, future research should also investigate the potential changes in workplace similaritydissimilarity evaluations across people's work lifespan and how this affects attitudes, motivation, and behavior.

Fourth, it is important to recognize that the potential differences across the ageism climate measures and their relationships with the outcome variables could be due to the fact that the perceptions of nurses who have remained in the profession and the workforce may be completely different than those who left the profession and workforce. In other words, the nurses who have "survived" the vetting process that occurs throughout their professional career could have accepted the norms of the workplace, which could result in having a recalibration and different conceptualization of the meaning of ageism climates. Changes in recalibration and conceptualization are discussed in the organizational change literature as beta and gamma changes (Armenakis, 
Bedeian, \& Pond, 1983). Beta change results from the respondent's subjective recalibration of the measurement scale. Gamma change results from the respondent's reconceptualization of the measured variable. Therefore, beta and gamma changes may occur as a function of a nurse's workplace experiences and survival in the profession which could be considered as being analogous to an organizational change intervention. In this case, beta and gamma would represent how the career process and workplace experiences change how people may evaluate the measurement scale throughout their career and that ageism climate may conceptually change throughout their career. Therefore, future research should implement a longitudinal design to investigate the potential recalibration and reconceptualization processes involving the ageism climate measures that may occur throughout people's careers.

Fifth, this study used a convenience sample of registered nurses, which could limit the generalizability of my findings. Certain industries and organizations, for instance, may have different age-related perspectives, and thus the results may not replicate across organizations and industries. In fact, research examining age-specific job norms (Lawrence, 1988) has found that different age norms exist for different types of jobs, which could impact people's perceptions of the treatment of workers according to their age. Therefore, nurses could have a different perspective about ageism climates than do members of other professions. For example, relative to other professions, a norm of "hazing" may exist in nursing, which could lead to younger nurses not being treated well by their older colleagues. However, the nurse workforce exemplifies the aging workforce trend that is occurring in the U.S. and seems to be an appropriate sample to use in my 
preliminary investigation of age climate. Future research should be conducted on different professions and industries to investigate whether the results in this study can be replicated.

Sixth, the results could suffer from inflation due to common method variance (CMV) because the outcomes and the ageism climate measures are self-report and were collected from the same source at the same time point. However, Spector (2006) argued and provided empirical evidence that showed that the method itself may not be producing systematic variance in observations that inflates correlations to any significant degree. Moreover, CMV and inflation are less of a problem when examining moderator effects as in the present study where differences in levels of CSE produced different slopes (i.e., the relationships between ageism climates and the outcomes were different for older and younger workers). However, to address the inflation concern, I analyzed the relationships between ageism climates (collected at Time 2) and the outcomes collected at Time 1, which served as a supplemental analysis to validate the results from the Time 2 . The supplemental analysis revealed similar results. However, predicting how climate predicts an outcome variable that was collected six months later may be conceptually inappropriate. Therefore, any differences in results between the two time points could be due to potential changes that occurred in the environment that changed people's ratings of the outcome variables. To address CMV, future research should implement a longitudinal design where the collection of the antecedents, interaction variables, and the outcomes are temporally separated, and researchers should attempt to collect some of the variables from multiple sources. 
Seventh, this study essentially used a cross-sectional design because even though there were variables used from the Time 1 data collection (i.e., CSE, tenure, chronological age), the ageism climates and outcomes were collected at Time 2.

Therefore, within person variations or developmental changes that may occur throughout an individual's career were not captured. As people age, their perceptions about agerelated organizational treatment of employees may change. For instance, I found that older workers' commitment was affected by their perceptions of older and younger worker treatment, but younger workers commitment was only affected by younger worker treatment. This difference could be due to changes that occur due to aging, it could be a cohort effect, or it could be due to something else altogether. For instance, the older nurses participating in the study represent those who "survived" versus those who left the profession, which could affect their perceptions of ageism climates. To examine these possibilities, future research investigating the potential changes in ageism climate perceptions over a longer period of time would provide additional insight into whether within person changes in perceptions occur as a person ages and how this affects workplace attitudes.

Eighth, potentially some of my observed findings may be due to chance. My post hoc analysis examining the probability that my results were by chance indicated that there was a high likelihood that at least one of my significant relationships was by chance. Therefore, in order to explore this possibility further, future research could attempt to replicate the results observed in this dissertation. 
Finally, future research will need to account for additional variables that could affect ageism climate perceptions. For instance, the age of the people that the nurses care for could potentially affect their perceptions about age and aging. In other words, a nurse working in a nursing home may have a different perspective on aging compared to a nurse who works in the emergency room because the age of the patient population may be different. Future research should examine the potential influence of the type of patient population cared for as a potential influence of people's ageism climate perceptions. In addition, organizational justice and fairness perceptions should be examined with ageism climates. For instance, people's perceptions of age-policy fairness could be highly related to perceptions of ageism climate and potentially could mediate or moderate the relationship between ageism climates and workplace outcomes. Finally, working in a Magnet-qualified hospital may also have an effect on nurses' ageism climate perceptions. Briefly, Magnet accreditation involves achieving excellence in creating an environment that supports nursing practice and leadership and has been observed to affect nurse satisfaction and turnover intentions (Stone et al., 2007). Therefore, nurses working at a Magnet hospital may have different perspectives about ageism climate than those who do not and this should be investigated in future research.

\section{Conclusion}

In conclusion, this dissertation has direct implications for the nurse workforce. The nurse workforce is facing a nurse shortage of epidemic proportions (Buerhaus, Staiger, \& Auerbach, 2000), and this dissertation provides insight into how organizations can adjust their age-related treatment of nurses in order to increase nurse retention, 
commitment, and engagement. The increased retention of nurses will help to address the impending nurse shortage, and will hopefully increase nurses' ability to provide quality health care because there will be enough nurses to fill staffing demands.

Moreover, this dissertation contributes to the workplace aging literature in several ways. First, I developed the concept of ageism climate for older and younger workers to the literature. Second, I found differential effects for each type of ageism climate measure which provides evidence for how age-related treatment affects people in the workplace. Third, I found that assessments of younger and older worker climate depend on the age of the respondent which has implications on the relational demography paradigm (Tsui \& O’Reilly, 1989). Finally, I provided insight into the complex relationship between personal characteristics and age-related treatment of workers and its effect on people's workplace experiences. CSE buffered the negative effects of negative older and younger worker climates and CSE enhanced the positive effects of a positive general age climate on turnover intentions and organizational commitment. I invite future research that further develops the ageism climate measures and investigates their effects on individual and organizational outcomes. 


\section{Table 1. Summary of Hypotheses}

\begin{tabular}{|c|c|}
\hline Hypothesis 1: & $\begin{array}{l}\text { After controlling for chronological age, tenure, and affective } \\
\text { commitment, ageism climates will be positively related to } \\
\text { organizational turnover intentions. }\end{array}$ \\
\hline Hypothesis 2: & $\begin{array}{l}\text { After controlling for chronological age, tenure, and affective } \\
\text { commitment, CSE will moderate the relationship between ageism } \\
\text { climates and turnover intentions such that the ageism climates- } \\
\text { turnover intentions relationship will be positive and stronger when } \\
\text { people's level of CSE are higher than when CSE levels are lower. }\end{array}$ \\
\hline Hypothesis 3: & $\begin{array}{l}\text { After controlling for chronological age and organizational tenure, } \\
\text { ageism climates will be negatively related to affective organizational } \\
\text { commitment. }\end{array}$ \\
\hline Hypothesis 4: & $\begin{array}{l}\text { After controlling for chronological age and organizational tenure CSE } \\
\text { will moderate the relationship between ageism climates and } \\
\text { organizational commitment such that the ageism climates- } \\
\text { organizational commitment relationship will be negative and stronger } \\
\text { when people's level of CSE are higher than when CSE levels are lower. }\end{array}$ \\
\hline Hypothesis 5: & $\begin{array}{l}\text { After controlling for chronological age, ageism climates will be } \\
\text { negatively related to work engagement. }\end{array}$ \\
\hline Hypothesis 6: & $\begin{array}{l}\text { After controlling for chronological age, CSE will moderate the } \\
\text { relationship between ageism climates and work engagement such that } \\
\text { the ageism climates-work engagement relationship will be negative } \\
\text { and stronger when people's levels of CSE are higher than when they are } \\
\text { lower. }\end{array}$ \\
\hline
\end{tabular}


Table 2. Ageism Climate Scale Items and Their Relationship with Age Stereotypes and Diversity Climate Research

\begin{tabular}{|c|c|c|}
\hline Item & Stereotype Relationship & $\begin{array}{l}\text { Diversity Theme } \\
\text { Relationship }\end{array}$ \\
\hline $\begin{array}{l}\text { 1. In my organization, older nurses } \\
\text { are viewed as less valuable than } \\
\text { younger nurses. }\end{array}$ & $\begin{array}{l}\text { Lower Performance, Resistance to } \\
\text { Change, Lower Ability to Learn, } \\
\text { Shorter Tenure, More Costly }\end{array}$ & $\begin{array}{l}\text { Equitable distribution } \\
\text { of resources }\end{array}$ \\
\hline $\begin{array}{l}\text { 2. My organization views } \\
\text { investments in older workers as } \\
\text { unlikely to yield a return. }\end{array}$ & $\begin{array}{l}\text { Lower Ability to Learn, Shorter } \\
\text { Tenure, More Costly }\end{array}$ & $\begin{array}{l}\text { Equitable distribution } \\
\text { of resources }\end{array}$ \\
\hline $\begin{array}{l}\text { 3. Older nurses are not given as } \\
\text { much access to career development } \\
\text { resources (i.e. training) as compared } \\
\text { to younger nurses. }\end{array}$ & $\begin{array}{l}\text { Lower Ability to Learn, Shorter } \\
\text { Tenure, More Costly }\end{array}$ & $\begin{array}{l}\text { Equitable distribution } \\
\text { of resources }\end{array}$ \\
\hline $\begin{array}{l}\text { 4. In my organization, older nurses } \\
\text { do not get as much support as they } \\
\text { might need. }\end{array}$ & & Support \\
\hline $\begin{array}{l}\text { 5. In my organization, younger } \\
\text { nurses are viewed as less valuable } \\
\text { than older nurses. }\end{array}$ & Less trustworthy, less loyal & $\begin{array}{l}\text { Equitable distribution } \\
\text { of resources }\end{array}$ \\
\hline $\begin{array}{l}\text { 6. My organization views } \\
\text { investments in younger nurses as } \\
\text { unlikely to yield a return. }\end{array}$ & Less trustworthy, less loyal & $\begin{array}{l}\text { Equitable distribution } \\
\text { of resources }\end{array}$ \\
\hline $\begin{array}{l}\text { 7. Younger nurses are not given as } \\
\text { much access to career development } \\
\text { resources (i.e., training) as } \\
\text { compared to older nurses. }\end{array}$ & Less trustworthy, less loyal & $\begin{array}{l}\text { Equitable distribution } \\
\text { of resources }\end{array}$ \\
\hline $\begin{array}{l}\text { 8. In my organization, younger } \\
\text { nurses do not get as much support as } \\
\text { they might need. }\end{array}$ & & Support \\
\hline $\begin{array}{l}\text { 9. Sometimes a person's age affects } \\
\text { how they are viewed in my } \\
\text { organization. }\end{array}$ & $\begin{array}{l}\text { Affective reaction toward a } \\
\text { person due to their age }\end{array}$ & \\
\hline $\begin{array}{l}\text { 10. People of certain ages are often } \\
\text { not well integrated into the } \\
\text { organization. }\end{array}$ & & Inclusion \\
\hline
\end{tabular}




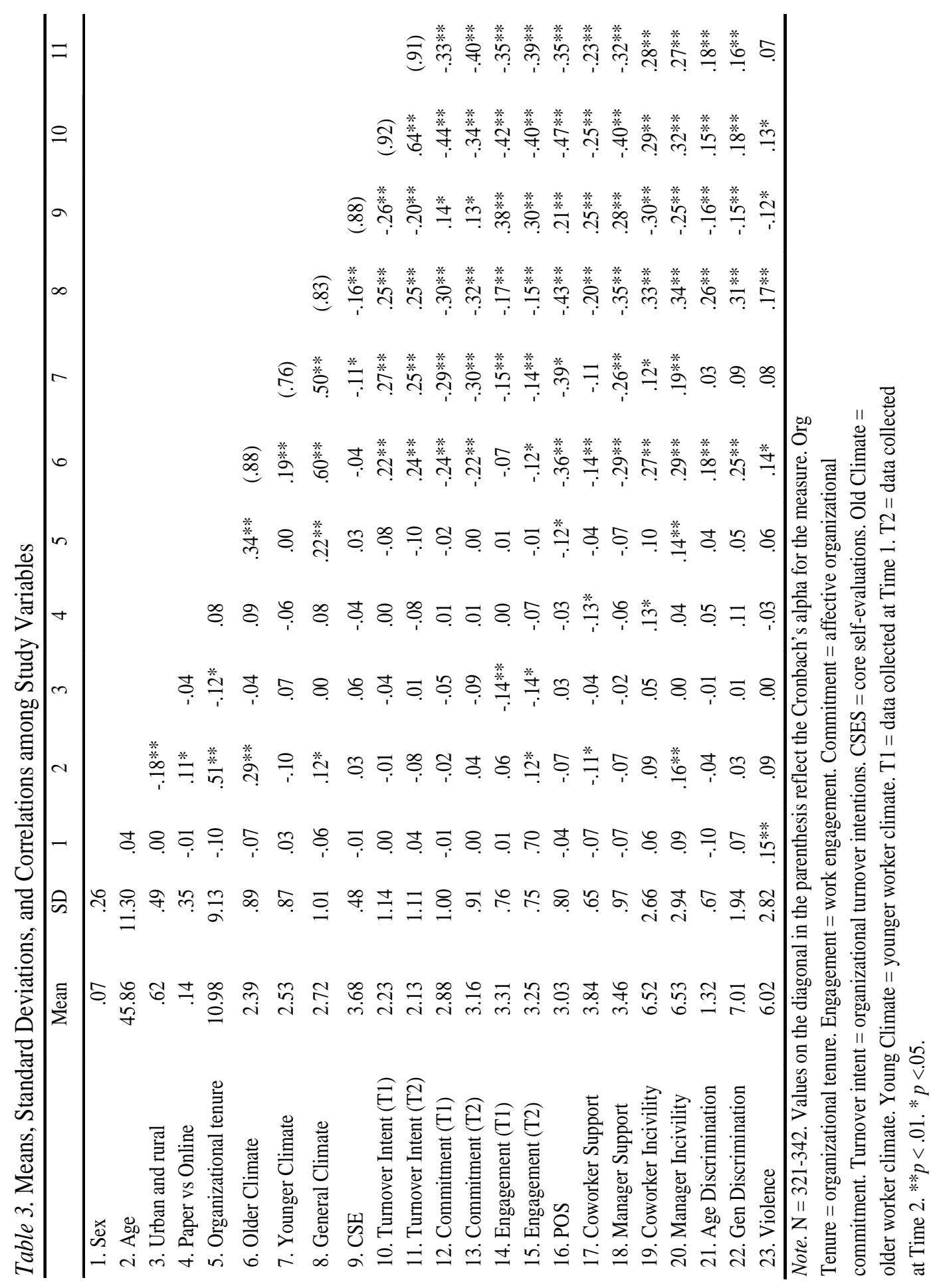


Ageism Climate 178

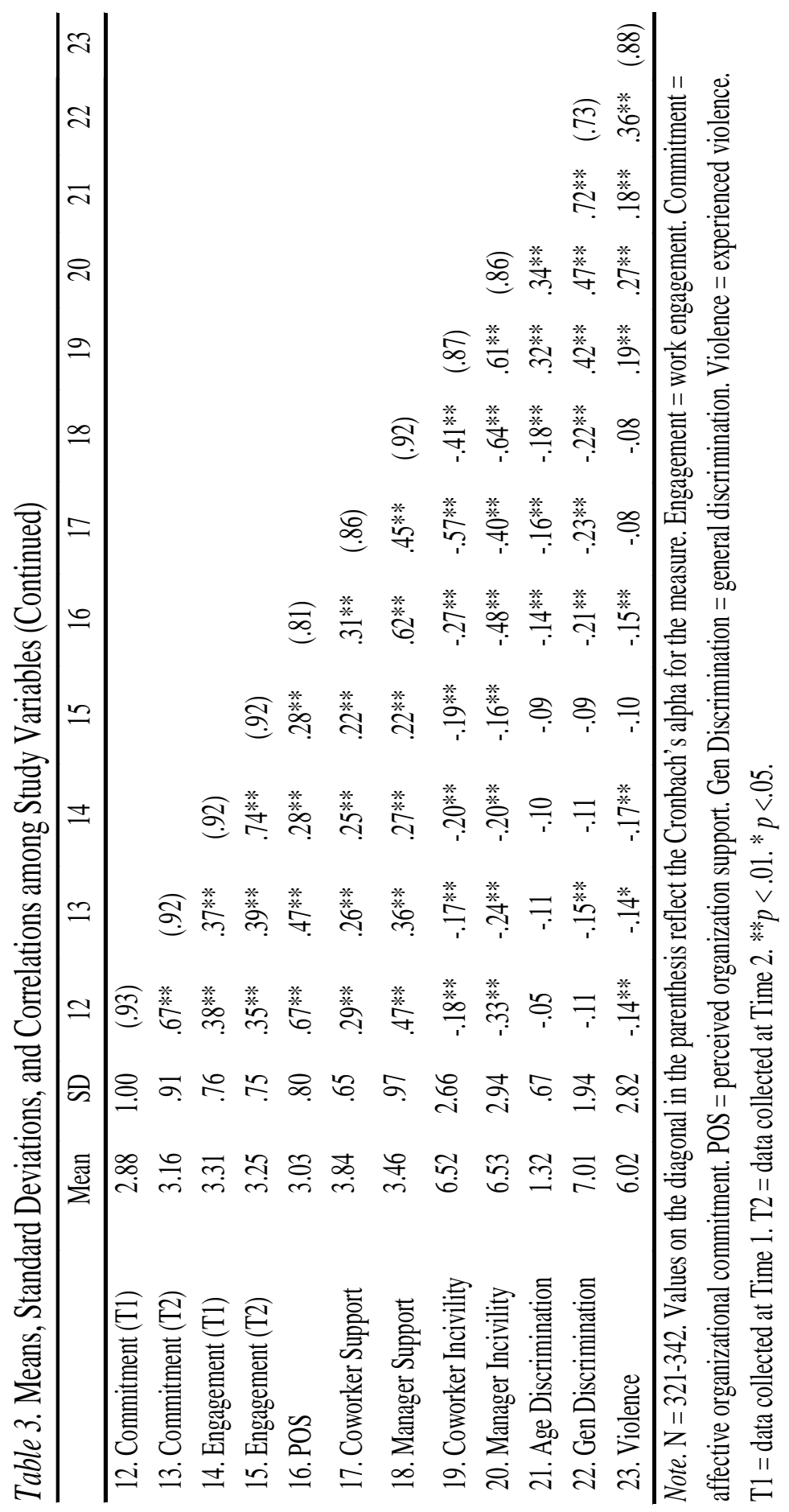


Ageism Climate 179

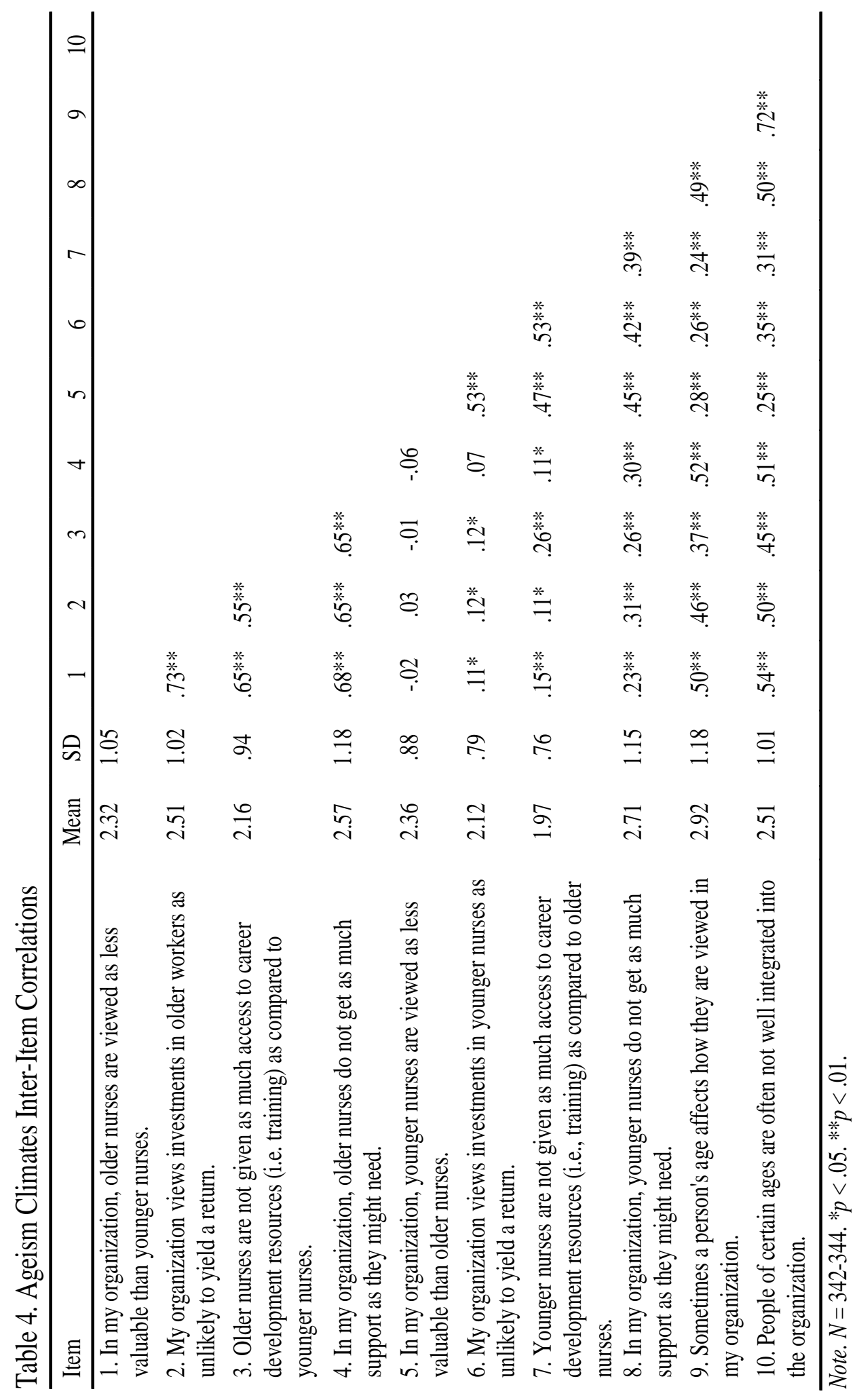




\section{Table 5. Exploratory Factor Analysis for the Ageism Climate Scales}

\begin{tabular}{lcc}
\hline & Factor 1 & Factor 2 \\
\hline $\begin{array}{l}\text { 1. In my organization, older nurses are viewed as } \\
\text { less valuable than younger nurses. }\end{array}$ & $\mathbf{. 8 9}$ & -.10 \\
$\begin{array}{l}\text { 2. My organization views investments in older } \\
\text { workers as unlikely to yield a return. }\end{array}$ & $\mathbf{. 8 4}$ & -.06 \\
$\begin{array}{l}\text { 3. Older nurses are not given as much access to } \\
\text { career development resources (i.e. training) as } \\
\text { compared to younger nurses. }\end{array}$ & $\mathbf{. 7 8}$ & -.04 \\
$\begin{array}{l}\text { 4. In my organization, older nurses do not get as } \\
\text { much support as they might need. }\end{array}$ & $\mathbf{. 8 9}$ & -.11 \\
$\begin{array}{l}\text { 5. In my organization, younger nurses are } \\
\text { viewed as less valuable than older nurses. }\end{array}$ & -.19 & $\mathbf{. 8 5}$ \\
$\begin{array}{l}\text { 6. My organization views investments in } \\
\text { younger nurses as unlikely to yield a return. }\end{array}$ & -.04 & $\mathbf{. 8 0}$ \\
$\begin{array}{l}\text { 7. Younger nurses are not given as much access } \\
\text { to career development resources (i.e., training) } \\
\text { as compared to older nurses. }\end{array}$ & .02 & $\mathbf{. 7 3}$ \\
$\begin{array}{l}\text { 8. In my organization, younger nurses do not get } \\
\text { as much support as they might need. }\end{array}$ & .27 & $\mathbf{. 6 5}$ \\
$\begin{array}{l}\text { 9. Sometimes a person's age affects how they are } \\
\text { viewed in my organization. }\end{array}$ & $\mathbf{. 6 1}$ \\
$\begin{array}{l}\text { 10. People of certain ages are often not well } \\
\text { integrated into the organization. }\end{array}$ & $\mathbf{. 6 4}$ & $\mathbf{. 3 5}$ \\
\hline
\end{tabular}

Note. $N=340$. Oblimin rotation was used. The correlation between the factors is .22 . 
Ageism Climate 181

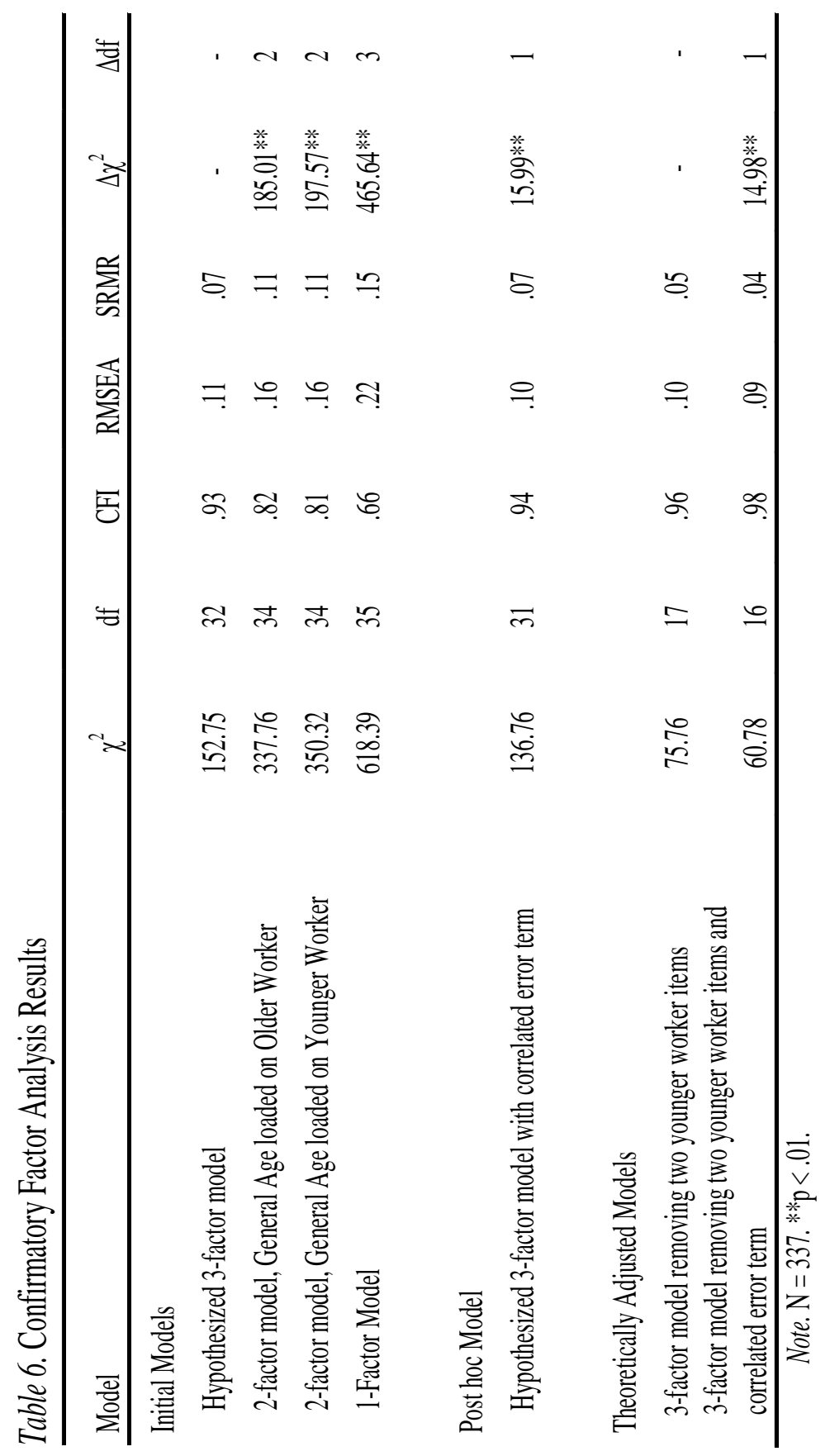




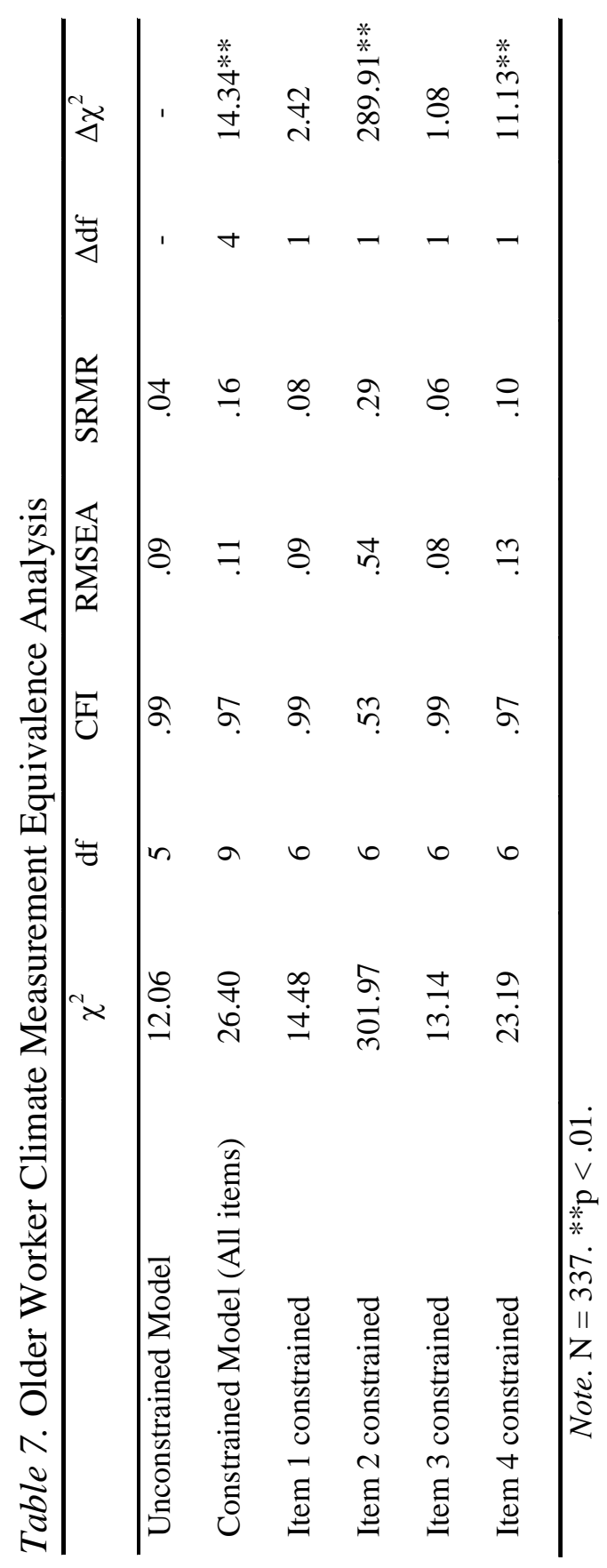




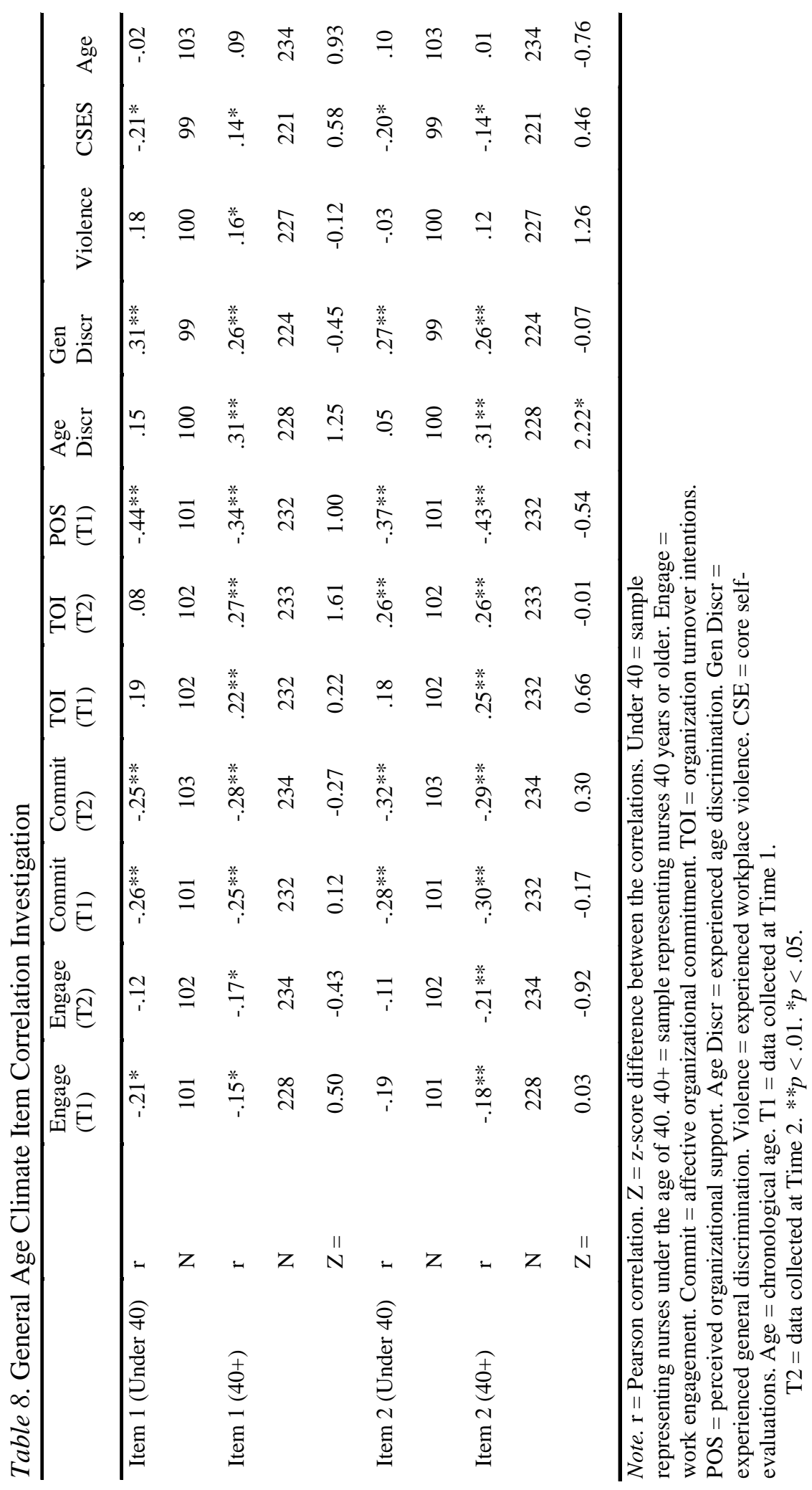




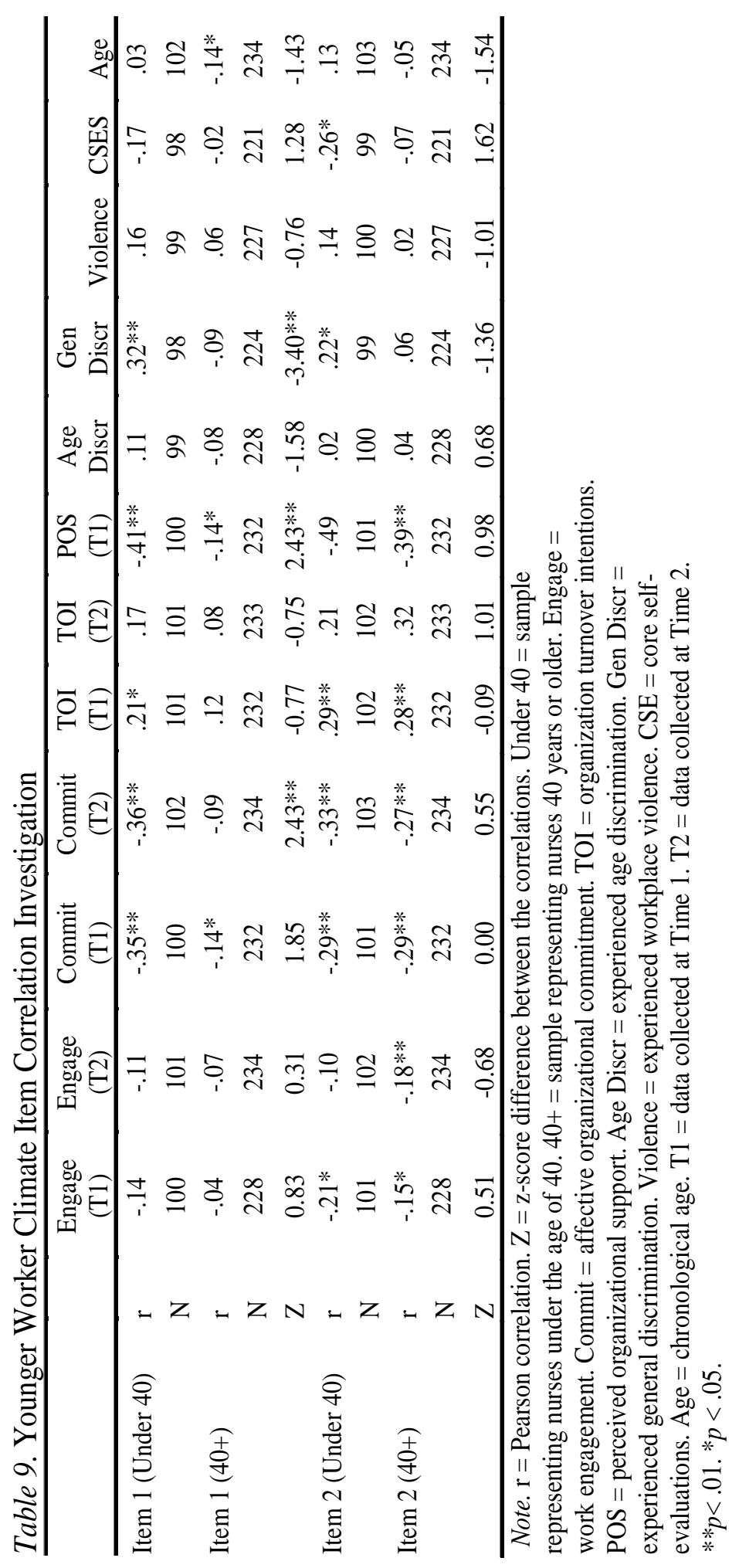


Ageism Climate 185

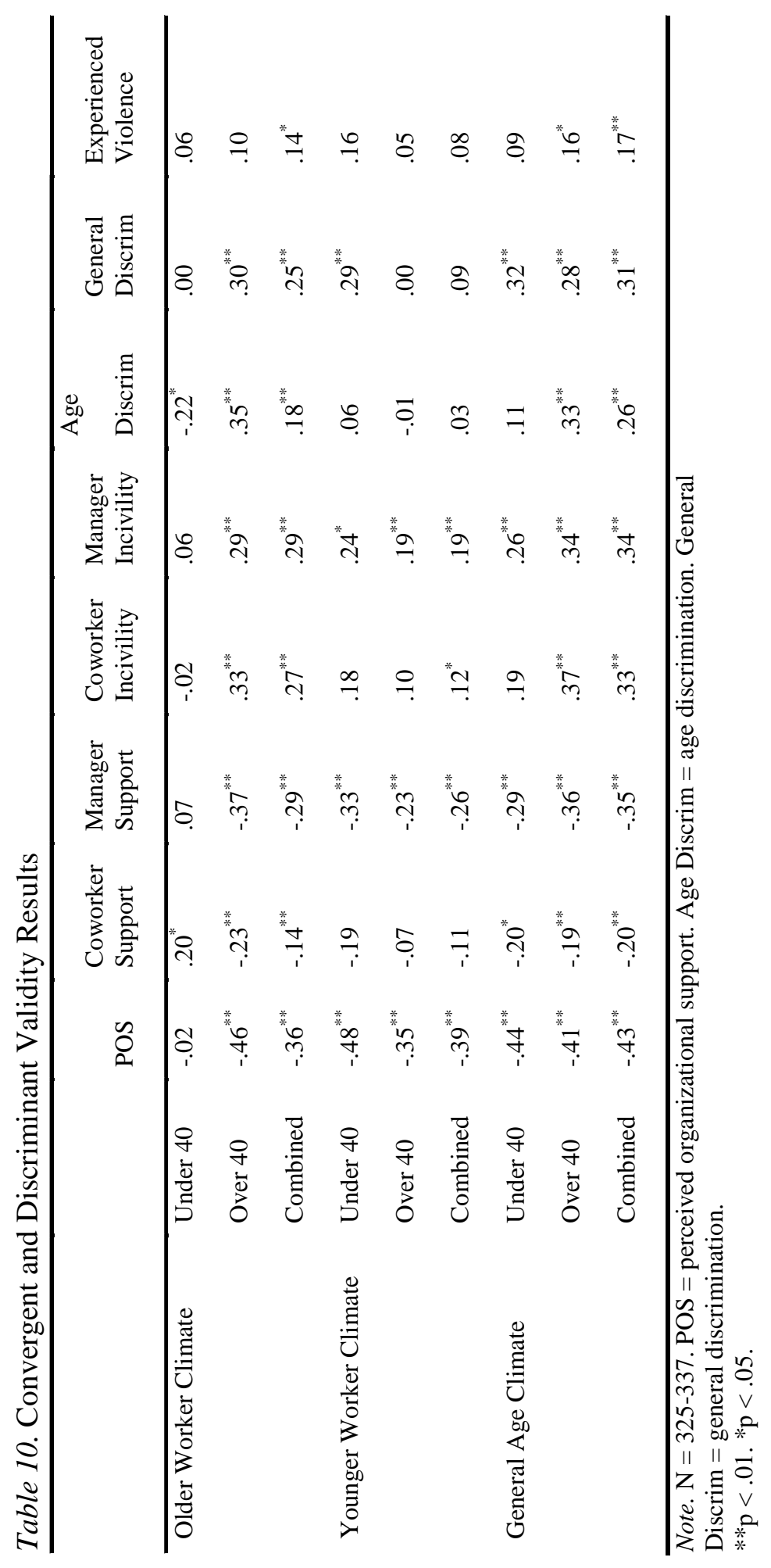


Ageism Climate 186

Table 11. Regression Analysis with Time 2 Organizational Turnover Intentions

\begin{tabular}{|c|c|c|c|c|}
\hline & & $\begin{array}{c}\text { Under } 40 \\
(\mathrm{~N}=95) \\
\beta\end{array}$ & $\begin{array}{c}40+ \\
(\mathrm{N}=218) \\
\beta\end{array}$ & $\mathrm{Z}$ test \\
\hline \multirow[t]{6}{*}{ Step 1} & Age & .07 & -.04 & $3.98 * *$ \\
\hline & Commitment & -.44 & -.37 & -.59 \\
\hline & Tenure & -.14 & -.08 & -1.83 \\
\hline & $\Delta \mathrm{R}^{2}$ & $.21^{* *}$ & $.15^{* *}$ & \\
\hline & $\Delta \mathrm{F}$ & 8.16 & 12.63 & \\
\hline & $\mathrm{df}$ & 3,92 & 3,215 & \\
\hline \multirow[t]{10}{*}{ Step 2} & Age & .07 & -.07 & $4.82 * *$ \\
\hline & Commitment & $-.43 * *$ & $-.25 * *$ & -1.35 \\
\hline & Tenure & -.13 & $-.15^{*}$ & 0.60 \\
\hline & CSE & .03 & $-.22 * *$ & $2.04 *$ \\
\hline & Older Worker Climate & -.11 & $.33 * *$ & $2.45 * *$ \\
\hline & General Age Climate & -.02 & -.06 & -.16 \\
\hline & Younger Worker Climate & .08 & .12 & .24 \\
\hline & $\Delta \mathrm{R}^{2}$ & .01 & $.15^{* *}$ & \\
\hline & $\Delta \mathrm{F}$ & .40 & 11.29 & \\
\hline & df & 4,88 & 4,211 & \\
\hline \multirow[t]{14}{*}{ Step 3} & Age & .04 & -.07 & $3.67 * *$ \\
\hline & Commitment & $-.38 * *$ & $-.24 * *$ & -1.08 \\
\hline & Tenure & -.08 & $-.14 *$ & $1.96^{*}$ \\
\hline & CSE & -.01 & $-.19 * *$ & 1.17 \\
\hline & Older Worker Climate & -.23 & $.30 * *$ & 2.54 \\
\hline & General Age Climate & .06 & -.04 & -.50 \\
\hline & Younger Worker Climate & .03 & $.14^{*}$ & .80 \\
\hline & Younger X CSE & $-.52 * *$ & .08 & $3.82 * *$ \\
\hline & Older X CSE & -.21 & $-.19 *$ & .14 \\
\hline & General X CSE & $.43 * *$ & .03 & $-1.97 *$ \\
\hline & $\Delta \mathrm{R}^{2}$ & $.09 *$ & $.03 *$ & \\
\hline & $\Delta \mathrm{F}$ & 3.72 & 2.87 & \\
\hline & df & 3,85 & 3,208 & \\
\hline & Total $\mathrm{R}^{2}$ & .31 & .33 & \\
\hline
\end{tabular}

Note. $\mathrm{Z}=\mathrm{Z}$-score difference between the correlations. Under $40=$ sample representing nurses under the age of $40.40+=$ sample representing nurses 40 years or older. Commitment $=$ affective organizational commitment. Tenure $=$ organizational tenure. $\mathrm{CSE}=$ core self-evaluations. Younger X CSE = interaction term between younger worker climate and CSE. Older X CSE = interaction term between older worker climate and CSE. General X CSE = general worker climate and CSE. **p $<.01 . * \mathrm{p}<.05$. 
Table 12. Regression Analysis with Time 1 Organizational Turnover Intentions

\begin{tabular}{|c|c|c|c|c|}
\hline & & $\begin{array}{c}\text { Under } 40 \\
\beta \\
(\mathrm{N}=96) \\
\end{array}$ & $\begin{array}{c}40+ \\
\beta \\
(\mathrm{N}=219) \\
\end{array}$ & $\mathrm{Z}$ test \\
\hline \multirow[t]{6}{*}{ Step 1} & Age & .04 & .00 & 0.34 \\
\hline & Aff Commitment & $-.43 * *$ & $-.43 * *$ & -0.03 \\
\hline & Tenure & -.15 & -.12 & -1.00 \\
\hline & $\Delta \mathrm{R}^{2}$ & $.22 * *$ & $.20 * *$ & \\
\hline & $\Delta \mathrm{F}$ & 8.56 & 17.78 & \\
\hline & $\mathrm{df}$ & 3,93 & 3,216 & \\
\hline \multirow[t]{10}{*}{ Step 2} & Age & .03 & -.02 & 0.36 \\
\hline & Commitment & $-.38 * *$ & $-.36 * *$ & -0.22 \\
\hline & Tenure & -.15 & $-.16^{*}$ & -0.79 \\
\hline & CSE & -.04 & $-.27 * *$ & $2.01 *$ \\
\hline & Older Worker Climate & -.02 & .15 & 1.15 \\
\hline & General Age Climate & -.04 & -.01 & 0.20 \\
\hline & Younger Worker Climate & .13 & .09 & -0.12 \\
\hline & $\Delta \mathrm{R}^{2}$ & .01 & $.11 * *$ & \\
\hline & $\Delta \mathrm{F}$ & .33 & 8.18 & \\
\hline & $\mathrm{df}$ & 4,89 & 4,212 & \\
\hline \multirow[t]{14}{*}{ Step 3} & Age & .01 & -.02 & 0.22 \\
\hline & Commitment & $-.33 * *$ & $-.37 * *$ & 0.30 \\
\hline & Tenure & -.12 & $-.15^{*}$ & -0.56 \\
\hline & CSE & -.13 & $-.23 * *$ & 0.64 \\
\hline & Older Worker Climate & -.19 & .12 & $2.17 *$ \\
\hline & General Age Climate & .09 & .00 & -0.60 \\
\hline & Younger Worker Climate & .08 & .12 & 0.47 \\
\hline & Younger X CSE & $-.46^{*}$ & .04 & $2.77 * *$ \\
\hline & Older X CSE & $-.32 *$ & $-.19 *$ & 0.96 \\
\hline & General X CSE & $.44 *$ & .11 & $-1.67 *$ \\
\hline & $\Delta \mathrm{R}^{2}$ & $.09^{* *}$ & .020 & \\
\hline & $\Delta \mathrm{F}$ & 3.89 & 1.90 & \\
\hline & $\mathrm{df}$ & 3,86 & 3,209 & \\
\hline & Total $\mathrm{R}^{2}$ & .32 & .32 & \\
\hline
\end{tabular}

Note. $\mathrm{Z}=\mathrm{z}$-score difference between the correlations. Under $40=$ sample representing nurses under the age of $40.40+=$ sample representing nurses 40 years or older. Commitment $=$ affective organizational commitment. Tenure $=$ organizational tenure. $\mathrm{CSE}=$ core self-evaluations. Younger $\mathrm{X} \mathrm{CSE}=$ interaction term between younger worker climate and CSE. Older X CSE $=$ interaction term between older worker climate and CSE. General X CSE $=$ general worker climate and CSE. ${ }^{*}$ p $<.01 .{ }^{*} p<.05$. 
Table 13. Regression Analysis with Time 2 Affective Organizational Commitment

\begin{tabular}{|c|c|c|c|c|}
\hline & & $\begin{array}{c}\text { Under } 40 \\
B \\
(\mathrm{~N}=96)\end{array}$ & $\begin{array}{c}40+ \\
\beta \\
(\mathrm{N}=219)\end{array}$ & $\mathrm{Z}$ test \\
\hline \multirow[t]{5}{*}{ Step 1} & Age & .05 & .06 & 0.08 \\
\hline & Tenure & .01 & -.04 & 0.24 \\
\hline & $\Delta \mathrm{R}^{2}$ & .00 & .00 & \\
\hline & $\Delta \mathrm{F}$ & .14 & .47 & \\
\hline & $\mathrm{df}$ & 2,94 & 2,217 & \\
\hline \multirow[t]{9}{*}{ Step 2} & Age & .12 & .05 & 0.78 \\
\hline & Tenure & -.06 & .05 & -0.70 \\
\hline & CSE & $.28^{* *}$ & -.00 & $2.77 * *$ \\
\hline & Older Worker Climate & .07 & $-.22 *$ & $-1.99 *$ \\
\hline & General Age Climate & .00 & -.10 & -0.60 \\
\hline & Younger Worker Climate & $-.30 *$ & $-.17 *$ & 0.69 \\
\hline & $\Delta \mathrm{R}^{2}$ & $.20^{* *}$ & $.14^{* *}$ & \\
\hline & $\Delta \mathrm{F}$ & 5.50 & 8.40 & \\
\hline & Df & 4,90 & 4,213 & \\
\hline \multirow[t]{13}{*}{ Step 3} & Age & .12 & .06 & 0.79 \\
\hline & Tenure & -.08 & .05 & -0.89 \\
\hline & CSE & .23 & -.01 & $1.73 *$ \\
\hline & Older Worker Climate & .13 & $-.22 *$ & $-2.14^{*}$ \\
\hline & General Age Climate & -.06 & -.10 & -0.19 \\
\hline & Younger Worker Climate & $-.27 *$ & $-.19 * *$ & 0.32 \\
\hline & Younger X CSE & .30 & .07 & -1.16 \\
\hline & Older X CSE & .06 & .14 & 0.49 \\
\hline & General X CSE & -.32 & -.15 & 0.87 \\
\hline & $\Delta \mathrm{R}^{2}$ & .03 & .01 & \\
\hline & $\Delta \mathrm{F}$ & .99 & 1.00 & \\
\hline & $\mathrm{df}$ & 3,87 & 3,210 & \\
\hline & Total $\mathrm{R}^{2}$ & .23 & .15 & \\
\hline
\end{tabular}

$\overline{\text { Note. } \mathrm{Z}=\mathrm{z} \text {-score difference between the correlations. Under } 40=\text { sample representing nurses under }}$ the age of $40.40+=$ sample representing nurses 40 years or older. Tenure $=$ organizational tenure. $\mathrm{CSE}=$ core self-evaluations. Younger X CSE $=$ interaction term between younger worker climate and CSE. Older X CSE $=$ interaction term between older worker climate and CSE.

General X CSE $=$ general worker climate and CSE. $* * p<.01 . * p<.05$. 
Ageism Climate 189

Table 14. Regression Analyses with Time 1 Affective Organizational Commitment

\begin{tabular}{|c|c|c|c|c|}
\hline & & $\begin{array}{c}\text { Under } 40 \\
\beta \\
(\mathrm{N}=96)\end{array}$ & $\begin{array}{c}40+ \\
\beta \\
(\mathrm{N}=219)\end{array}$ & $\mathrm{Z}$ test \\
\hline \multirow[t]{5}{*}{ Step 1} & Age & -.08 & .10 & -1.26 \\
\hline & Tenure & .16 & -.04 & 1.54 \\
\hline & $\Delta \mathrm{R}^{2}$ & .02 & .01 & \\
\hline & $\Delta \mathrm{F}$ & 1.00 & 1.12 & \\
\hline & df & 2,94 & 2,217 & \\
\hline \multirow[t]{9}{*}{ Step 2} & Age & -.02 & .09 & -0.67 \\
\hline & Tenure & .09 & .05 & 0.67 \\
\hline & CSE & $.27 * *$ & -.02 & $2.88 * *$ \\
\hline & Older Worker Climate & .08 & $-.23 * *$ & $-2.16^{*}$ \\
\hline & General Age Climate & -.04 & -.07 & -0.19 \\
\hline & Younger Worker Climate & -.26 & $-.19 * *$ & 0.26 \\
\hline & $\Delta \mathrm{R}^{2}$ & $.19 * *$ & $.13^{* *}$ & \\
\hline & $\Delta \mathrm{F}$ & 5.29 & 7.95 & \\
\hline & df & 4,90 & 4,213 & \\
\hline \multirow[t]{13}{*}{ Step 3} & Age & -.02 & .09 & -0.70 \\
\hline & Tenure & .06 & .05 & 0.34 \\
\hline & CSE & .11 & .00 & 0.77 \\
\hline & Older Worker Climate & .15 & $-.25 * *$ & $-2.55^{* *}$ \\
\hline & General Age Climate & -.10 & -.05 & 0.37 \\
\hline & Younger Worker Climate & -.25 & $-.19 * *$ & 0.10 \\
\hline & Younger X CSE & $.43^{*}$ & .12 & -1.53 \\
\hline & Older X CSE & -.03 & .00 & 0.22 \\
\hline & General X CSE & $-.52 * *$ & -.04 & $2.42 * *$ \\
\hline & $\Delta \mathrm{R}^{2}$ & $.07 *$ & .01 & \\
\hline & $\Delta \mathrm{F}$ & 2.82 & .89 & \\
\hline & $\mathrm{df}$ & 3,87 & 3,210 & \\
\hline & Total $\mathrm{R}^{2}$ & .28 & .15 & \\
\hline
\end{tabular}

Note. $\mathrm{Z}=\mathrm{z}$-score difference between the correlations. Under $40=$ sample representing nurses under the age of $40.40+=$ sample representing nurses 40 years or older. Tenure $=$ organizational tenure.

$\mathrm{CSE}=$ core self-evaluations. Younger X CSE $=$ interaction term between younger worker climate and CSE. Older X CSE $=$ interaction term between older worker climate and CSE. General X CSE $=$ general worker climate and CSE. **p $<.01 .{ }^{*} \mathrm{p}<.05$. 
Table 15. Regression Analysis with Time 2 Work Engagement

\begin{tabular}{|c|c|c|c|c|}
\hline & & $\begin{array}{c}\text { Under } 40 \\
\beta \\
(\mathrm{N}=95)\end{array}$ & $\begin{array}{c}40+ \\
\beta \\
(\mathrm{N}=220)\end{array}$ & $\mathrm{Z}$ test \\
\hline \multirow[t]{5}{*}{$\overline{\text { Step } 1}$} & Age & .09 & -.02 & 1.01 \\
\hline & Urban versus Rural & -.16 & -.12 & -0.51 \\
\hline & $\Delta \mathrm{R}^{2}$ & .04 & .01 & \\
\hline & $\Delta \mathrm{F}$ & 1.80 & 1.57 & \\
\hline & df & 2,93 & 2,218 & \\
\hline \multirow[t]{9}{*}{ Step 2} & Age & .12 & .01 & 1.12 \\
\hline & Urban versus Rural & -.16 & $-.14^{*}$ & -0.34 \\
\hline & CSE & $.25^{*}$ & $.31 * *$ & -0.39 \\
\hline & Older Worker Climate & -.08 & $-.18^{*}$ & -0.37 \\
\hline & General Age Climate & .00 & -.01 & -0.07 \\
\hline & Younger Worker Climate & -.06 & -.08 & -0.21 \\
\hline & $\Delta \mathrm{R}^{2}$ & .08 & $.15^{* *}$ & \\
\hline & $\Delta \mathrm{F}$ & 1.94 & 9.84 & \\
\hline & $\mathrm{df}$ & 4,89 & 4,214 & \\
\hline \multirow[t]{13}{*}{ Step 3} & Age & .11 & .01 & 0.93 \\
\hline & Urban versus Rural & -.17 & -.13 & -0.51 \\
\hline & CSE & .18 & $.31 * *$ & -0.71 \\
\hline & Older Worker Climate & .02 & $-.18^{*}$ & -1.02 \\
\hline & General Age Climate & -.08 & -.01 & 0.44 \\
\hline & Younger Worker Climate & -.03 & -.08 & -0.44 \\
\hline & Younger X CSE & $.37 *$ & .03 & $-1.77 *$ \\
\hline & Older X CSE & .10 & .02 & -0.51 \\
\hline & General X CSE & $-.44 *$ & -.07 & $1.77^{*}$ \\
\hline & $\Delta \mathrm{R}^{2}$ & .05 & .00 & \\
\hline & $\Delta \mathrm{F}$ & 1.60 & .20 & \\
\hline & df & 3,86 & 3,211 & \\
\hline & Total $\mathrm{R}^{2}$ & .16 & .17 & \\
\hline
\end{tabular}

Note. $\mathrm{Z}=\mathrm{z}$-score difference between the correlations. Under $40=$ sample representing nurses under the age of $40.40+=$ sample representing nurses 40 years or older. Urban versus Rural $=$ categorical variable indicating the population of the city where the nurse practices. CSE $=$ core self-evaluations. Younger X CSE $=$ interaction term between younger worker climate and CSE. Older X CSE = interaction term between older worker climate and CSE. General X CSE $=$ general worker climate and CSE. $* * \mathrm{p}<.01 . * \mathrm{p}<.05$. 
Ageism Climate 191

Table 16. Regression Analysis with Time 1 Work Engagement

\begin{tabular}{|c|c|c|c|c|}
\hline & & $\begin{array}{c}\text { Under } 40 \\
\beta \\
(\mathrm{N}=96)\end{array}$ & $\begin{array}{c}40+ \\
\beta \\
(\mathrm{N}=220)\end{array}$ & $\mathrm{Z}$ test \\
\hline \multirow[t]{5}{*}{ Step 1} & Age & .00 & -.05 & 0.35 \\
\hline & Urban versus Rural & -.15 & $-.15^{*}$ & -0.11 \\
\hline & $\Delta \mathrm{R}^{2}$ & .02 & .02 & \\
\hline & $\Delta \mathrm{F}$ & 1.01 & 2.64 & \\
\hline & df & 2,94 & 2,217 & \\
\hline \multirow[t]{4}{*}{ Step 2} & Age & .02 & -.02 & 0.29 \\
\hline & Urban versus Rural & -.12 & $-.18 * *$ & 0.33 \\
\hline & CSE & $.36^{* *}$ & $.35 * *$ & 0.35 \\
\hline & Older Worker Climate & .10 & -.10 & -1.56 \\
\hline \multirow[t]{18}{*}{ Step 3} & General Age Climate & -.08 & -.04 & 0.27 \\
\hline & Younger Worker Climate & .01 & -.05 & -0.49 \\
\hline & $\Delta \mathrm{R}^{2}$ & $.15^{* *}$ & $.16^{* *}$ & \\
\hline & $\Delta \mathrm{F}$ & 4.19 & 10.39 & \\
\hline & df & 4,90 & 4,213 & \\
\hline & Age & .00 & -.02 & 0.16 \\
\hline & Urban versus Rural & -.15 & $-.19 * *$ & 0.18 \\
\hline & CSE & $.39 * *$ & $.36^{* *}$ & 0.39 \\
\hline & Older Worker Climate & .23 & -.10 & $-2.26 *$ \\
\hline & General Age Climate & -.19 & -.06 & 0.86 \\
\hline & Younger Worker Climate & .04 & -.03 & -0.48 \\
\hline & Younger X CSE & .27 & -.12 & $-2.28 *$ \\
\hline & Older X CSE & .22 & -.13 & $-2.16^{*}$ \\
\hline & General X CSE & -.37 & $.19^{*}$ & $2.69 * *$ \\
\hline & $\Delta \mathrm{R}^{2}$ & .04 & .02 & \\
\hline & $\Delta \mathrm{F}$ & 1.46 & 1.60 & \\
\hline & df & 3,87 & 3,210 & \\
\hline & Total $\mathrm{R}^{2}$ & .21 & .20 & \\
\hline
\end{tabular}

Note. $\mathrm{Z}=\mathrm{z}$-score difference between the correlations. Under $40=$ sample representing nurses under the age of $40.40+=$ sample representing nurses 40 years or older. Urban versus Rural $=$ categorical variable indicating the population of the city where the nurse practices. CSE $=$ core self-evaluations. Younger X CSE $=$ interaction term between younger worker climate and CSE. Older X CSE = interaction term between older worker climate and CSE. General X CSE = general worker climate and CSE. $* * p<.01 . * \mathrm{p}<.05$. 
Table 17. Regression Analysis with General Age Climate and Time 2 Outcomes (entire sample)

\begin{tabular}{|c|c|c|c|c|}
\hline & & $\begin{array}{c}\text { Turnover } \\
\beta\end{array}$ & $\begin{array}{c}\text { Commitment } \\
\beta\end{array}$ & $\begin{array}{c}\text { Engagement } \\
B\end{array}$ \\
\hline \multirow[t]{7}{*}{$\overline{\text { Step } 1}$} & Commitment & $-.39 * *$ & - & - \\
\hline & Age & -.01 & .06 & .11 \\
\hline & Tenure & -.09 & -.04 & - \\
\hline & Urban versus Rural & - & - & $-.12 *$ \\
\hline & $\Delta \mathrm{R}^{2}$ & .17 & .00 & $.03 * *$ \\
\hline & $\Delta \mathrm{F}$ & 20.61 & .43 & 5.26 \\
\hline & $\mathrm{df}$ & 3,313 & 2,316 & 2,316 \\
\hline \multirow[t]{9}{*}{ Step 2} & Commitment & $-0.34 * *$ & - & - \\
\hline & Age & -.01 & .06 & $.12 *$ \\
\hline & Tenure & -.11 & .02 & - \\
\hline & Urban versus Rural & - & - & $-.14 * *$ \\
\hline & CSE & $-.15 * *$ & .09 & $.29 * *$ \\
\hline & General Age Climate & $.12^{*}$ & $-.27 * *$ & $-.13 *$ \\
\hline & $\Delta \mathrm{R}^{2}$ & $.04 * *$ & $.09 * *$ & $.12 * *$ \\
\hline & $\Delta \mathrm{F}$ & 7.31 & 14.93 & 21.12 \\
\hline & $\mathrm{df}$ & 2,311 & 2,314 & 2,314 \\
\hline \multirow[t]{11}{*}{ Step 3} & Commitment & $-.35 * *$ & - & - \\
\hline & Age & -.01 & .06 & $.12 *$ \\
\hline & Tenure & -.11 & .02 & - \\
\hline & Urban versus Rural & - & - & $-.14 *$ \\
\hline & CSE & $-.16 * *$ & .08 & $.28 * *$ \\
\hline & General Age Climate & .11 & $-.28 * *$ & $-.14 *$ \\
\hline & General X CSE & -.09 & -.03 & -.08 \\
\hline & $\Delta \mathrm{R}^{2}$ & .01 & .00 & .00 \\
\hline & $\Delta \mathrm{F}$ & 2.78 & .38 & 1.52 \\
\hline & $\mathrm{df}$ & 1,310 & 1,313 & 1,313 \\
\hline & Total $\mathrm{R}^{2}$ & .21 & .09 & .15 \\
\hline
\end{tabular}

Note. $N=315-318$. Turnover $=$ organizational turnover intentions. Commitment $=$ affective organizational commitment. Engagement $=$ work engagement. Tenure $=$ organizational tenure. Urban versus Rural $=$ Categorical variable indicating the population of the city where the nurse practices. CSE $=$ core self-evaluations. General X CSE $=$ general worker climate and CSE. $* * p<.01 . * p<.05$. 
Table 18. Regression Analysis with General Age Climate and Time 1 Outcomes (entire sample)

\begin{tabular}{|c|c|c|c|c|}
\hline & & $\begin{array}{c}\text { Turnover } \\
\beta\end{array}$ & $\begin{array}{c}\text { Commitment } \\
\beta\end{array}$ & $\begin{array}{c}\text { Engagement } \\
\beta\end{array}$ \\
\hline \multirow[t]{7}{*}{ Step 1} & Age & .06 & .00 & .030 \\
\hline & Tenure & $-.12 *$ & -.02 & - \\
\hline & Commitment & $-.44 * *$ & - & - \\
\hline & Urban versus Rural & - & - & $-.14 *$ \\
\hline & $\Delta \mathrm{R}^{2}$ & $.20 * *$ & .00 & $.02 *$ \\
\hline & $\Delta \mathrm{F}$ & 26.35 & .07 & 3.70 \\
\hline & Df & 3,315 & 2,316 & 2,316 \\
\hline \multirow[t]{9}{*}{ Step 2} & Age & .06 & .00 & .04 \\
\hline & Tenure & $-.14 *$ & .04 & - \\
\hline & Commitment & $-.39 * *$ & - & - \\
\hline & Urban versus Rural & - & - & $-.16^{* *}$ \\
\hline & CSE & $-.19 * *$ & .07 & $.36^{* *}$ \\
\hline & General Age Climate & .10 & $-.26 * *$ & $-.11 *$ \\
\hline & $\Delta \mathrm{R}^{2}$ & $.05^{* *}$ & $.08^{* *}$ & $.15^{* *}$ \\
\hline & $\Delta \mathrm{F}$ & 10.55 & 12.95 & 29.45 \\
\hline & $\mathrm{df}$ & 2,313 & 2,314 & 2,314 \\
\hline \multirow[t]{11}{*}{ Step 3} & Age & .06 & .01 & .04 \\
\hline & Tenure & $-.14 *$ & .04 & - \\
\hline & Commitment & $-.39 * *$ & - & - \\
\hline & Urban versus Rural & - & - & $-.16^{* *}$ \\
\hline & CSE & $-.20 * *$ & .07 & $.36^{* *}$ \\
\hline & General Age Climate & .09 & $-.27 * *$ & $-.11 *$ \\
\hline & General X CSE & -.03 & -.02 & .01 \\
\hline & $\Delta \mathrm{R}^{2}$ & .00 & .00 & .00 \\
\hline & $\Delta \mathrm{F}$ & .35 & .17 & .03 \\
\hline & $\mathrm{df}$ & 1,312 & 1,313 & 1,313 \\
\hline & Total $\mathrm{R}^{2}$ & .25 & .08 & .18 \\
\hline
\end{tabular}

Note. $N=315-318$. Turnover $=$ organizational turnover intentions. Commitment $=$ affective organizational commitment. Engagement $=$ work engagement. Tenure $=$ organizational tenure. Urban versus Rural $=$ Categorical variable indicating the population of the city where the nurse practices. CSE $=$ core self-evaluations. General X CSE $=$ general worker climate and CSE. $* * p<.01 .{ }^{*} p<.05$. 
Table 19. Summary of Significant Regression Coefficients Across Regressions Analyses

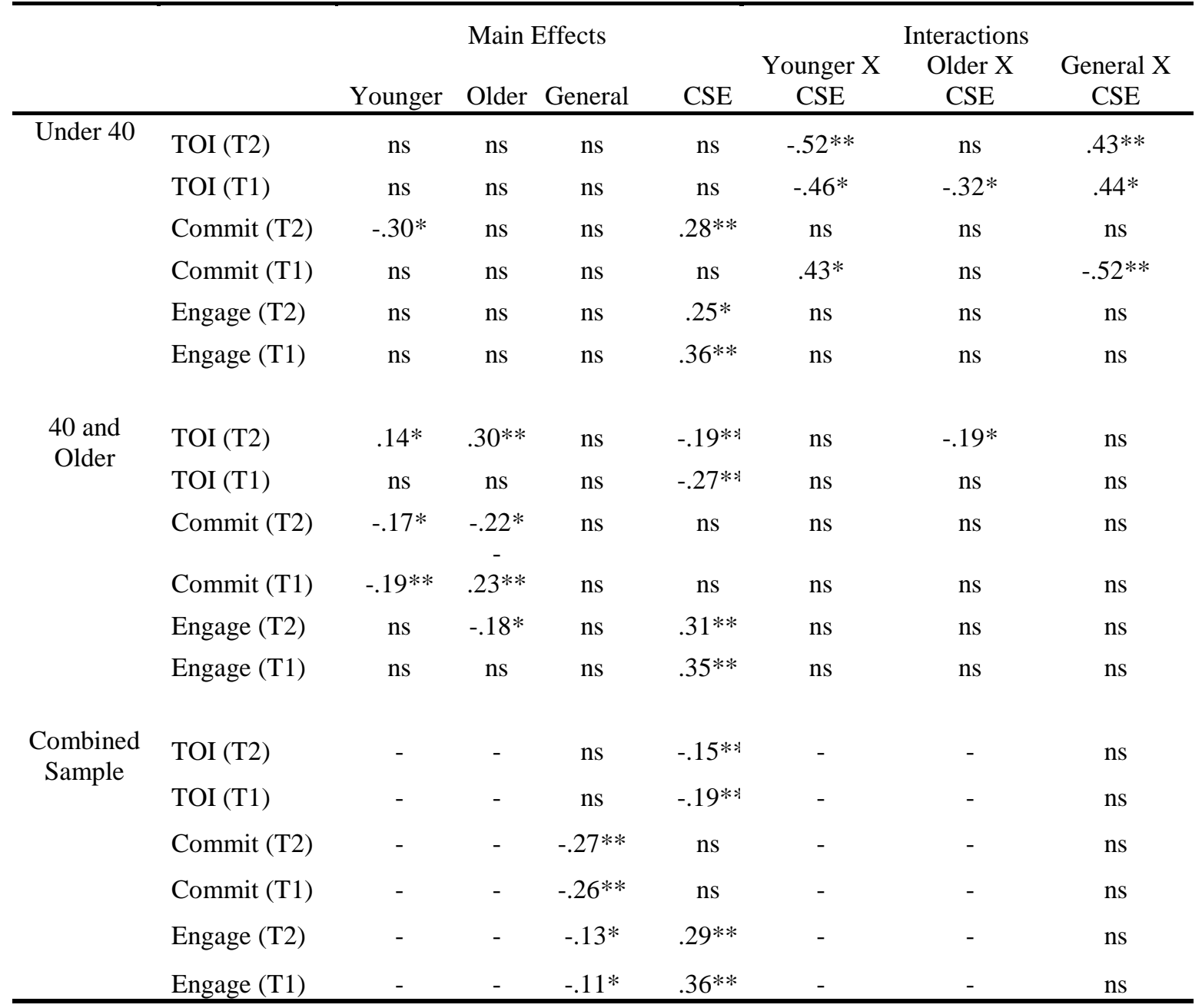

Note. Younger $=$ younger worker age climate. Older $=$ older worker age climate. General $=$ general age climate. Younger X CSE $=$ the interaction between younger worker age climate and core self-evaluations. Older X CSE $=$ the interaction between older worker climate and core self-evaluations. General X CSE $=$ the interaction between general age climate and core self-evaluations. TOI $=$ turnover intentions.

Commitment $=$ affective organizational commitment. Engagement $=$ work engagement. $\mathrm{T} 1=$ data collected at Time $1 . \mathrm{T} 2=$ data collected at Time $2 . \mathrm{ns}=$ not significant. Chronological age was controlled for in all analyses. $* * p<.01 . * p<.05$. 
Table 20. Post Hoc Power Analysis

\begin{tabular}{|c|c|c|c|c|c|c|}
\hline Outcome (Sample) & $\begin{array}{c}\text { Observed total } \\
\mathrm{R}^{2}\end{array}$ & $\mathrm{~F}^{2}$ & $\mathrm{~N}$ & Alpha & $\begin{array}{c}\text { Total } \\
\text { Predictors }\end{array}$ & Power \\
\hline T2 TOI (Under 40) & .31 & .26 & 95 & .05 & 10 & 0.93 \\
\hline T2 TOI (Over 40) & .33 & .44 & 218 & .05 & 10 & 1.00 \\
\hline T2 TOI (Combined) & .21 & .22 & 315 & .05 & 6 & 1.00 \\
\hline T1 TOI (Under 40) & .32 & .28 & 95 & .05 & 10 & 1.00 \\
\hline T1 TOI (Over 40) & .32 & .43 & 218 & .05 & 10 & 1.00 \\
\hline T1 TOI (Combined) & .25 & .27 & 315 & .05 & 6 & 1.00 \\
\hline T2 Commitment (Under 40) & .23 & .32 & 96 & .05 & 9 & 0.98 \\
\hline T2 Commitment (Over 40) & .15 & .18 & 219 & .05 & 9 & 1.00 \\
\hline T2 Commitment (Combined) & .09 & .13 & 318 & .05 & 5 & 1.00 \\
\hline T1 Commitment (Under 40) & .28 & .45 & 96 & .05 & 9 & 1.00 \\
\hline T1 Commitment (Over 40) & .15 & .21 & 219 & .05 & 9 & 1.00 \\
\hline T1 Commitment (Combined) & .08 & .11 & 318 & .05 & 5 & 1.00 \\
\hline T2 Engagement (Under 40) & .16 & .21 & 96 & .05 & 9 & 0.87 \\
\hline T2 Engagement (Over 40) & .17 & .22 & 219 & .05 & 9 & 1.00 \\
\hline T2 Engagement (Combined) & .15 & .17 & 318 & .05 & 5 & 1.00 \\
\hline T1 Engagement (Under 40) & .21 & .39 & 96 & .05 & 9 & .99 \\
\hline T1 Engagement (Over 40) & .20 & .25 & 219 & .05 & 9 & 1.00 \\
\hline T1 Engagement (Combined) & .18 & .22 & 318 & .05 & 5 & 1.00 \\
\hline
\end{tabular}

Note. $\mathrm{T} 1=$ Time $1 . \mathrm{T} 2=$ Time $2 . \mathrm{TOI}=$ organizational turnover intentions. Commitment $=$ affective organizational commitment. Engagement $=$ work engagement. 
Ageism Climate 196

Table 21. $\mathrm{R}_{\mathrm{wg}(\mathrm{j})}$ and ICC Analysis for the Ageism Climate Measures

\begin{tabular}{lccccc}
\hline & Mean $\mathrm{r}_{\mathrm{wg}(\mathrm{j})}$ & Range & ICC & $\begin{array}{c}\mathrm{N} \\
\text { Groups }\end{array}$ & $\begin{array}{c}\mathrm{N} \\
\text { Respondents }\end{array}$ \\
\hline Older Ageism Climate & 0.73 & $(.14-.96)$ & .05 & 18 & 313 \\
Younger Ageism Climate & 0.83 & $(.66-.98)$ & .01 & 18 & 315 \\
General Ageism Climate & 0.54 & $(0-.87)$ & .00 & 18 & 315 \\
\hline
\end{tabular}

Note. $\mathrm{r}_{\mathrm{wg}(\mathrm{j})}=$ within group agreement. $\mathrm{ICC}=$ intraclass correlation. 
Figure 1. Hypothesized Conceptual Model

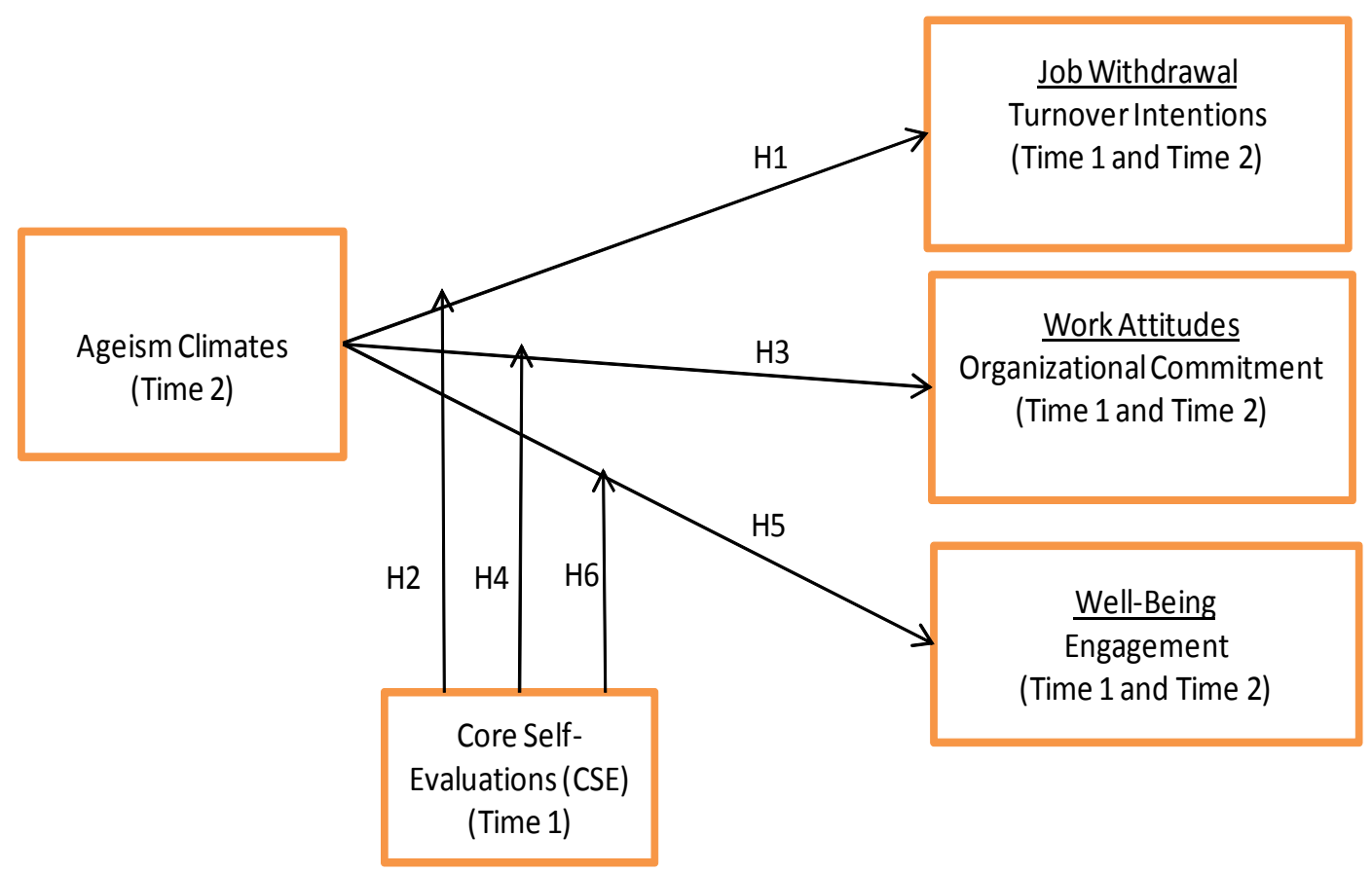


Figure 2. Best Fitting Ageism Climate Model

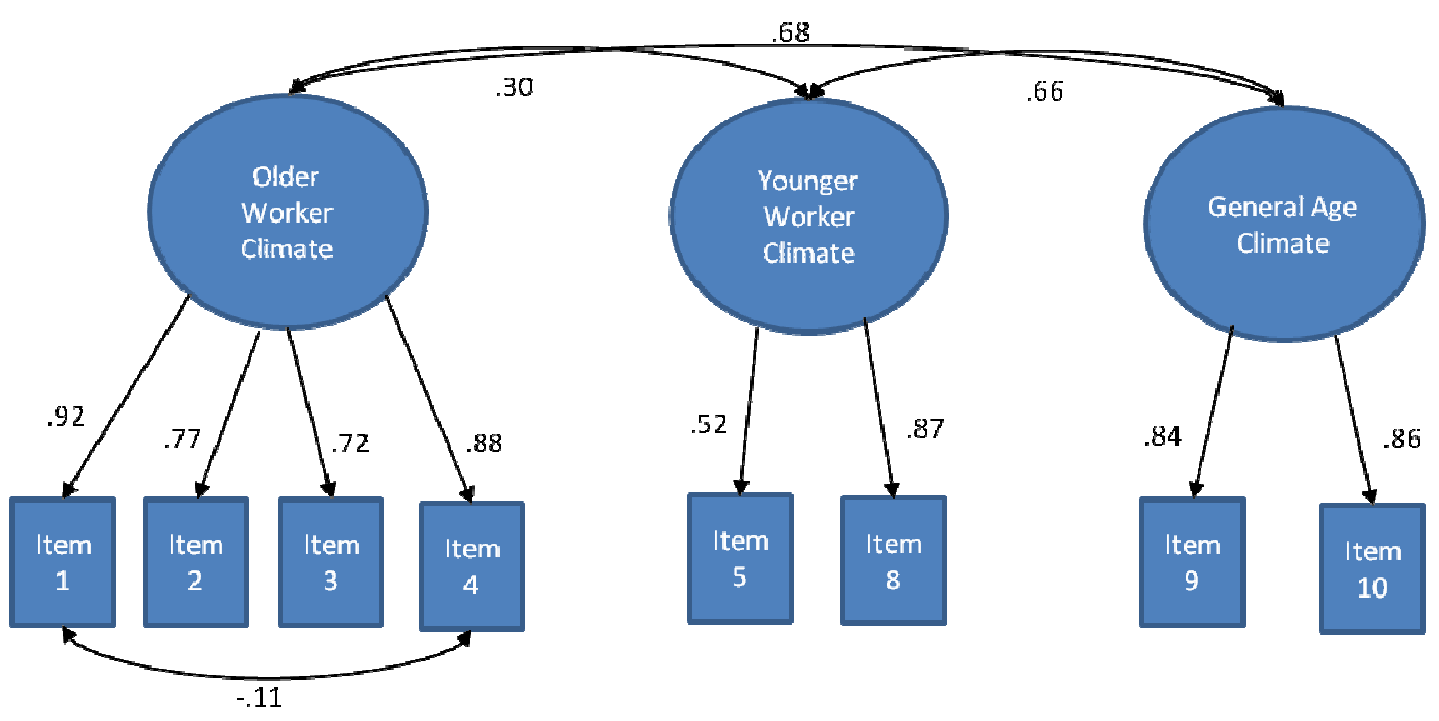

Note. Model is displaying standardized loadings. The model's fit statistics are $\chi^{2}(16)=60.78 ; \mathrm{p}<$ $.001 ; \mathrm{N}=344 ; \mathrm{CFI}=.98 ; \mathrm{SRMR}=.04 ; \mathrm{RMSEA}=.09$. 
Figure 3. Young Age Climate X CSE Interaction on Time 2 Organizational Turnover Intentions (Under 40)

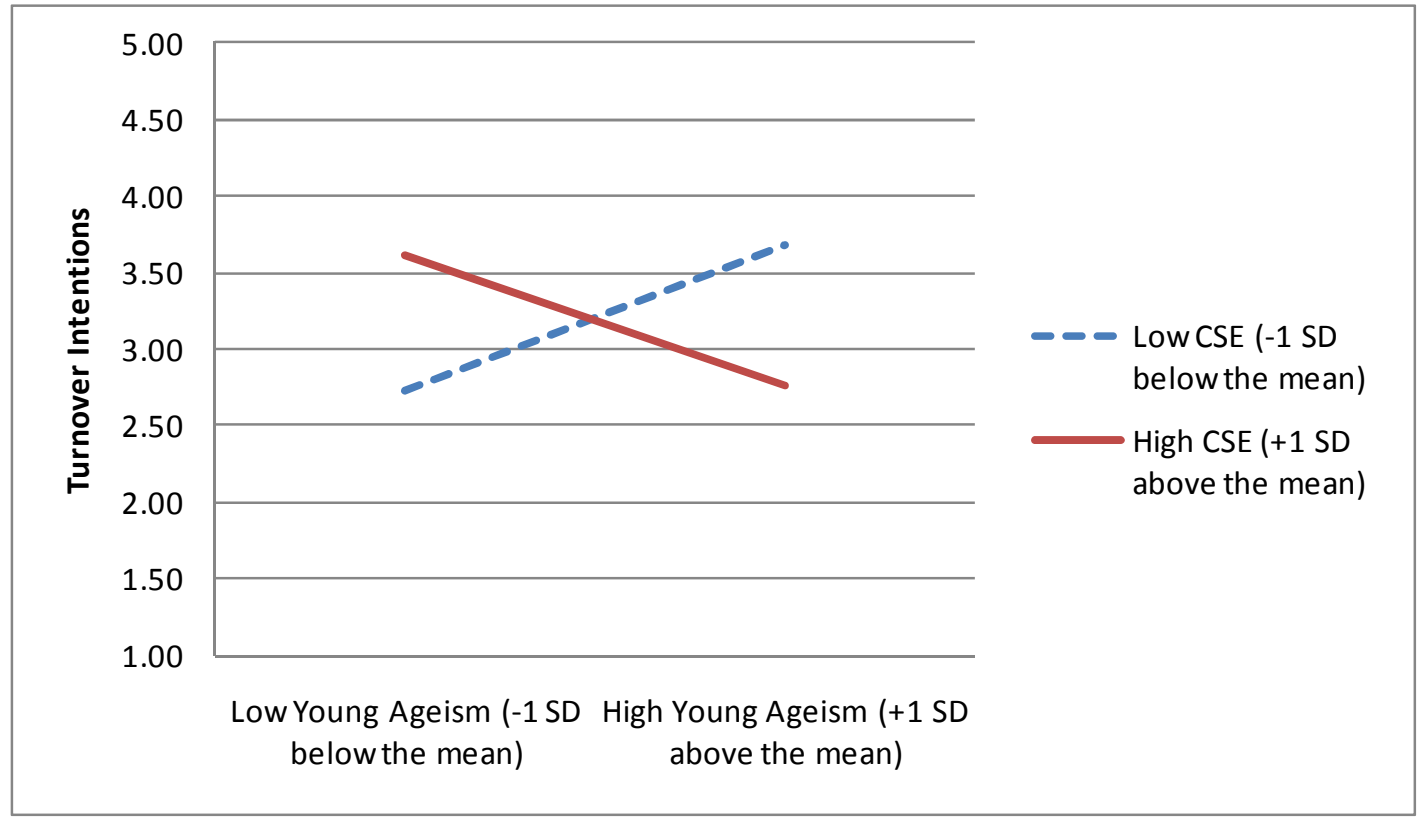


Figure 4. General Age Climate X CSE Interaction on Time 2 Organizational Turnover Intentions (Under 40)

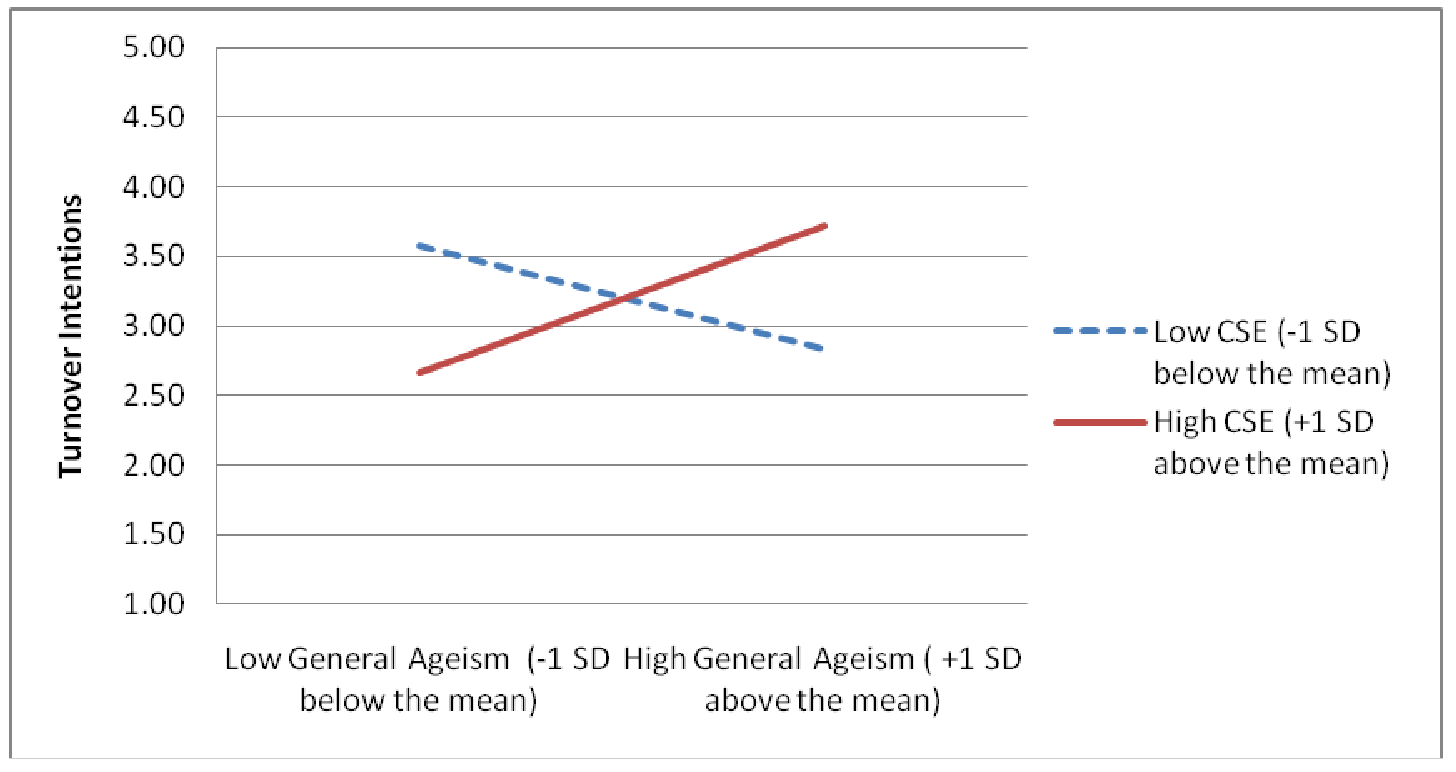


Figure 5. Older Worker Climate X CSE Interaction on Time 2 Organizational Turnover Intentions (40 and older)

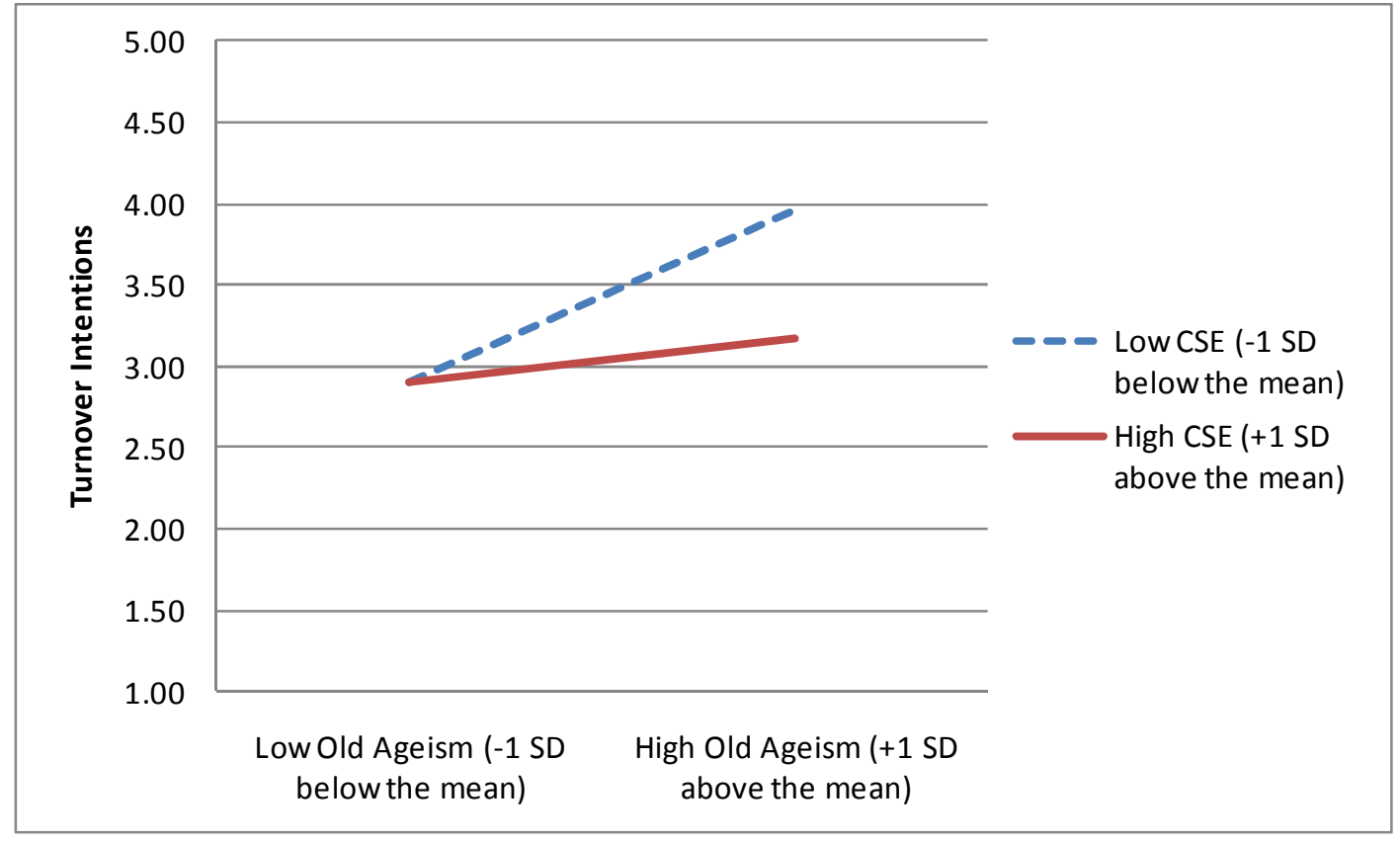


Figure 6. Younger Worker Climate X CSE Interaction on Time 1 Organizational Turnover Intentions (under 40)

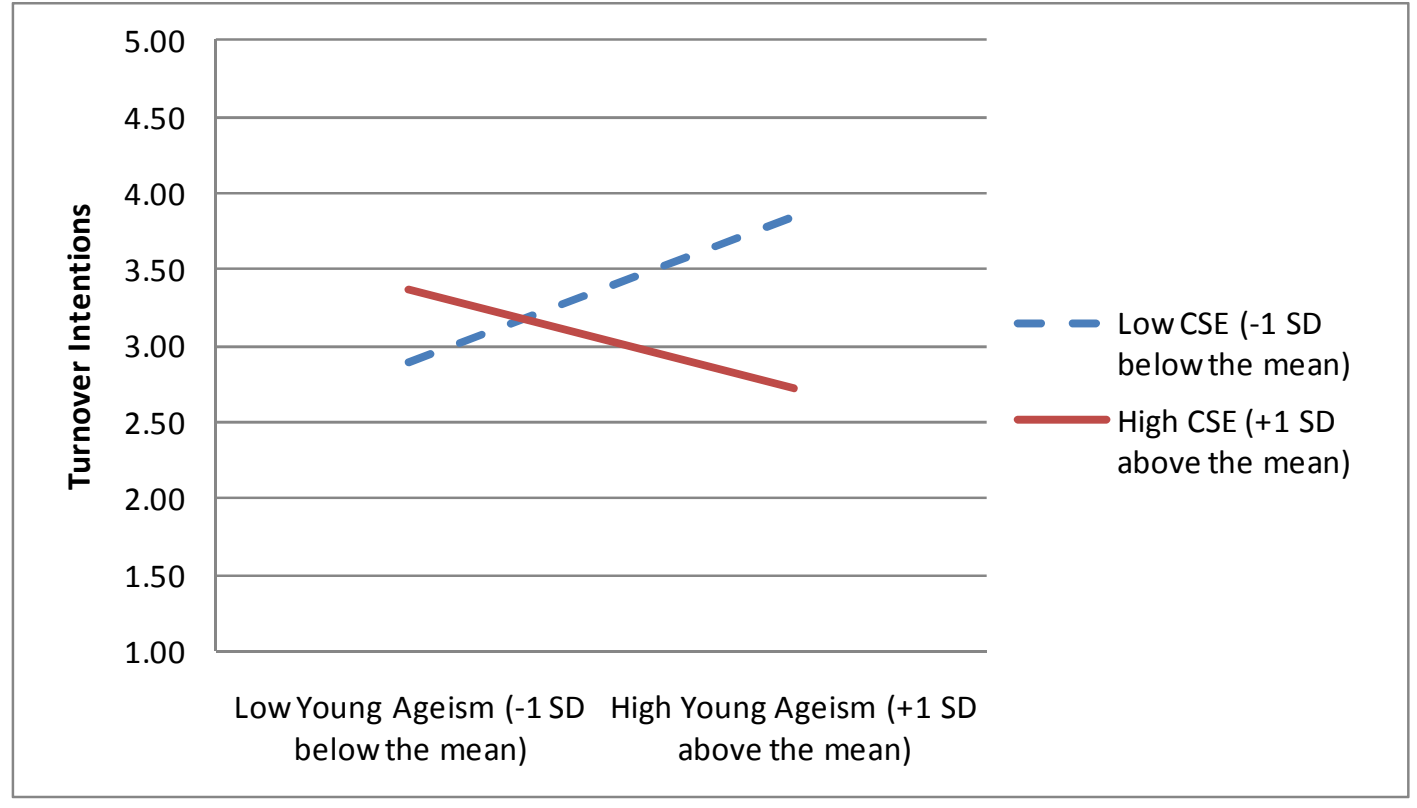


Figure 7. Older Worker Climate X CSE Interaction on Time 1 Organizational Turnover Intentions (under 40)

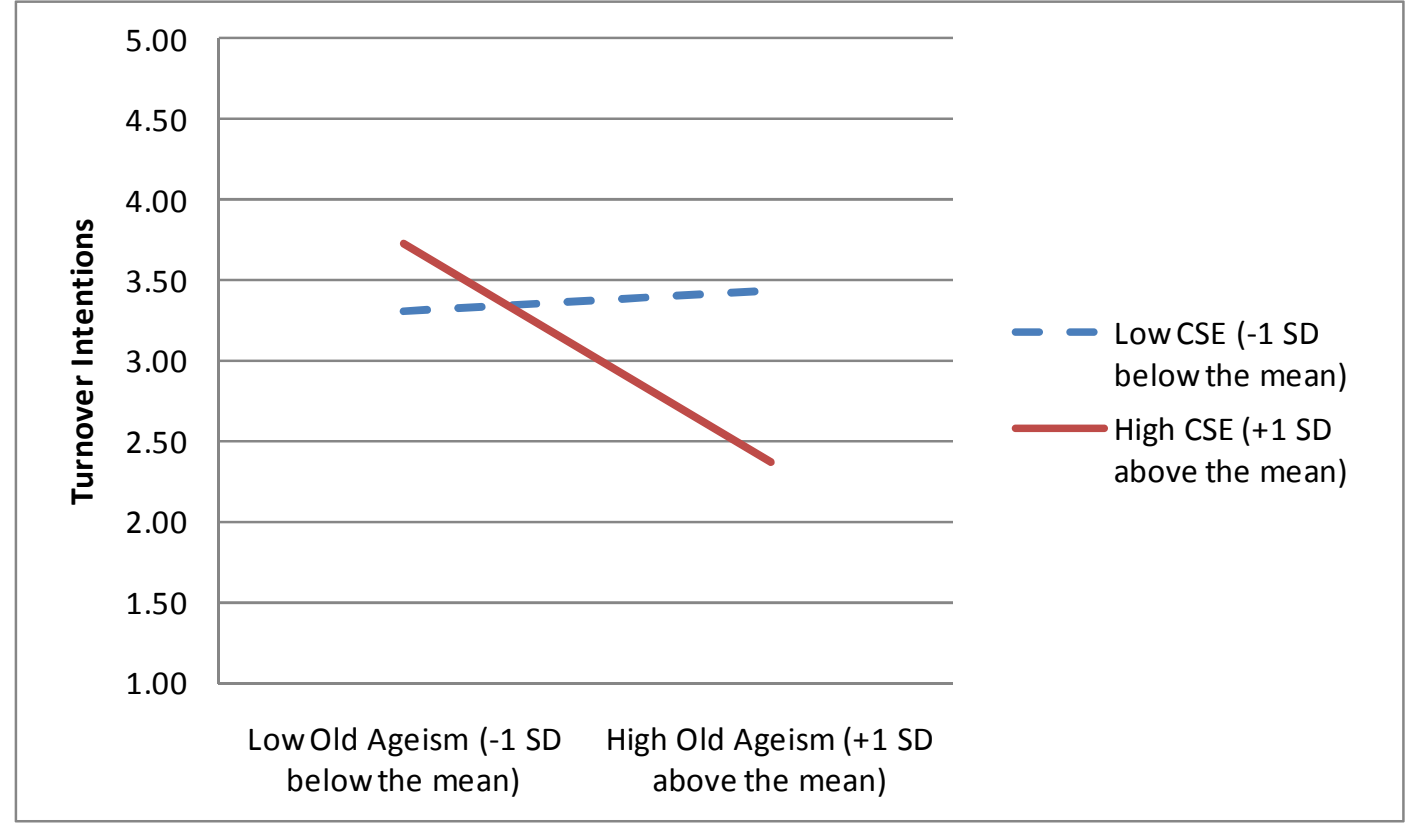


Figure 8. General Age Climate X CSE Interaction on Time 1 Organizational Turnover Intentions (under 40)

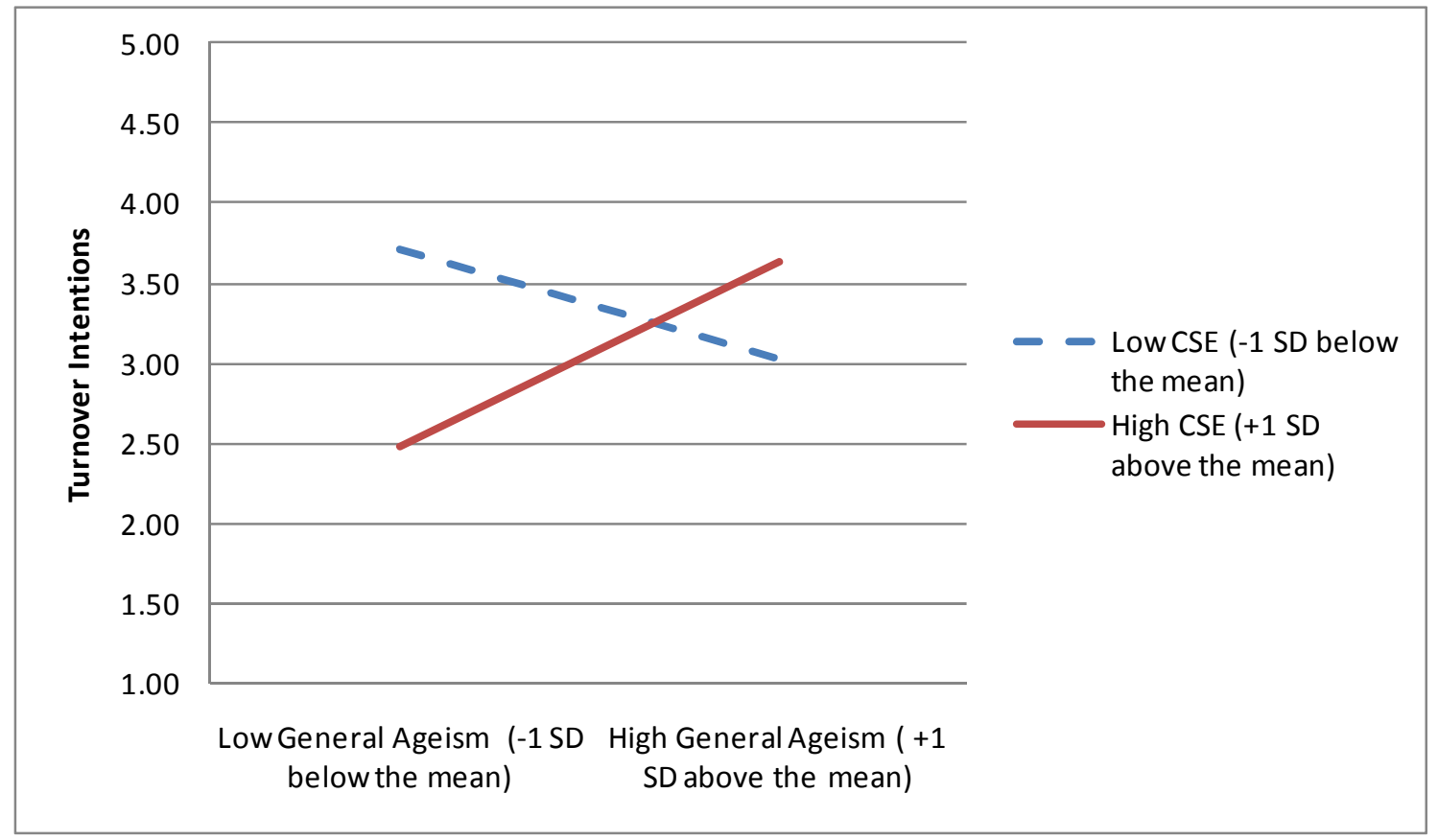


Figure 9. Younger Worker Climate X CSE Interaction on Time 1 Affective Organizational Commitment (under 40)

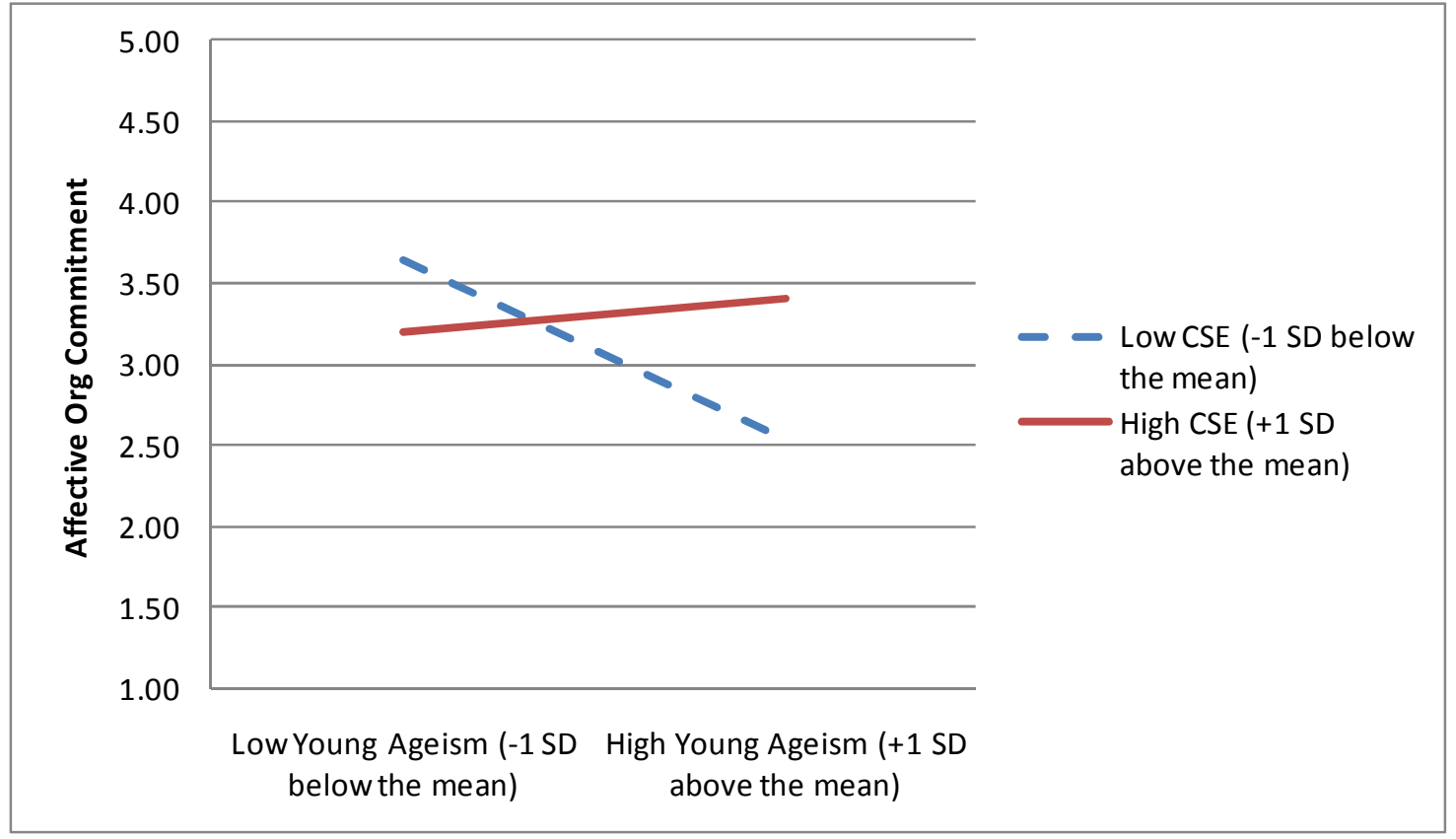


Figure 10. General Age Climate X CSE Interaction on Time 1 Organizational Commitment (under 40)

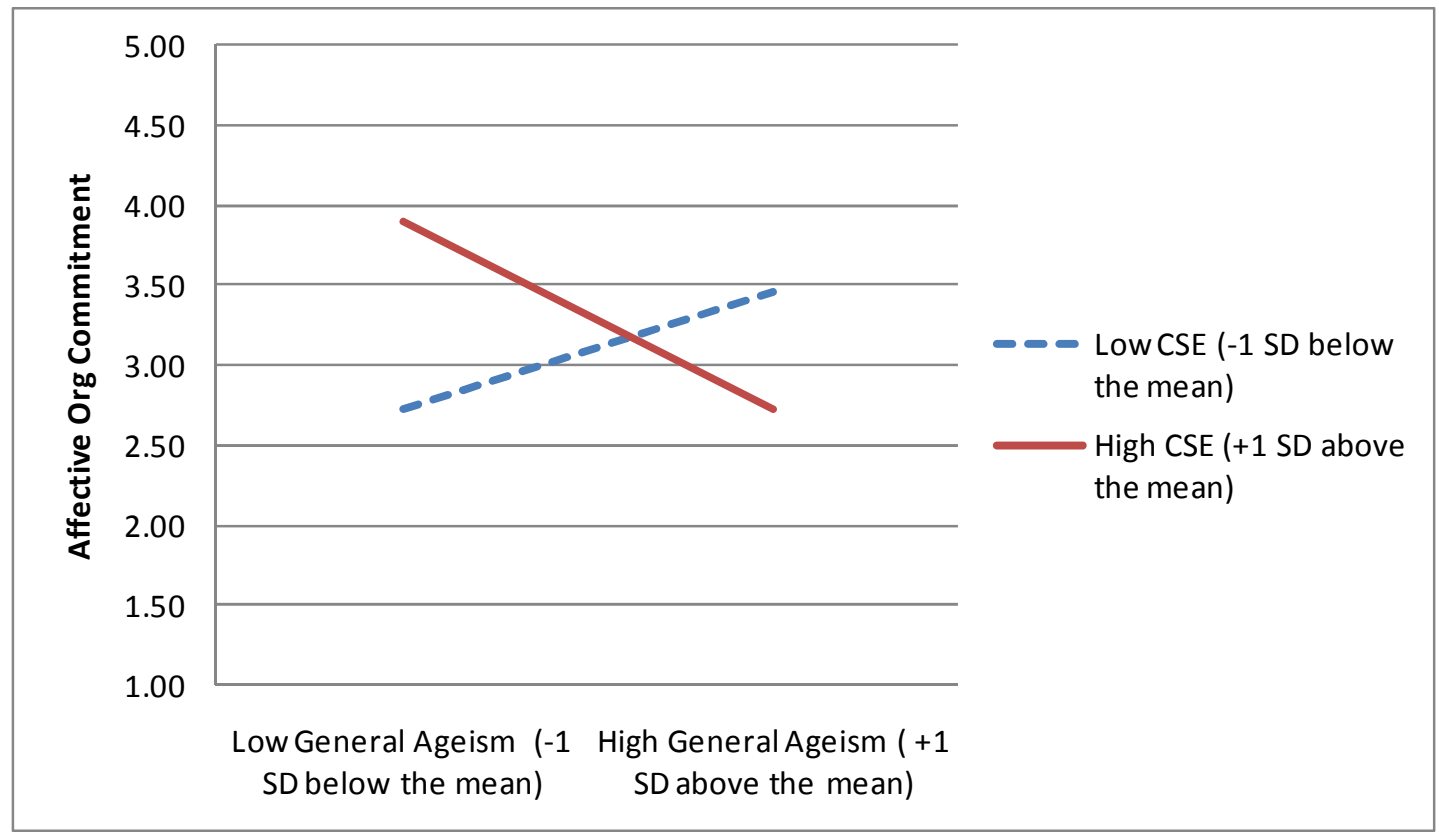




\section{References}

Adams G. A., \& Beehr, T. A. (1998). Turnover and retirement: A comparison of their similarities and differences. Personnel Psychology, 51, 643-665.

Aiken L.H., Clarke S.P., Sloane D.M., Sochalski J.A., Busse R., Clarke H., Giovannetti P., Hunt J., Rafferty A., \& Shamian J. (2001). Nurses' reports on hospital care in five countries. Health Affairs, 20, 43-53.

Aiken, L.S., \& West, S.G. (1991). Multiple regression: Testing and interpreting interactions. Newbury Park, CA: Sage

American Organization of Nurse Executives (AONE) (2002). Acute Care Hospital Survey of RN Vacancy and Turnover Rates in 2000. American Organization of Nurse Executives. Washington, DC, USA.

Ashkanksy, N. M., Hartel, C. E. J., \& Daus, C. S. (2002). Diversity and emotion: The new frontiers in organizational behavior research. Journal of Management, 28, 307-338.

Avery, D. R., McKay, P. F., Wilson, D. C., \& Tonidandel, S. (2007). Unequal attendance: The relationships between race, organizational diversity cues, and absenteeism. Personnel Psychology, 60, 875-902.

Avolio, B. J., \& Barrett, G. V. (1987). Effects of age stereotyping in a simulated interview. Psychology and Aging, 2, 56-63.

Avolio, B. J., Waldman, D. A., \& McDaniel, M. A. (1990). Age and work performance in nonmanagerial jobs: The effects of experience and occupational type. Academy of Management Journal, 33, 407-422. 
Bakker, A. B., Schaufeli, W. B., Leiter, M. P., \& Taris, T. W. (2008). Work engagement: An emerging concept in occupational health psychology. Work \& Stress, 22, 187200.

Bakker, A.B., Demerouti, E., \& Verbeke, W. (2004). Using the job demands-resources model to predict burnout and performance. Human Resource Management, 43, 83-104.

Baltes, B. B. (2001). Psychological climate in the work-setting. In N.J. Smelser \& P.B. Baltes (Eds), International encyclopedia of the social and behavioral sciences (pp. 12355-12359). New York: Elsevier/Pergamon.

Baltes, P. B., \& Baltes, M. M. (Eds.). (1990). Successful aging: Perspectives from the behavioral sciences. New York: Cambridge University Press.

Baltes, B. B., Zhdanova, L. S., \& Parker, C. P. (2009). Psychological climate: A comparison of organizational and individual referents. Human Relations, 62, 669700.

Barak, B. (1987). Cognitive age: A new multidimensional approach to measuring age identity. The International Journal of Aging and Human Development, 25, 109127.

Barnes-Farrell, J., \& Matthews, R. (2007). Age and work attitudes. In K. Shultz \& G. Adams (Eds). Aging and work in the 21st century (pp. 139-162). Mahwah, NJ: LEA. 
Barrick, M. R., Mount, M. K., \& Judge, T. A. (2001). Personality and performance at the beginning of the new millennium: What do we know and where do we go next? Personality and Performance, 9, 9-30.

Bauer, T. N., Bodner, T., Erdogan, B., Truxillo, D. M., \& Tucker, J. S. (2007). Newcomer adjustment during organizational socialization: A meta-analytic review of antecedents, outcomes, and methods. Journal of Applied Psychology, 92, 707-721.

Armenakis, A. A., Bedeian, A. G., \& Pond, S. B. (1983). Research issues in OD evaluation: Past, present, and future. Academy of Management Review, 8, 320328.

Bégat, I., Ellefsen, B., \& Severinnsson, E. (2005). Nurses' satisfaction with their work environment and the outcomes of clinical nursing supervision on nurses' experiences of wellbeing - a Norwegian study. Journal of Nursing Management, $13,221-230$.

Best, R. G., Stapleton, L. M., \& Downey, R. G. (2005). Core self-evaluations and job burnout: the test of alternative models. Journal of Occupational Health Psychology, 10, 441-451.

Blau, G. (2007). Does a corresponding set of variables for explaining voluntary organizational turnover transfer to explaining voluntary occupational turnover? Journal of Vocational Behavior, 70, 135-148.

Bono, J. E., \& Colbert, A. E. (2005). Understanding responses to multi-source feedback: The role of core self-evaluations. Personnel Psychology, 58, 171-203. 
Bowen, D. E., \& Schneider, B. (1988). Services marketing and management: Implications for organizational behavior. Research in Organizational Behavior, $10,43-80$.

Brief, A. P., Umphress, E. E., Dietz, J., Burrows, J. W., Butz, R. M., \& Scholten, L. (2005). Community matters: Realistic group conflict theory and the impact of diversity. Academy of Management Journal, 48, 830-844.

Bradbury-Jones, C., Sambrook, S., \& Irvine, F. (2007). The meaning of empowerment for nursing students: a critical incident study. Journal of Advanced Nursing, 59, $342-351$.

Buerhaus, P. I., Donelan, K., Ulrich, B. T., Norman, L., \& Dittus, R. (2006). State of the registered nurse workforce in the United States. Nursing Economics, 24, 6-12.

Buerhaus, P., Staiger, D., \& Auerbach, D. (2000). Implications of an aging registered nurse workforce. Journal of the American Medical Association, 283, 2948-2954.

Burton, D. A., Morris, B. A., \& Campbell, K. K. (2005). When, not if... A report on Oregon's registered nurse workforce. Unpublished Technical Report.

Byrne, D. (1971). The attraction paradigm. New York: Academic Press.

Cadiz, D. M. (2009). Subjective age in the workplace: Exploring the nomological network. Unpublished master's thesis, Portland State University.

Capowski, G. (1994). Ageism: The new diversity issue. Management Review, 53, 10-15.

Carr, J. Z., Schmidt, A. M., Ford, K., \& DeShon, R. P. (2003). Climate perceptions matter: A meta-analytic path analysis relating molar climate, cognitive and 
affective States, and individual level work outcomes. Journal of Applied Psychology, 88, 605-619.

Chiu, W. C. K., Chan, A. W., Snape, E., \& Redman, T. (2001). Age stereotypes and discriminatory attitudes towards older workers: An east-west comparison. Human Relations, 54, 629-661.

Christian, M. S., Bradley, J. C., Wallace, C. J., \& Burke, M. J. (2009). Workplace safety: A meta-analysis of the roles of person and situation factors. Journal of Applied Psychology, 94, 1103-1127.

Clarke, S. (2006). The relationship between safety climate and safety performance: A meta-analytic review. Journal of Occupational Health Psychology, 11, 315-327.

Cleveland, J. N., Festa, R. M., \& Montgomery, L. (1988). Applicant pool composition and job perceptions: Impact on decisions regarding an older applicant. Journal of Vocational Behavior, 32, 112-125.

Cleveland, J. N., \& McFarlane-Shore, L. (1992). Self- and supervisory perspectives on age and work attitudes and performance. Journal of Applied Psychology, 77, 469484.

Cohen, J. (1988). Statistical power analysis for the behavioral sciences (2nd ed.). New Jersey: Lawrence Erlbaum.

Cooper-Hakim, A., \& Viswesvaran, C. (2005). The construct of work commitment: Testing an integrative framework. Psychological Bulletin, 131, 241-259.

Cortina, L. M. (2008). Unseen injustice: Incivility as modern discrimination in organizations. Academy of Management Review, 33, 55-75. 
Ageism Climate 212

Cortina, L. M., Magley, V. J., Williams, J. H., \& Langhout, R. D. (2001). Incivility at the workplace: Incidence and impact. Journal of Occupational Health Psychology, 6, 64-80.

Costa, P. T., \& McCrae, R. R. (1988). Personality in adulthood: A six-year longitudinal study of self-reports and spouse ratings on the NEO Personality Inventory. Journal of Personality and Social Psychology, 54, 853-863.

Cox, Jr., T., \& Nkomo, S. M. (1992). Candidate age as a factor in promotability ratings, Public Personnel Management, 21, 197-210.

Coy, P., Conlin, M., \& Thorton, E. (November 2002). A lost generation? Young and mid-career job seekers are bearing the brunt of U.S. layoffs. Business Week. Retrieved September 1, 2009, from http://www.businessweek.com/magazine/content/02_44/b3806042.htm

Cuddy, A. J., \& Fiske, S. T. (2002). Doddering but dear: Process, content and function in stereotyping of older persons. In T. Nelson (Ed.), Ageism: Stereotyping and prejudice against older persons (pp. 3-26). Cambridge, MA: MIT Press.

DeArmond, S., Tye, M., Chen, P. Y., Krauss, A., Rogers, D. A., \& Sintek, E. (2006). Age and gender stereotypes: New challenges in a changing workplace and workforce. Journal of Applied Social Psychology, 36, 2184-2214.

Dennison, D. R. (1996). What is the difference between organizational culture and organizational climate? A native's point of view on a decade of paradigm wars. Academy of Management Review, 2l, 619-654. 
Doverspike, D., Taylor, M. A., Shultz, K. S., \& McKay, P. F. (2000). Responding to the challenge of a changing workforce: Recruiting nontraditional demographic groups. Public Personnel Management, 29, 445-457.

Eisenberger, R., Huntington, R., Hutchison, S., \& Sowa, D. (1986). Perceived organizational support. Journal of Applied Psychology, 71, 500-507.

Ely, R. J., \& Thomas, D. A. (2001). Cultural diversity at work: The effects of diversity perspectives on work group processes and outcomes. Administrative Science Quarterly, 46, 229-273.

Erdheim, J., Wang, M., \& Zickar, M. J. (2006). Linking the Big 5 personality constructs to organizational commitment. Personality and Individual Differences, 41, 959970.

Erez A., \& Judge, T. A. (2001). Relationship of core self-evaluations to goal setting, motivation, and performance. Journal of Applied Psychology, 86, 1270-1279.

Faboni, M., Saltstone, R., \& Hughes, S. (1990). The Fraboni Scale of Ageism (FSA): An attempt at a more precise measure of ageism. Canadian Journal on Aging, 9, 5666.

Faul, F., Erdfelder, E., Lang, A.-G., \& Buchner, A. (2007). G*Power 3: A flexible statistical power analysis program for the social, behavioral, and biomedical sciences. Behavior Research Methods, 39, 175-91.

Finkelstein, L. M., Allen, T. D., \& Rhoton, L. A. (2003). An examination of the role of age in mentoring relationships. Group \& Organization Management, 28, 249-281. 
Finkelstein, L. M., Burke, M. J., \& Raju, N. S. (1995). Age discrimination in simulated employment contexts: An integrative analysis. Journal of Applied Psychology, 80, 652-663.

Finkelstein, L. M., \& Farrell, S. K. (2007). An expanded view of age bias in the workplace. In K. S. Shultz \& G. A. Adams (Eds.), Aging and work in the $21^{\text {st }}$ century (pp.73-108). Mahwah, New Jersey: LEA.

Finkelstein, L. M., Higgins, K., \& Clancy, M. (2000). Justifications for ratings of old and young job applicants: An exploratory content analysis. Experimental Aging Research, 26, 263-283.

Fiske, S. T. (2004). Stereotyping, prejudice, and discrimination: Social biases. In Social beings: A core motives approach to social psychology (pp.397-457). New Jersey: Wiley.

Fiske, S. T., Cuddy, A. J. C., Glick, P., \& Xu, J. (2002). A model of (often mixed) stereotype content: Competence and warmth respectively follow from perceived status and competition. Journal of Personality and Social Psychology, 82, 878902.

French, S. E., Lenton, R., Walters, V., \& Eyles, J. (2000). An empirical evaluation of an expanded nurse stress scale. Journal of Nursing Measurement, 8, 161-178.

Gee, G. G., Pavalko, E. K., \& Long, S. J. (2007). Age, cohort and perceived age discrimination: Using the life course to assess self-reported age discrimination. Social Forces, 86, 265-290. 
Gelfand, M. J., Nishii, L. H., Raver, J., \& Schneider, B. (2005). Discrimination in organizations: An organizational level systems perspective. In R. Dipboye \& A. Colella (Eds.), Discrimination at work: The psychological and organizational bases (pp. 89-116). Hillsdale, NJ: Lawrence Erlbaum Associates.

Gist, M. E., \& Mitchell, T. R. (1992). Self-efficacy: A theoretical analysis of its determinants and malleability. The Academy of Management Review, 17, 183211.

Goldberg, C. (2007). Diversity issues for an aging workforce. In K. S. Shultz \& G. A. Adams (Eds.), Aging and Work in the $21^{\text {st }}$ Century (pp.51-72). Mahwah, New Jersey: LEA.

Goldberg, L. R. (1990). An alternative 'description of personality': The big-five factor structure. Journal of Personality and Social Psychology, 59, 1216-1229.

Goldberg, C., Perry, E., \& Finkelstein, L. (2006, August). Antecedents and implications of targeting older workers in recruitment. Paper presented at the Annual meeting of the Academy of Management, Atlanta, GA.

Goldberg, C., Finkelstein, L., Perry, E., \& Konrad, A. (2004). Job and industry fit: The effects of age and gender matches on career progress outcomes. Journal of Organizational Behavior, 25, 807-829.

Golde, P., \& Kogan, N. (1959). A sentence completion procedure for assessing attitudes toward old people. Journal of Gerontology, 14, 355-363.

Gordon, R. A., \& Arvey, R. D. (2004). Age bias in laboratory and field settings: A metaanalytic investigation. Journal of Applied Psychology, 34, 468-492. 
Green, M. T., \& Puetzer, M. (2002). The value of mentoring: A strategic approach to retention and recruitment. Journal of Nursing Care Quality, 17, 63-70.

Hanisch, K. A., \& Hulin, C. L. (1990). Job attitudes and organizational withdrawal behaviors. Journal of Vocational Behavior, 39, 110-128.

Hanisch, K. A., \& Hulin, C. L. (1991). General attitudes and organizational withdrawal: An evaluation of a causal model. Journal of Vocational Behavior, 39, 110-128.

Harman, W. S., Lee, T. W., Mitchell, T. R., Felps, W., \& Owens, B. P. (2007). The psychology of voluntary employee turnover. Current Directions in Psychological Science, 16, 51-54.

Harris, K. J., Harvey, P., \& Kacmar, M. (2009). Do social stressors impact everyone equally? An examination of the moderating impact of core self-evaluations. Journal of Business and Psychology, 24, 153-164.

Harter, S. (1990). Causes, correlates and the functional role of global self-worth: A lifespan perspective. In R. Sternberg and J.J. Kolligian (Eds.), Competence considered (pp. 67-98). New Haven, CT: Yale University Press.

Hedge, J. W., Borman, W. C., \& Lammlein, S. E. (2006). The aging workforce: Realities, myths, and implications for organizations. Washington, DC: American Psychological Association.

Hedges, L., \& Olkin, I. (1985). Statistical methods for meta-analysis. New York: Academic Press.

Hicks-Clarke D., \& Iles, P. (2000). Climate for diversity and its effects on career and organizational attitudes and perceptions. Personnel Review, 29, 324-345. 
Hinkin, T. R. (1998). A brief tutorial on the development of measures for use in survey questionnaires. Organizational Research Methods, 1, 104-121.

Hobfoll, S. (1989). Conservation of resources: A new attempt at conceptualizing stress. American Psychologist, 44, 513-524.

Hobfoll, S. (2001). The influence of culture, community, and the nested-self in the stress process: Advancing conservation of resources theory. Applied Psychology: An International Review, 50, 337-369.

Hobfoll, S. E., \& Wells, J. D. (1998) Conservation of resources, stress, and aging: Why do some slide and others spring? In J. Lormanz \& Y. Lomrants (Eds.), Handbook of aging and mental health: An integrative approach (pp. 121-134). New York, NY: Plenum Press.

Hom, P. W., Griffeth, R. W., \& Sellaro, L. (1984). The validity of Mobley's (1977) model of employee turnover. Organizational Behavior and Human Performance, $34,141-174$.

Howell, D.C. (2008). The analysis of missing data. In Outhwaite, W. \& Turner, S. Handbook of Social Science Methodology. London: Sage.

Hu, L. \& Bentler, P.M. (1999). Cutoff criteria for fit indexes in covariance structure analysis: Conventional criteria versus new alternatives. Structural Equation Modeling, 6, 1-55.

Hulin, C. L., Fitzgerald, L. F., \& Drasgow, F. (1996). Organizational influences on sexual harassment. In M.S. Stockdale (Ed.), Sexual harassment in the workplace (pp. 127-150). Thousand Oaks, CA: Sage. 
Hulin, C. L., \& Judge, T. A. (2003). Job attitudes. In W. C. Borman, D. R. Ilgen, \& R. J. Klimoski (Eds.), Handbook of psychology: Industrial and organizational psychology (pp. 255-276). Hoboken, NJ: Wiley.

Hunthausen, J. M., Truxillo, D. M., Bauer, T. N., \& Hammer, L. B. (2003). A field study of frame-of-reference on personality test validity. Journal of Applied Psychology, $88,545-551$.

Jackson, S. E., Joshi, A., \& Erhardt, N. L. (2003). Recent research on team and organizational diversity: SWOT analysis and implications. Journal of Management, 29, 801-830.

James, L. R. (1982). Aggregation bias in estimates of perceptual agreement. Journal of Applied Psychology, 67, 219-229.

James, L. R., Choi, C. C., Ko, C. E., McNeil, P. K., Minton, M. K., Wright, M. A., \& Kim, K. (2007). Organizational and psychological climate: A review of theory and research. European Journal of Work and Organizational Psychology, 17, 532.

James, L. R., Demaree, R. G., \& Wolf, G. (1993). $\mathrm{r}_{\mathrm{wg}}$ : An assessment of within-group interrater agreement. Journal of Applied Psychology, 78, 306-309.

James, L. A., \& James, L. R. (1989). Integrating work environment perceptions: Explorations into the measurement of meaning. Journal of Applied Psychology, 74, 739-751. 
Jex, S. M., Wang, M., \& Zarubin, A. (2007). Aging and occupational health. In K. S. Shultz \& G. A. Adams (Eds.), Aging and work in the $21^{\text {st }}$ century (pp.199-224). Mahwah, New Jersey: LEA.

Jones, A. P., \& James, L. R. (1979). Psychological climate: Dimensions and relationships of individual and aggregated work environment perceptions. Organizational Behavior and Human Performance, 23, 201-250.

Judge T. A., \& Bono, J. E. (2001). Relationship of core self-evaluation traits—selfesteem, generalized self-efficacy, locus of control, and emotional stability—with job satisfaction and job performance: A Meta-Analysis. Journal of Applied Psychology, 86, 80-92.

Judge, T. A., Bono, J. E., \& Locke, E. A. (2000). Personality and job satisfaction: The mediating role of job characteristics. Journal of Applied Psychology, 85, 237249.

Judge, T., Bono, J., Erez, A., \& Locke, E. (2005). Core self-evaluations and job and life satisfaction: The role of self-concordance and goal attainment. Journal of Applied Psychology, 90, 257-268.

Judge, T. A., Erez, A., \& Bono, J. E. (1998). The power of being positive: The relation between positive self-concept and job performance. Human Performance, 11, $167-187$.

Judge, T., Erez, A., Bono, J., \& Thoresen, C. (2003). The core self-evaluations scale: Development of a measure. Personnel Psychology, 56, 303-331. 
Judge T. A., \& Hurst, C. (2007). Capitalizing on one's advantages: Role of core selfevaluations. Journal of Applied Psychology, 92, 1212-1227.

Judge T. A., \& Ilies, R. (2001). Relationship of personality to performance motivation: A meta-analytic review. Journal of Applied Psychology, 87, 797-807.

Judge, T. A., Klinger, R., Simon, L. S., \& Wen Feng Yang, I. (2008). The contributions of personality to organizational behavior and psychology: Findings, criticisms, and future research directions. Social and Personality Compass, 2, 1982-2000.

Judge, T. A., Locke, E. A., \& Durham, C. C. (1997). The dispositional causes of job satisfaction: A core evaluations approach. Research in Organizational Behavior, $19,151-188$.

Judge, T. A., Locke, E. A., Durham, C. C., \& Kluger, A. N. (1998). Dispositional effects on job and life satisfaction: The role of core self-evaluations. Journal of Applied Psychology, 83, 17-34.

Judge, T. A., Thoresen, C. J., Pucik, V., \& Welbourne, T. M. (1999). Managerial coping with organizational change: A dispositional perspective. Journal of Applied Psychology, 84, 107-122.

Judge, T. A., Van Vianen, A. E., \& De Pater, I. E. (2004). Emotional stability, core-selfevaluation, and job outcomes: A review of the evidence and agenda for future research, Human Performance, 17, 325-346.

Kacmar, K. M., Collins, B. J., Harris, K. J., \& Judge, T. A. (2009). Core self-evaluations and job performance: The role of the perceived work environment. Journal of Applied Psychology, 94, 1572-1580. 
King, E. B., Dawson, J. F., Kravitz, D. A., \& Gulick, L. M. V. (in press). A multilevel study of the relationships between diversity training, ethnic discrimination and satisfaction in organizations. Journal of Organizational Behavior.

King, E. B., Gulick, L. M., \& Avery, D. R. (in press). The divide between diversity training and diversity education: Integrating best practices. Journal of Management Education.

Kite, M. E., Stockdale, G. D., Whitley, B. E., \& Johnson, B. T. (2005). Attitudes toward younger and older adults: An updated meta-analytic review. Journal of Social Issues, 61, 241-266.

Kline, R. B. (2005). Principles and practice of structural equation modeling. (2nd ed.) New York: Guilford Press.

Kogan, N. (1961). Attitudes toward old people: The development of a scale and an examination of correlates. Journal of Abnormal and Social Psychology, 62, 44-54.

Kogan, N., \& Shelton, F. C. (1960). Differential cue value of age and occupation in impression formation. Psychological Reports, 7, 203-216.

Kopelman, R. E., Brief, A. P., \& Guzzo, R. A. (1990). The role of climate and culture in productivity. In B. Schneider (Ed.), Organizational climate and culture (pp. 282318). San Francisco: Jossey-Bass.

Kossek, E.E., Markel, K.S., \& McHugh, P.P. (2003). Increasing diversity as an HRM change strategy. Journal of Organizational Change Management, 16, 328-352. 
Kossek, E.E., \& Zonia, S.C. (1993). Assessing diversity climate: A field study of reactions to employer efforts to promote diversity. Journal of Organizational Behavior, 14, 61-81.

Kozlowski, S. W. J., \& Doherty, M. L. (1989). Integration of climate and leadership: Examination of a neglected issue. Journal of Applied Psychology, 74, 721-742.

Kozlowski, S. W. J., \& Hults, B. M. (1987). An exploration of climates for technical updating and performance. Personnel Psychology, 40, 539-563.

Landy, F. J. (2008). Stereotypes, bias, and personnel decisions: Strange and stranger. Industrial and Organizational Psychology, 1, 379-392.

Lawrence, B. S. (1988). New wrinkles in the theory of age: Demography, norms, and performance ratings. Academy of Management Journal, 31, 309-337.

Levy, B. R. (2003). Mind matters: Cognitive and physical effects of aging selfstereotypes. Journals of Gerontology: Psychological Sciences and Social Sciences, 58: 203-211.

Lewin, K. (1951). Field theory in social science. New York: Harper and Row.

Lewin, K., Lippitt, R., \& White, R. K. (1939). Patterns of aggressive behavior in experimentally created "social climates." Journal of Social Psychology, 10, 271299.

Lieber, R. (December 19, 1999). First jobs aren't child's play. Fast Company, 25. Retrieved from http://owl.english.purdue.edu/owl/resource/560/10/

Liu, S., Wang, M., Piccolo, R. F., Zhan, Y., \& Shi, J. (2008). Core self-evaluation in china: Predicting job satisfaction and job performance. Poster session presented 
Ageism Climate 223

at the annual meeting of the Society for Industrial and Organizational Psychologists (SIOP), San Francisco, CA.

Locke, E. A. (1976). The nature and causes of job satisfaction. In M. D. Dunnette (Ed.), Handbook of industrial and organizational psychology (pp. 1297 - 1350). Skokie, IL: Rand McNally.

Loretto, W., Duncan, C., \& White, P. J. (2000). Ageism in employment: controversies, ambiguities and younger people's perceptions. Ageing and Society, 20, 279-302.

Maertz, C. P., \& Campion, M. A. (2004). Profiles in quitting: Integrating process and content turnover theory. Academy of Management Journal, 47, 566-592.

Manning, M. M., \& Wright, T. L. (1983). Self-efficacy expectancies, outcome expectancies, and the persistence of pain control in childbirth. Journal of Personality and Social Psychology, 45, 421-431.

Maslach, C., \& Leiter, M.P. (1997). The truth about burnout: How organizations cause personal stress and what to do about it. San Francisco, CA: Jossey-Bass.

Maurer, T. (2001). Career-relevant learning and development, worker age, and beliefs about self-efficacy for development. Journal of Management, 27, 123-40.

Maurer, T. J., Barbeite, F., Weiss, E. M., \& Lippstreu, M. (2008). New measures of stereotypical beliefs about older workers' ability and desire for development: Exploration among employees age 40 and over. Journal of Managerial Psychology, 23, 395-418. 
Maurer, T. J., \& Rafuse, N. E. (2001). Learning, not litigating: Managing employee development and avoiding claims of age discrimination. Academy of Management Executive, 15, 110-121.

Maurer, T., Weiss, M., \& Barbeite, F. (2003). A model of involvement in work-related learning and development activity: The effects of individual, situational, motivational and age variables. Journal of Applied Psychology, 88, 707-24.

Maurer, T., Wrenn, K., \& Weiss, E. (2003), Toward understanding and managing stereotypical beliefs about older workers' ability and desire for learning and development. Research in Personnel and Human Resources Management, 22, 253-85.

McCann, R., \& Giles, H. (2002). Ageism in the workplace: A communication perspective. In T. Nelson (Ed.), Ageism: Stereotyping and prejudice against older persons (pp. 163-199). Cambridge, MA: MIT Press.

McEvoy, G. M., \& Cascio, W. F. (1989). Cumulative evidence of the relationship between employee age and job performance. Journal of Applied Psychology, 74, $11-17$

McKay, P.F., \& Avery, D.R. (2006). What has race got to do with it? Unraveling the role of racioethnicity in job seekers' reactions to site visits. Personnel Psychology, 59, $395-429$.

McKay, P. F., Avery, D. R., \& Morris, M. A. (2008). Mean racial-ethnic differences in employee sales performance: The moderating role of diversity climate. Personnel Psychology, 61, 349-374. 
McKay, P.F., Avery, D.R., Tonidandel, S., Morris, M.A., Hernandez, M., \& Hebl, M.R. (2007). Racial differences in employee retention: Are diversity climate perceptions the key? Personnel Psychology, 60, 35-62.

Meyer, J. P., \& Allen, N. J. (1991). A three-component conceptualization of organizational commitment. Human Resource Management Review, 1, 61-89.

Meyer, J. P., Allen, N. J., \& Smith, C. A. (1993). Commitment to organizations and occupations: Extension and test of a three-component conceptualization. Journal of Applied Psychology, 78, 538-551.

Meyer, J. P., Stanley, D. J., Herscovich, L., \& Topolnytsky, L. (2003). Affective, continuance, and normative commitment to the organization: A meta-analysis of antecedents, correlates, and consequences. Journal of Vocational Behavior, 61, $20-52$.

Mischel, W. (1977). The interaction of person and situation. In D. Magnusson \& N. Endler (Eds.), Personality at the crossroads: Current issues in interactional psychology. Hillsdale, NJ: Erlbaum.

Mischel, W., \& Shoda, Y. (1995). A cognitive-affective system theory of personality: Reconceptualizing situations, dispositions, dynamics, and invariance in personality structure. Psychological Review, 102, 246-268.

Mor Barak, M.E., Cherin, D.A., \& Berkman, S. (1998). Organizational and personal dimensions in diversity climate. Journal of Applied Behavioral Science, 34, 82104. 
Ageism Climate 226

Mowaday, R. T., Porter, L. W., \& Steers., R. M. (1982). Employee-organization linkages: The psychology of commitment, absenteeism, and turnover. New York: Academic Press.

Naumann S. E., \& Bennett, N. (2000). A case of procedural justice climate: Development and test of a multilevel model. Academy of Management Journal, 43, 881-889.

Ng, T. W. H., \& Feldman, D. C. (2008). The relationship of age and to ten dimensions of job performance. Journal of Applied Psychology, 93, 392-423.

Nishii, L. H., \& Raver, J. L. (2003). Collective climates for diversity: Evidence from a field study. Paper presented at the annual conference of Society for Industrial and Organizational Psychology, Orlando, FL.

Noe, R. A. (1986). Trainees' attributes and attitudes: Neglected influences on training effectiveness. Academy of Management Review, 11, 736-749.

O'Higgins, N. (2001). Youth unemployment and employment policy: A global perspective, Geneva: International Labour Office.

O’Reilly C. A., \& Chatman, J. (1986). Organizational commitment and psychological attachment: The effects of compliance, identification, and internalization on prosocial behavior. Journal of Applied Psychology, 71, $492-499$.

Osborne, T., \& McCann, L. A. (2004). Forced ranking and age-related employment discrimination. Human Rights, 31, 6-9.

Ostroff, C., \& Atwater, L. E. (2003). Does whom you work with matter? Effects of referent group gender and age composition on managers' compensation. Journal of Applied Psychology, 88, 725-740. 
Ostroff, C., Kinicki, A. J., \& Tamkins, M. M. (2003). Organizational climate and culture. In W. C. Borman, D. R. Ilgen \& R. J. Klimoski (Eds.), Comprehensive handbook of psychology, Volume 12: Industrial and organizational psychology (pp. 365402). Mahwah, NJ: Erlbaum.

Parker, C. P. (1999). A test of alternative hierarchical models of psychological climate: PCg, satisfaction, or method effects? Organizational Research Methods, 2, 257 274.

Parker, C. P., Baltes, B. B., Young, S. A., Huff, J. W., Altmann, R. A., Lacost, H. A., \& Roberts, J. E. (2003). Relationships between psychological climate perceptions and work outcomes: A meta-analytic review. Journal of Organizational Behavior, 24, 389-416.

Payne, R. L., \& Pugh, D. S. (1976). Organizational structure and climate. In M. Dunnette (Ed.), Handbook of Industrial and Organizational Psychology (pp. 1125-1173). Chicago: Rand McNally.

Perry, E. L., Kulik, C. T., \& Bourhis, A. C. (1996). Moderating effects of personal and contextual factors in age discrimination. Journal of Applied Psychology, 81, 628647.

Perry, E. L., \& Finkelstein, L. M. (1999). Toward a broader view of age discrimination in employment-related decisions: A joint consideration of organizational factors and cognitive processes. Human Resource Management Review, 9, 21-49. 
Piccolo, R. F., Judge, T. A., Takahashi, K., Watanabe, N., \& Locke, E. A. (2005). Core self-evaluations in Japan: Relative effects on job satisfaction, life satisfaction, and happiness. Journal of Organizational Behavior, 26, 965-984.

Posthuma, R. A., \& Campion, M. A. (2009). Age stereotypes in the workplace: Common stereotypes, moderators, and future research directions. Journal of Management, $35,158-188$.

Pritchard, R. D., \& Karasick, B. W. (1973). The effect of organizational climate on managerial job performance and job satisfaction. Organizational Behavior and Human Performance, 9, 126-146.

Pugh, S. D., Dietz, J., Brief, A. P., \& Wiley, J. W. (2008). Looking inside and out: The impact of employee and community demographic composition on organizational diversity climate. Journal of Applied Psychology, 93, 1422-1428.

Reichers, A. E., \& Schneider, B. (1990). Climate and culture: An evolution of constructs. In B. Schneider (Ed.), Organizational climate and culture (pp. 5-39). San Francisco: Jossey-Bass.

Remery, C., Henkens, K., Schippers, J., \& Ekamper, P. (2003). Managing an aging workforce in a tight labor market: Views held by Dutch employers. Population Research and Policy Review, 22, 21-40.

Rhoades, L., \& Eisenberger, R. (2002). Perceived organizational support: A review of the literature. Journal of Applied Psychology, 87, 698-714.

Riordan, C. M., Schaffer, B., \& Stewart, M. (2005). Relational demography within groups: Through the lens of discrimination. In R. Diboye \& A. Colella (Eds.), 
Discrimination at work: The psychological and organizational bases (pp. 37-62). Mahwah, NJ: Erlbaum.

Riordan, C. M., \& Shore, L. M. (1997). Demographic diversity and employee attitudes: An empirical examination of relational demography within work units. Journal of Applied Psychology, 82, 342-358.

Roberson, Q. M., \& Stevens, C.K. (2006). Making sense of diversity in the workplace: Organizational justice and language abstraction in employees' accounts of diversity related incidents. Journal of Applied Psychology, 91, 379-391.

Roberts, B. W., Wood, K. E., \& Viechtbauer, W. (2006). Patterns of mean-level change in personality traits across the life course: A meta-analysis of longitudinal studies. Psychological Bulletin, 132, 1-25.

Rocco, T. S., Stein, D., \& Lee, C. (2003). An exploratory examination of the literature on age and HRD policy development. Human Resource Development Review, 2, $155-180$.

Rogelberg, S. G., \& Stanton, J. M. (2007). Introduction: Understanding and dealing with organizational survey nonresponse. Organizational Research Methods, 10, 195209.

Rosen, B., \& Jerdee, T. H. (1976a). The nature of job-related age stereotypes. Journal of Applied Psychology, 61, 180-183.

Rosen, B., \& Jerdee, T. H. (1976b). The influence of age stereotypes on managerial decisions. Journal of Applied Psychology, 61, 428-432. 
Rosen, B., \& Jerdee, T. H. (1977). Too old or not too old? Harvard Business Review, 55, 97-106.

Rotter, J. B. (1966). Generalized expectancies for internal versus external control of reinforcement. Psychological Monographs, 80, 1-28.

Rupp, D. E., Vodanovich, S. J., \& Credé, M. (2005). The multidimensional nature of ageism: Construct validity and group differences. Journal of Social Psychology, $145,335-362$.

Rynes, S., \& Rosen, B. (1995). A field survey of factors affecting the adoption and perceived success of diversity training. Personnel Psychology, 48, 247-270.

Saks, A. M., \& Waldman, D. A. (1998). The relationship between age and job performance evaluations for entry-level professionals. Journal of Organizational Behavior, 19, 409-419.

Salanova, M., Agut, S., \& Peiró, J.M. (2005). Linking organizational resources and work engagement to employee performance and customer loyalty: The mediation of service climate. Journal of Applied Psychology, 90, 1217-1227.

Salgado, J. F. (2002). The big five personality dimensions and counterproductive behaviors. International Journal of Selection and Assessment, 10, 117-125.

Salin, D. (2003). Ways of explaining workplace bullying: A review of enabling, motivating, and precipitating structures and processes in the work environment. Human Relations, 56, 1213-1232. 
Salthouse, T., \& Maurer, T. (1996). Aging, job performance, and career development. In J. Birren, K. Schaie (Eds.), Handbook of the psychology of aging (4th ed.) (pp. 353-364). San Diego, CA: Academic Press.

Schaufeli, W. B., \& Bakker, A. B. (2001). Work and well-being: Towards a positive approach in Occupational Health Psychology. Gedrag \& Organisatie, 14, 229253.

Schaufeli, W. B., Bakker, A. B., \& Salanova, M. (2006). The measurement of work engagement with a short questionnaire: A cross-national study. Educational and Psychological Measurement, 66, 701-716.

Schaufeli, W.B., Bakker, A.B., \& Van Rhenen, W. (2009). How changes in job demands and resources predict burnout, work engagement, and sickness absenteeism. Journal of Organizational Behavior, 30, 893-917.

Schaufeli, W.B., Salanova, M., Gonzalez-Romá, V., \& Bakker, A.B. (2002). The measurement of engagement and burnout: A two sample confirmatory factor analytic approach. Journal of Happiness Studies, 3, 71-92.

Schein, E. H. (1992). Organizational culture and leadership: A dynamic view. San Francisco: Jossey-Bass.

Schneider, B. (1990). The climate for service: An application of the climate construct. In B. Schneider (Ed.) Organizational climate and culture (pp. 383-412). San Francisco: Jossey-Bass. 
Schneider, B. (2000). The psychological life of organizations. In N. M. Ashkanaksy, C. P. M. Wilderom, \& M. F. Peterson (Eds.), Handbook of organizational culture and climate (pp. xvii-xxi). Thousand Oaks, CA: Sage.

Schneider, B., \& Gunnarson, S. (1990). Organizational climate and culture: The psychology of the workplace. In J. W. Jones, B. D. Steffy, \& D. Bray (Eds.), Applying psychology in business: The manager's handbook (pp. 542-551). Lexington, MA: Lexington Books.

Schneider, B., \& Reichers, A. E. (1983). On the etiology of climates. Personnel Psychology, 36, 19-39.

Schneider, B. J., White, S. S., \& Paul, M. C. (1998). Linking service climate and customer perceptions of service quality: test of a causal model. Journal of Applied Psychology, 83, 150-163.

Shore, L. M., Chung-Herrera, B. G., Dean, M. A., Ehrhart, K. H., Jung, D. I., Randel, A., E., \& Singh, G. (2009). Diversity in organizations: Where are we now and where are we going? Human Resource Management Review, 19, 117-133.

Shore, L. M., Cleveland, J. N., \& Goldberg, C. B. (2003). Work attitudes and decisions as a function of manager age and employee age. Journal of Applied Psychology, 88, $529-537$.

Shore, L. M., \& Goldberg, C. B. (2005). Age discrimination in the workplace. In R. L. Dipboye \& A. Colella (Eds.), Discrimination at work (pp. 203-225). Mawhaw, NJ: Lawrence Erlbaum. 
Sinclair, R. R., Mohr, C. P., Davidson, S., Sears, L. E., Deese, M. N., Wright, R. R., Waitsman, M., Jacobs, L., \& Cadiz, D. (2009). The Oregon Nurse Retention Project: Final Report to the Northwest Health Foundation. Unpublished Technical Report.

Spector, P. E. (2006). Method variance in organizational research: Truth or urban legend? Organizational Research Methods, 9, 221-232.

Stanley, K. M., Martin, M. M., Michel, Y., Welton, J. M., \& Nemeth, L. S. (2007). Examining lateral violence in the nurse workforce. Issues in Mental Health Nursing, 28, 1247-1265.

Steiner, D. D., Bertolino, M., Fraccaroli, F., \& Truxillo, D. M. (2007, April). Justice perceptions of organizational practices concerning older employees. Paper presented at the annual meeting of the Society for Industrial and Organizational Psychology, San Francisco, CA.

Stone, P.W., Mooney-Kane, C., Larson, E. L., Pastor, D. K., Zwanziger, J., \& Dick, A. W. (2007). Nurse working conditions, organizational climate, and intent to leave in ICUs: An instrumental variable approach. Health Services Research, 42, 1085 1104.

Symes L., Krepper K.R., Lindy C., Byrd M.N., Jacobus C., \& Throckmorton T. (2005). Stressful life events among new nurses: implications for retaining new graduates. Nursing Administration Quarterly, 29, 292-296. 
Tajfel, H., \& Turner, J. C. (1979). An integrative theory of intergroup conflict. In Austin, W. \& Worche, S. (Eds.), The social psychology of intergroup relations (pp. 3348). Pacific Grove, CA: Brooks-Cole.

Tett, R. P., \& Burnett, D. D. (2003). A personality trait-based interactionist model of job performance. Journal of Applied Psychology, 88, 500-517.

Tett, R., \& Gutterman, H. (2000). Situation trait relevance, trait expression, and crosssituational consistency: Testing a principle of trait activation, Journal of Research in Personality, 34, 397-423.

Tharenou, P. (1979). Employee self-esteem: A review of the literature. Journal of Vocational Behavior, 15, 331-346.

Tossi, M. (2009). Labor force projections to 2018 : Older workers staying more active. Monthly Labor Review, 132, 30-51.

Truxillo, D. M., McCune, E. A., Bertolino, M., \& Fraccaroli, F. (2008). Perceptions of personality, cognitive ability, and job performance of older versus younger workers. Paper presented at the annual Academy of Management meeting, Anaheim, CA.

Tsaousis, I., Nikolaou, I., Serdaris, N., \& Judge, T. A. (2007). Do core self-evaluations moderate the relationship between subjective well-being and physical and psychological health? Personality and Individual Differences, 42, 1441-1452.

Tsui, A. S., \& O’Reilly, C. A. (1989). Beyond simple demographic effects: The importance of relational demography in superior-subordinate dyads. Academy of Management Journal, 32, 402-423. 
Ageism Climate 235

Tuckman, J., \& Lorge, I. (1953). Attitudes toward old people. The Journal of Social Psychology, 37, 249-260.

Twenge, J. M., Campbell, S. M., Hoffman, B. J., \& Lance, C. E. (2010). Generational differences in work values: Leisure and extrinsic values increasing, social and intrinsic values decreasing. Journal of Management, 36, 1117-1142.

U.S. Department of Labor, Bureau of Labor Statistics (2000). US Bureau of the Census Current Population Survey Technical Paper 63: Design and Methodology.

Retrieved June 3, 2008, from http://www.census.gov/prod/2000pubs/tp63.pdf.

Waldman D. A., \& Avolio, B. J. (1986). A meta-analysis of age differences in job performance. Journal of Applied Psychology, 71, 33-38.

Wanberg, C. R., Glomb, T. M., Song, Z., \& Sorenson, S. (2005). Job search persistence during unemployment: A 10-wave longitudinal study. Journal of Applied Psychology, 90, 411-430.

Warr, P., \& Pennington, J. (1993). Views about age discrimination and older workers. In Age and employment: policies, attitudes and practices (pp. 75-106). London: Institute of Personnel Management.

Weiss, E. M., \& Maurer, T. J. (2004). Age discrimination in personnel decisions: A reexamination. Journal of Applied Social Psychology, 34, 1551-1562.

Wiggins, J. S. (Ed). (1996). The five-factor model of personality: Theoretical perspectives. New York: Guilford Press. 
Ageism Climate 236

Williams, H. M., Parker, S. K., \& Turner, N. (2007). Perceived dissimilarity and perspective taking within work teams. Group \& Organizational Management, 32, 569-597.

Witt, L. A. (1992). Exchange ideology as a moderator of the relationships between importance of participation in decision-making and job attitudes. Human Relations, 45, 73-85.

Xanthopoulou, D., Bakker, A.B., Demerouti, E., \& Schaufeli, W.B. (2009). Work engagement and financial returns: A diary study on the role of job and personal resources. Journal of Occupational and Organizational Psychology, 74, 235-244.

Xanthopoulou, D., Bakker, A.B., Demerouti, E., \& Schaufeli, W.B. (2007). The role of personal resources in the job demands-resources model. International Journal of Stress Management, 14, 121-141.

Xanthopoulou, D., Bakker, A.B., Demerouti, E., \& Schaufeli,W.B. (2008). Working in the sky: A diary study on work engagement among flight attendants. Journal of Occupational Health Psychology, 13, 345-356.

Zenger, T. R., \& Lawrence, B. S. (1989). The differential effects of age and tenure distributions on technical communication. Academy of Management Journal, 32, 353-376.

Zohar, D. (2000). A group-level model of safety climate: Testing the effect of group climate on microaccidents in manufacturing jobs. Journal of Applied Psychology, $85,587-596$. 
Ageism Climate 237

\section{Appendix: Informed Consent Form and Utilized Oregon Nurse Retention Survey Items}

\section{INFORMED CONSENT}

\section{The Oregon Nurse Retention Project}

You are invited to participate in a research study conducted by Dr. Robert Sinclair and Dr. Cynthia Mohr from the Department of Psychology at Portland State University (PSU) in collaboration with the Oregon Nurses Association (ONA). This study will investigate the kinds of positive and stressful experiences you have at work and your attitudes and perceptions about yourself at work, your organization, and the profession of nursing. The general goal of the study is to investigate how occupational stress and positive experiences at work influence nurses' desires to stay in the profession of nursing as well as their thoughts about leaving the profession. We will compile a series of recommendations based on our findings across the entire group of participants and will report these findings to acute care facilities. In doing so, we hope to help create healthier and more rewarding work environments for nurses.

\section{What will I have to do?}

- If you decide to participate, you will be given the option to complete web-based or hardcopy versions of the surveys.

- You will be asked to answer an initial survey, which will ask you various questions regarding your nursing work life, including your perspectives on the field of nursing, your career as a nurse, the organization you work for, the people you work with, your current job, and some questions about you as a person.

- $\quad$ Following a five month period, you will be asked to complete a second survey that will ask similar questions to the first survey.

- $\quad$ The two surveys are designed to take approximately 30 minutes in length each.

- You may contact the researchers throughout the study via email (sinclair@pdx.edu) and/or telephone (503) 725-3986 to ask any questions you have and address any problems you might be having.

\section{Are there any risks?}

- $\quad$ There is no direct cost associated with your completion of the surveys in this study

- There are no anticipated physical or psychological risks from participating in this study. It is possible that you may be upset by the recollection of unpleasant experiences. However, our past experience with questionnaire research suggests this is extremely unlikely.

\section{Your participation is voluntary}

- Your participation in this study is completely voluntary. You are under no obligation to participate and choosing not to participate will not affect your relationship with Portland State University or the Oregon Nurses Association.

- You may choose to not answer questions or withdraw from participating in this study at any time.

- If you do not complete the initial survey, you will be terminated from the study. If you do not complete the second survey, you will still be paid for completing the first survey. 
Ageism Climate 238

\section{What will I get in return?}

- In exchange for your participation, you will receive $\$ 10$ for completing the initial survey and $\$ 10$ for completion of the final survey.

- $\quad$ Thus, you can earn up to $\$ 20$ for participating in this study.

- $\quad$ A full report on the purpose of and findings of this study will be published and freely available. We will provide a copy of this report to all study participants at no charge.

\section{What are you doing to protect me?}

Any information that is obtained in connection with this study and that can be linked to you or identify you will be kept confidential. Confidentiality of your responses will be maintained through several means:

- Information about your identity will be kept in a separate (secure and passwordprotected) database from your responses to the survey questions.

- $\quad$ Data from the surveys will be identified by code numbers that only will be able to be accessed by research personnel.

- $\quad$ Your responses cannot be accessed from the web without a password; only research personnel will be able to download your responses.

- As soon as responses are downloaded there will be no online access to responses. Also, any information that you provide in your responses that could potentially identify you, such as if you named your facility, will be deleted from any reports that include those responses.

\section{Any questions?}

- Please contact the Human Subjects Research Review Committee, Office of Research and Sponsored Projects, 111 Cramer Hall, Portland State University, (503) 725-4288.

- If you have questions about the study itself, please contact Dr. Robert Sinclair by telephone at (503) 725-3986, by e-mail at sinclair@pdx.edu, or by mail at Department of Psychology, P.O. Box 751, Portland State University, Portland, OR 97207.

- Or, you may contact Dr. Sue Davidson at the Oregon Nurses Association by telephone at (503) 293-0011, by e-mail at davidson@ oregonm.org, or by mail at Oregon Nurses Association, 18765 SW Boones Ferry Rd., Ste 200, Tualatin, OR 97062.

You may keep this letter for your records. 
YOUR INTENTIONS: This section asks you about your plans for the future in your organization.

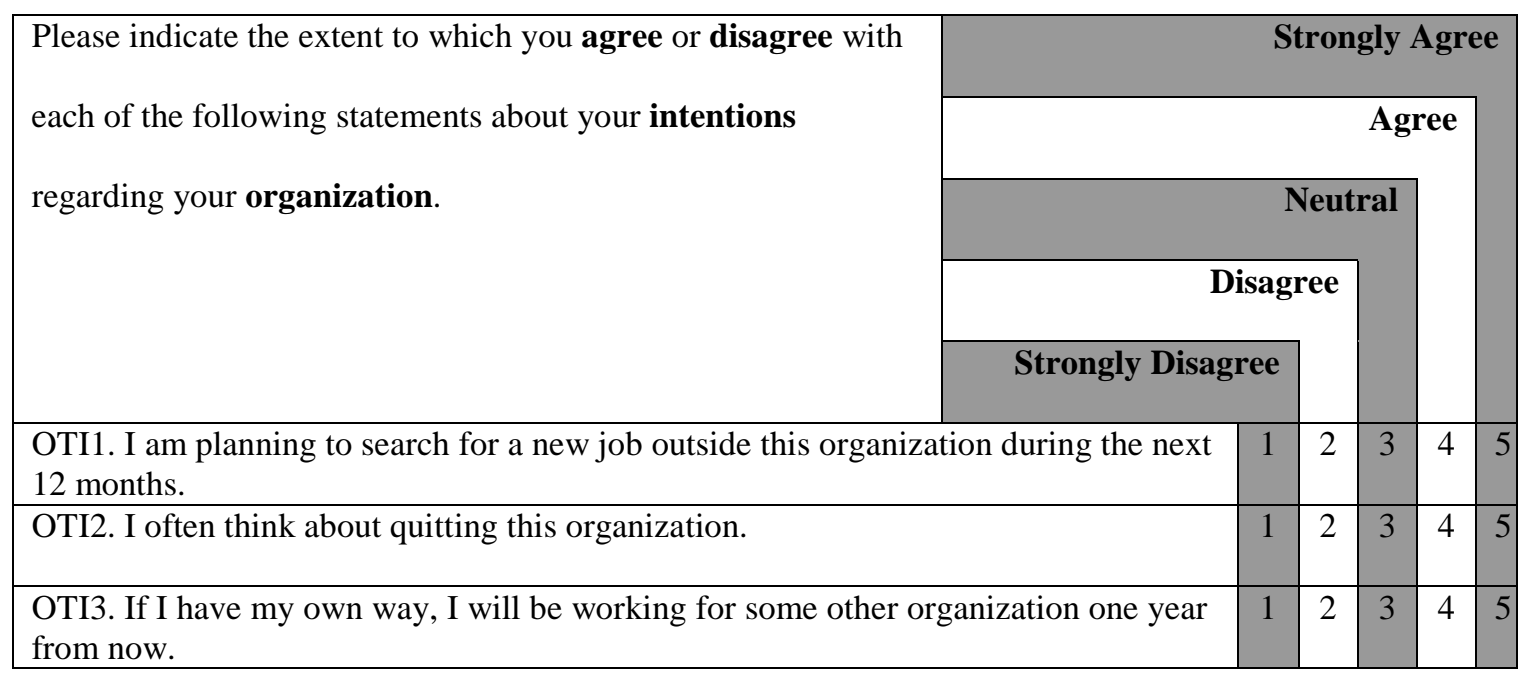

YOUR CURRENT JOB: This section asks you about aspects of your current job.

\begin{tabular}{|c|c|c|c|c|c|}
\hline \multirow[t]{4}{*}{$\begin{array}{l}\text { Please indicate how often you have experienced each of the } \\
\text { following about your job. }\end{array}$} & \multicolumn{5}{|c|}{$\begin{array}{l}\text { Very Often } \\
\text { Often }\end{array}$} \\
\hline & \multicolumn{3}{|c|}{ Sometimes } & & \\
\hline & \multicolumn{3}{|c|}{ Almost Never } & & \\
\hline & Never & & & & \\
\hline UWE1. I was enthusiastic about my job. & 1 & 2 & 3 & 4 & 5 \\
\hline UWE2. My job inspired me. & 1 & 2 & 3 & 4 & 5 \\
\hline UWE3. I was proud of the work that I did. & 1 & 2 & 3 & 4 & 5 \\
\hline UWE4. At my work, I felt bursting with energy. & 1 & 2 & 3 & 4 & 5 \\
\hline UWE5. At my job, I felt strong and vigorous. & 1 & 2 & 3 & 4 & 5 \\
\hline UWE6. When I got up in the morning, I felt like going to work. & 1 & 2 & 3 & 4 & 5 \\
\hline UWE7. I felt happy when I was working intensely. & 1 & 2 & 3 & 4 & 5 \\
\hline UWE8. I was immersed in my work. & 1 & 2 & 3 & 4 & 5 \\
\hline UWE9. I was absorbed in my work. & 1 & 2 & 3 & 4 & 5 \\
\hline
\end{tabular}


YOU AS A PERSON: This section is about you as a person and how you typically react, think, and feel in your life in general. Please read the instructions carefully.

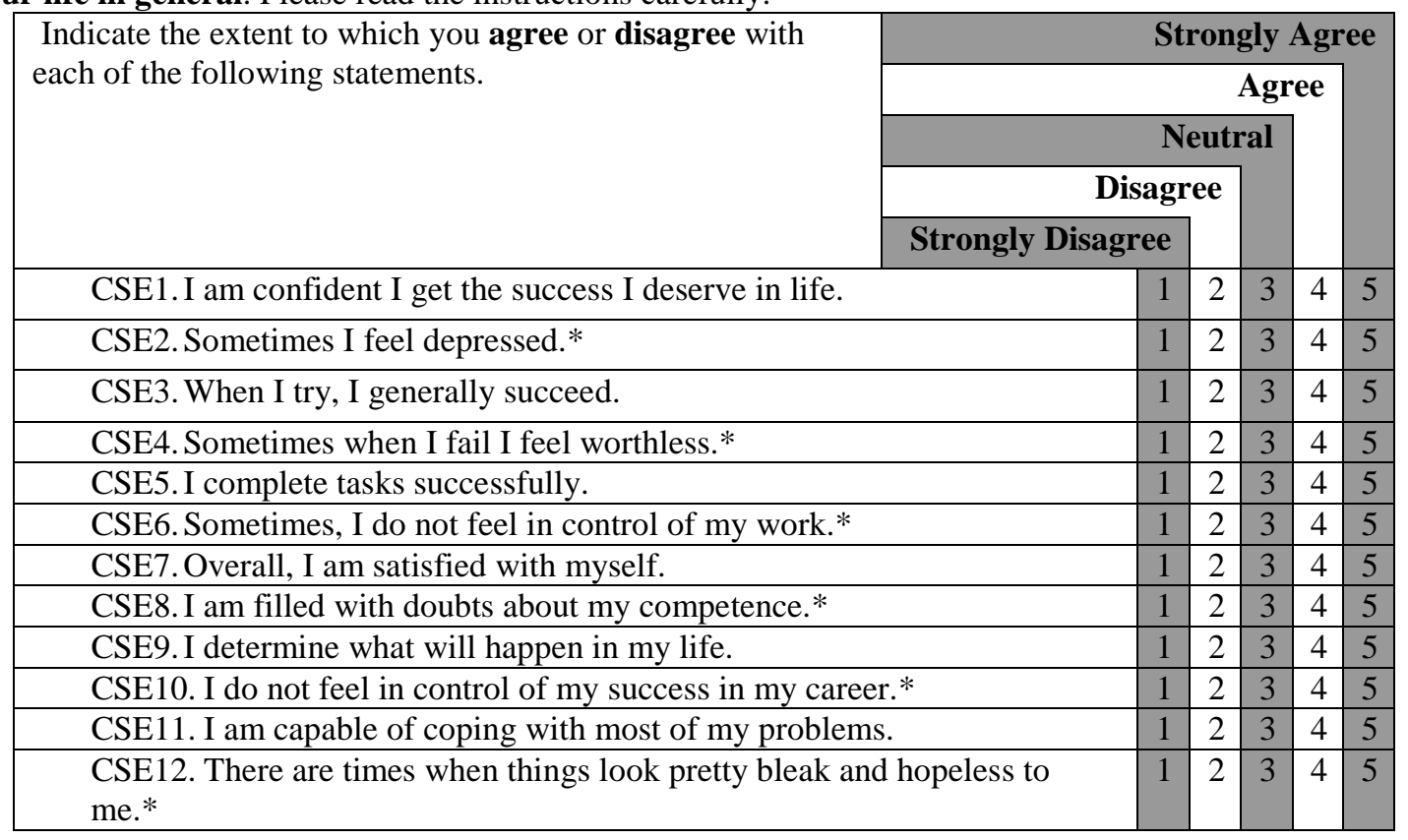

YOUR ORGANIZATION: Now we will ask you a few questions regarding your thoughts and feelings about your organization.

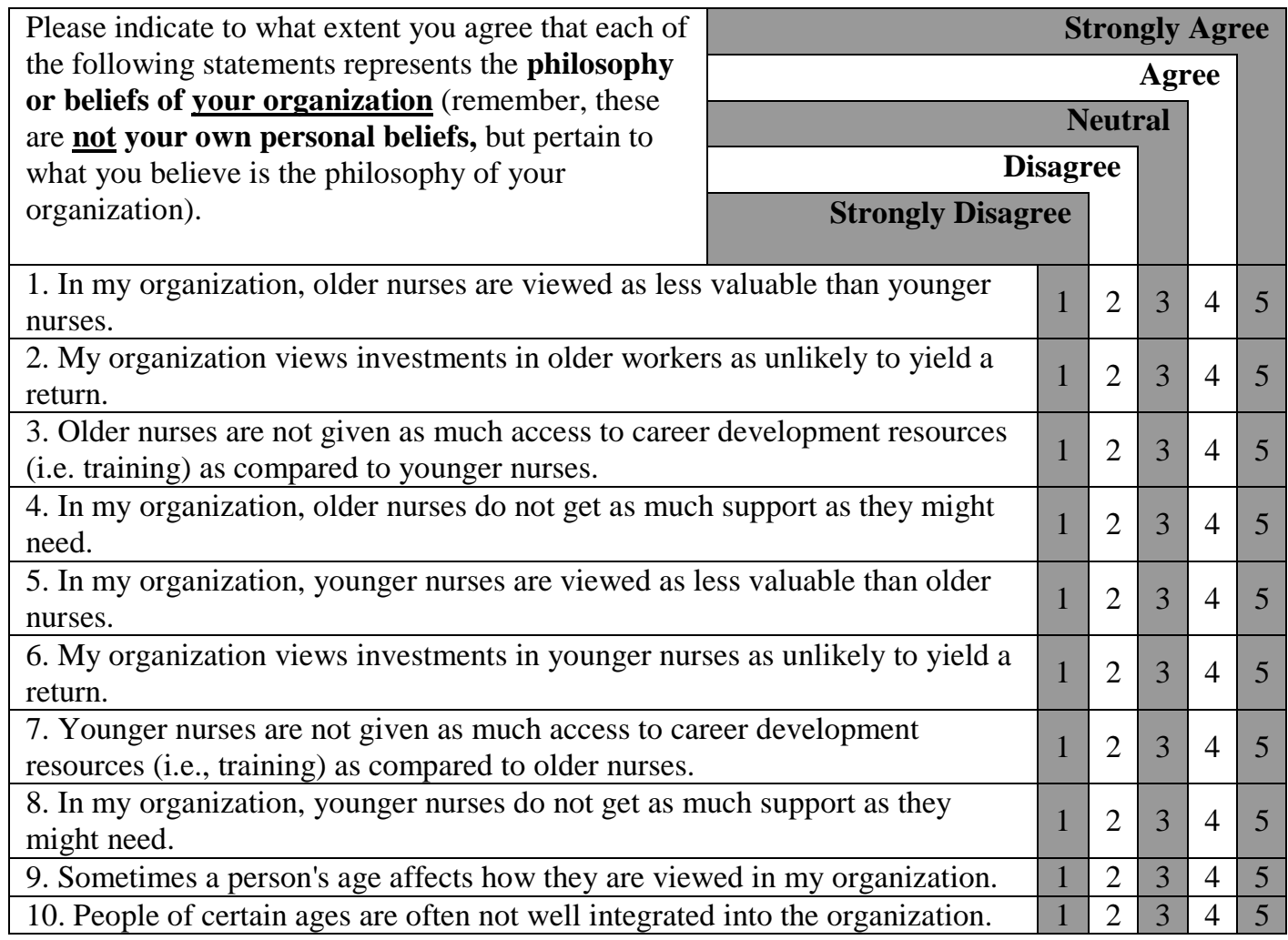




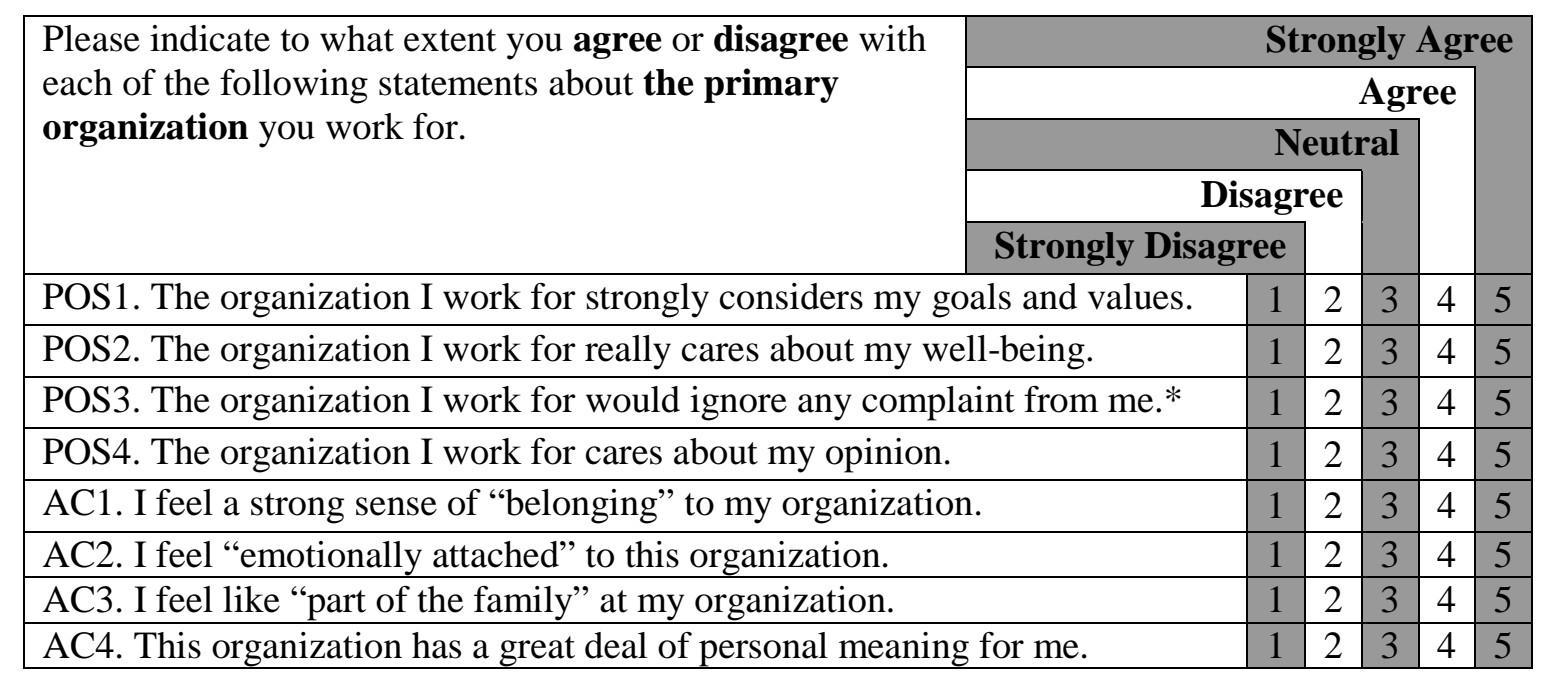

THE PEOPLE AT YOUR JOB: Now we would like to understand more about your relationships with people at your primary job, including the patients you care for, patients' families, physicians, managers, and coworkers. Please remember these surveys are completely confidential (your individual answers will not be shared with anyone).

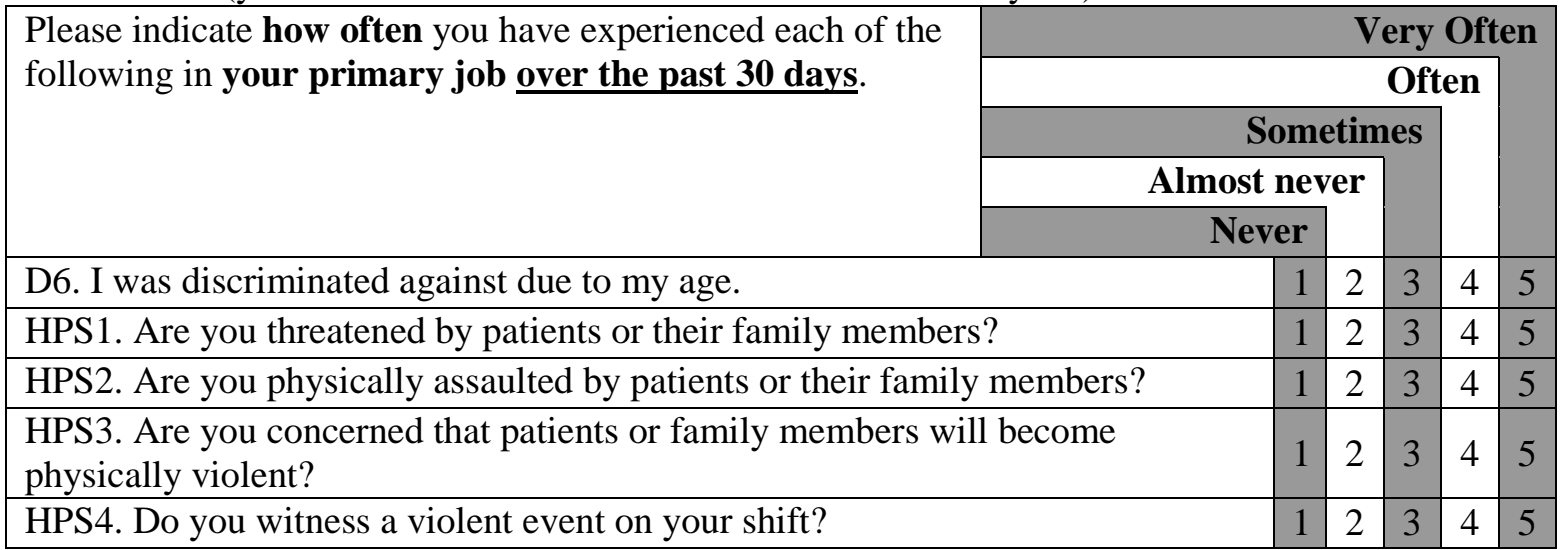

